\title{
CAMA
}

Centre for Applied Macroeconomic Analysis

\section{Commodity prices and fiscal policy design: Procyclical despite a rule}

\section{CAMA Working Paper 27/2016 May 2016}

\section{Hilde C. Bjørnland}

Centre for Applied Macro- and Petroleum economics (CAMP) - BI Norwegian Business School

Norges Bank and

Centre for Applied Macroeconomic Analysis, ANU

\section{Leif Anders Thorsrud}

Centre for Applied Macro- and Petroleum economics (CAMP) - BI Norwegian Business School

\begin{abstract}
We analyse if the adoption of a fiscal rule insulates the domestic economy from commodity price fluctuations in a resource-rich economy. To do so we develop a timevarying Dynamic Factor Model, in which both the volatility of structural shocks and the systematic fiscal policy responses are allowed to change over time. We focus on a particular country, Norway, that is put forward as exemplary with its handling of resource wealth; income from the sale of petroleum is first saved in a sovereign wealth fund for then to be spent following a fiscal rule. We find that, contrary to common perception, fiscal policy has been more (not less) procyclical with commodity prices since the adoption of the rule. Fiscal policy has thereby exacerbated the commodity price fluctuations on the domestic economy. Still, compared to many other resource-rich economies practising a more spend-as-you-go strategy the responses are modest, as also documented in our counterfactual analysis. From a policy point of view, the implications of our findings are therefore of general interest since they highlight strengths and weaknesses of fiscal rules adopted in resource rich countries.
\end{abstract}




\section{Keywords}

Time-varying Dynamic Factor Model, commodity prices, fiscal policy, sovereign wealth fund

\section{JEL Classification}

C32, E32, E62, F41, Q33

\section{Address for correspondence:}

(E) cama.admin@anu.edu.au

\section{ISSN 2206-0332}

The Centre for Applied Macroeconomic Analysis in the Crawford School of Public Policy has been established to build strong links between professional macroeconomists. It provides a forum for quality macroeconomic research and discussion of policy issues between academia, government and the private sector.

The Crawford School of Public Policy is the Australian National University's public policy school, serving and influencing Australia, Asia and the Pacific through advanced policy research, graduate and executive education, and policy impact. 


\title{
Commodity prices and fiscal policy design: Procyclical despite a rule*
}

\author{
Hilde C. Bjørnland ${ }^{\dagger} \quad$ Leif Anders Thorsrud ${ }^{\ddagger}$
}

March 30, 2016

\begin{abstract}
We analyse if the adoption of a fiscal rule insulates the domestic economy from commodity price fluctuations in a resource-rich economy. To do so we develop a time-varying Dynamic Factor Model, in which both the volatility of structural shocks and the systematic fiscal policy responses are allowed to change over time. We focus on a particular country, Norway, that is put forward as exemplary with its handling of resource wealth; income from the sale of petroleum is first saved in a sovereign wealth fund for then to be spent following a fiscal rule. We find that, contrary to common perception, fiscal policy has been more (not less) procyclical with commodity prices since the adoption of the rule. Fiscal policy has thereby exacerbated the commodity price fluctuations on the domestic economy. Still, compared to many other resource-rich economies practising a more spend-as-you-go strategy the responses are modest, as also documented in our counterfactual analysis. From a policy point of view, the implications of our findings are therefore of general interest since they highlight strengths and weaknesses of fiscal rules adopted in resource rich countries.
\end{abstract}

JEL-codes: C32, E32, E62, F41, Q33

Keywords: Time-varying Dynamic Factor Model, commodity prices, fiscal policy, sovereign wealth fund

*We thank Martin Eichenbaum, Knut Moum, James Stock, Ragnar Torvik and seminar and conference participants at Melbourne University, Norges Bank, BI Norwegian Business School, the CFE 2014 conference in Pisa, the 23rd SNDE Symposium 2015 in Oslo and the IAAE 2015 Annual Conference in Thessaloniki for valuable comments. The usual disclaimers apply. The views expressed in this paper are those of the authors and do not necessarily reflect the views of Norges Bank.

${ }^{\dagger}$ Centre for Applied Macro- and Petroleum economics (CAMP) - BI Norwegian Business School, Centre for Applied Macroeconomic Analysis (CAMA) - Australian National University and Norges Bank. Email: hilde.c.bjornland@bi.no

${ }^{\ddagger}$ Centre for Applied Macro- and Petroleum economics (CAMP) - BI Norwegian Business School. Email: leif.a.thorsrud@bi.no 


\section{Introduction}

In countries where the resource revenue constitutes a large component of total government revenues, commodity price fluctuations will have a direct impact on public spending. Many resource-rich countries are therefore advised to adopt some type of fiscal policy framework (i.e., a fiscal spending rule), which, if operated countercyclically, should shelter the economy from commodity price fluctuations and prevent over-spending on the part of the government, see e.g. Barro (1979) for related arguments from the tax and consumption smoothing literature, or Portes and Wren-Lewis (2014) for a recent overview.

The adoption of a fiscal rule, however, does not in itself ensure that fiscal policy works to insulate the domestic economy from commodity price fluctuations: The constructed rule may be too lax over the commodity price cycle, the actual conduct of fiscal policy might not be in accordance with the rule, or both. Hence, what works in theory may not necessarily work in practice.

We examine if fiscal rules work in practice. More specifically, we analyze fiscal policy's response in a resource-rich economy to commodity price shocks over time and the extent to which this response has insulated the domestic economy from commodity price fluctuations or, conversely, exacerbated their effect. To account for the changing nature of economic conditions and complexity of fiscal rules, we address this question by developing a time-varying Dynamic Factor Model (DFM), in which we allow the volatility of structural shocks, the systematic fiscal policy responses, and the macroeconomic conditions, to change over time. Our proposed model compares to existing time-varying DFMs, but differs in how the factors are identified in terms of economic quantities, permitting identification of structural shocks. Herein lies the methodological novelty of our approach. From the perspective of the empirical application, we believe this is the first time fiscal policy has been evaluated in this way, for a resource rich country, or for any country in general.

We focus on a particular country, Norway, whose handling of its petroleum wealth has been described as exemplary (see e.g. OECD (2005), OECD (2007) and Velculescu (2008) among many others). Unlike most oil exporters, Norway has adopted a fiscal framework in 2001, with a view to shielding the fiscal budget, and therefore also the domestic economy, from oil price fluctuations. In particular, oil and gas revenue is first put in a Savings Fund, of which only the expected real return of the fund is drawn annually to finance public spending or tax cuts. Thus, in comparing how fiscal policy responds to oil market shocks before and after the rule's implementation, our study provides us with a natural experiment for assessing fiscal policy over commodity price cycles.

Two simple stylized facts help motivate our work. Figure 1 reports the development in GDP in mainland (non-oil) Norway relative to GDP in neighbouring country Sweden, an 
Relative growth in GDP

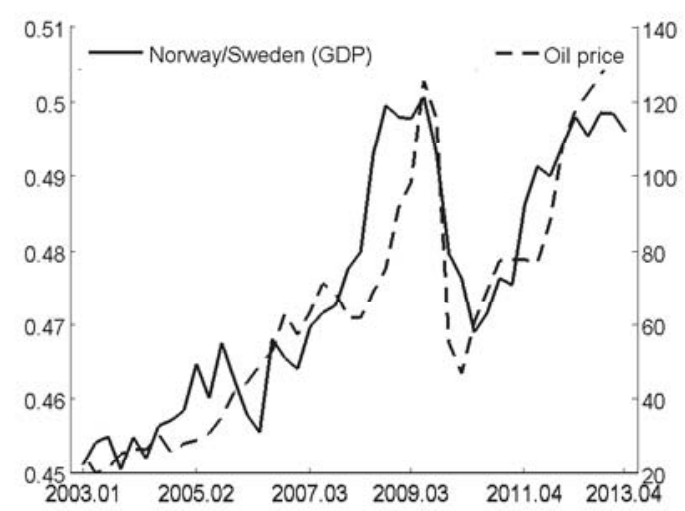

Relative growth in public value added

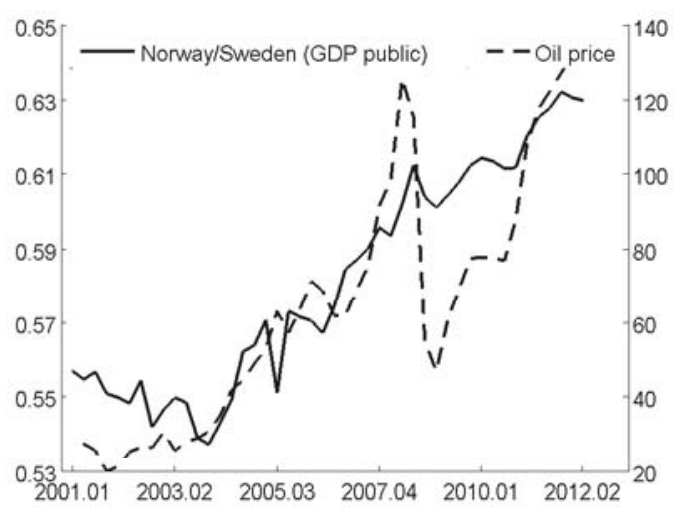

Figure 1. Reduced form evidence: Norway, Sweden and the price of oil. The left frame displays GDP in mainland Norway relative to GDP in Sweden plotted against the oil price. The right frame displays value added in the public sector in Norway relative to value added in the public sector Sweden, plotted against the oil price.

oil importer, together with the price of oil. ${ }^{1}$ The figure shows clearly that the growth in the Norwegian economy, relative to Sweden's GDP, is highly correlated with the price of oil (left frame). This not only holds for GDP, but for value added in the public sector as well (right frame). This is at odds with theoretical predictions and common perceptions, and motivates a closer scrutiny of fiscal policy over the business cycles.

However, Figure 1 suggests yet another stylized fact; the price of oil is highly correlated with global activity. This is in particular evident during the financial crisis, when both global activity and oil prices fell sharply. But also prior to the crisis, global demand and oil prices moved together. In line with this, recent studies have emphasized the role of global demand as a driver of oil prices, see, e.g., Kilian (2009). Furthermore, Kilian (2009) shows that if oil prices increase due to spurs of demand (rather than disruptions of supply capacity, see, e.g., Hamilton (1983)), global economic activity will be positively affected, at least in the short run. Corroborating results are shown in, e.g., Lippi and Nobili (2012), Peersman and Van Robays (2012), Aastveit et al. (2015), Charnavoki and Dolado (2014) and Bjørnland and Thorsrud (2015) for various oil importing and oil exporting countries.

Thus, and in line with these findings, when analysing fiscal policy responses to commodity price shocks, we control for shocks to global activity. Previous studies addressing this issue have typically ignored any simultaneity between global activity and oil prices, and treat instead oil prices as exogenous, see e.g., Pieschacon (2012) and Céspedes and Velasco (2014) among others. In particular, Céspedes and Velasco (2014) draw their

\footnotetext{
${ }_{1}^{1} \overline{\text { Apart from Sweden being an oil importer, }}$ the two countries share many other important characteristics, e.g., they are both small and open economies, enjoy good institutions, have a generous welfare state etc.
} 
conclusion from comparing government expenditures over two different commodity price cycles by a large panel of commodity exporting countries, while Pieschacon (2012) designs a counterfactual analysis comparing the impulse responses to an exogenous oil price shock in Norway and Mexico in the period 1986-2006. Doing so, both studies provide evidence of reduced fiscal procyclicality to commodity price changes in the recent commodity price boom, and attributes this to improved institutional quality, i.e., adopted fiscal policy rules. $^{2}$ Yet, if global demand is an important source of variation in commodity prices, in particular in the recent commodity price boom, one should expect fiscal policy to be, exactly, countercylical. Not necessarily because the countries have reduced government expenditures relatively to GDP, but simply because GDP has increased.

And indeed, when we control for aggregate activity, we confirm that the countercyclical fiscal responses found in the recent commodity price boom should be attributed to global activity shocks and their domestic propagation, rather than the adopted fiscal framework.

Our framework contributes to the literature in two additional ways. First, comparing fiscal policy responses across different commodity exporters, as many other studies do, implicitly assumes that the countries are in the same stages of development. This is seldom the case, as countries may have extracted the windfall gain at different points in time. For instance, Mexico was producing oil already by the turn of the twentieth century, and is today a mature oil exporter, with oil and gas production accounting for 7-8 percent of GDP. Norway, on the other hand, discovered its oil fields 70 years later and oil and gas production accounts today for close to 25 percent of total GDP. In this sense, comparing the effects of commodity price shocks on a mature and a new oil producer, like in, e.g., Pieschacon (2012), is likely to suggest different responses that have nothing to do with he adoption of fiscal rules per se, but simply reflect different stages of development. ${ }^{3}$ Moreover, apart from being commodity exporters, Mexico and Norway in most other areas are highly dissimilar. We argue that it is more informative to compare fiscal responses in one country consistently over time than to compare fiscal responses across countries at a given time. Doing so, we confirm that if Norway has a more muted response to oil price

${ }^{2}$ Céspedes and Velasco (2014) find that in the earlier cycle (1970s), the fiscal balance deteriorates as expenditures pick up. For the latter cycle (2000s), however, they find evidence of reduced procyclicality in a number of countries, as fiscal expenditures falls relatively to GDP when commodity prices increase. This, they argue, corresponds well with the adoption of fiscal spending rules in many countries, including Norway. Using a counterfactual analysis, Pieschacon (2012) finds that had Norway adopted a fiscal policy framework similar to Mexico's, commodity price shocks would have had a larger effect on the (Norwegian) economy. She therefore concludes that the fiscal framework adopted by Norway does indeed shield the economy from oil price fluctuations.

${ }^{3}$ Using a related argument, Alexeev and Conrad (2009) control for initial endowment when comparing growth performance in resource rich countries, and find natural resources to enhance long term growth, which is quite the contrary to the findings of the traditional resource curse literature. 
shocks than countries like Mexico, it is for other reasons than the adoption of the fiscal rule.

Second, countries adopt fiscal rules in response to changing economic conditions. In addition, the fiscal policy design is often particularly complex insofar as countries combine the objectives of sustainability with the need for flexibility in response to shocks, see Schaechter et al. (2012) for details. Norway is no exception. The current fiscal framework states that the government's non-oil structural deficit should equal the long-run real return of the sovereign wealth fund, i.e., the Government Pension Fund - Global (GPF), projected to be 4 percent. To ensure against inherent procyclical behaviour, the fiscal guidelines also allow temporary deviations from the rule over the business cycle and in the event of extraordinary changes in the value of the GPF. The GPF is therefore a hybrid between a savings- and a stabilization fund; As a savings fund, the main purpose is to build up reserves and save for future generations. As a stabilization fund; the aim is to protect and stabilize the budget, and hence the economy, from excess volatility in petroleum revenues. As a consequence, when one compares economic effects of fiscal policy designs prior to and following their implementation, one need to control for time-varying changes in macroeconomic conditions as much as in the specific policy implementation.

The Dynamic Factor Model we develop permits us to address these shortcomings in the existing literature in a consistent manner. We include stochastic volatility components to allow for changes in the size of the structural shocks, e.g., the Great Moderation effect and the recent financial crisis and Great Recession, ${ }^{4}$ and we include time-varying factor loadings to allow for changes in systematic policy responses across time, e.g., before and after the adoption of the fiscal rule. The time-varying Dynamic Factor Model developed here relates to the models used by Lopes and Carvalho (2007), Del Negro and Otrok (2008), and Ellis et al. (2014), but differs in the way we identify the dynamic factors, and in the way we model the law of motion of the dynamic factors. In our contribution the dynamic factors are all identified in terms of economic quantities. Importantly, this allows us, in contrast to most other factor model studies, to build on the structural VAR literature, Primiceri (2005) in particular, and identify the structural shocks driving the dynamic factors. For this reason we are also able to trace out the effect of different oil market shocks, i.e., global demand and oil price shocks, on a number of public and non-public variables.

We have two main results. First, we find that in the wake of oil price shocks (that are orthogonal to global activity), fiscal policy is procyclical on impact and over response horizons. In particular, public spending, employment and wages in Norway all increase ${ }^{4}$ See, e.g., Cogley and Sargent (2005), Primiceri (2005), and Nakov and Pescatori (2010), and the references therein, for a broader discussion of these effects and their possible causes. 
in light of the higher oil prices, and, if anything, fiscal policy has been more (not less) procyclical since the adoption of the fiscal policy rule in 2001. That is, given an equally sized oil price shock, public spending and costs increase more today than they did in the preceding decades. We also find a stronger pass-through of oil price shocks to the macro economy after the adoption of the fiscal rule, in particular during the last decade. Hence, taking everything else as given and following an oil price shock, the adoption of the spending rule has not meant that fiscal policy effectively insulates the economy from an oil price shock. These findings stand in rather stark contrast to the arguments put forward in, e.g., Pieschacon (2012).

Second, following a global activity shock, that also increases oil prices, the picture becomes somewhat more nuanced, with some components of public spending alternating from countercyclical to acyclical in the last decade, while others are more procyclical. Thus, the main message is still that of a tendency for more (not less) fiscal procyclicality since the adoption of the spending rule. At the same time, the domestic non-resource economy responds strongly procyclically following the global activity shock. This shock also explains an increasing share of the variation in the economy since the turn of the millennium. The strong countercyclical fiscal policy responses (relative to GDP) in the last boom, as reported by Céspedes and Velasco (2014), among others, are therefore most likely due to global activity shocks and their domestic propagation, rather than fiscal policy governed by a rule.

Our results make it clear that as a stabilization fund the Norwegian GPF and the fiscal framework has been procyclical despite a rule. From a theoretical perspective, this may seem surprising. As discussed more fully in Section 4.4, our interpretation is that a fiscal rule that withdraws a fixed percentage of a growing fund each year will simply not be sufficiently countercyclical over the commodity price cycles. This has been particularly evident during the large increase in spending potential caused by the massive hike in commodity prices the last decade. Yet, as a savings fund, many of the goals of the Norwegian GPF have been achieved. In particular, by only using a small share of the windfall gain every year, the Norwegian authorities have saved a large amount of money for future generations. Compared to many other resource-rich economies practising a more spend-as-you-go strategy, this is, of course, a great success, as also documented in our counterfactual analysis. From a policy point of view, the implications of our findings are therefore of practical importance and general interest for resource rich countries, since they highlight the strengths and weaknesses of the fiscal framework adopted in country whose handling of petroleum wealth is considered to be exemplary.

The remainder of the paper is structured as follows. In Section 2 we briefly describe the historical evolution of Norway's fiscal framework, paying particular attention to the 
introduction of the fiscal rule. Section 3 details the model and the estimation procedure. Section 4 discusses the oil market shocks and analyses their effect on fiscal policy and the domestic economy. Section 5 concludes.

\section{The Fiscal framework}

Since the mid 1990s, Norway has been transferring the totality of its petroleum cash flow to a sovereign wealth fund. The fund was established in 1990 as the Government Petroleum Fund; in 2006, it was renamed the Government Pension Fund Global (GPF). The change highlighted the fund's role in saving government revenue to finance an expected increase in future public pension costs. Despite its name, the fund has no formal pension liabilities. As emphasized in the introduction, the GPF is a hybrid between a saving and a stabilisation fund. It's main purpose is to save and invest petroleum income in international capital markets, the product of which can be used in the Norwegian economy at a later date. Doing so will leave part of the oil wealth to future generations, while also protect and stabilize the budget, and hence the economy, from excess volatility in petroleum revenues, see Johnson-Calari and Rietveld (2007) for details on saving and stabilization funds.

The idea of establishing a hybrid fund came after periods of large budget deficits and poor economic conditions in Norway following the severe oil price decline in 1986, see Lie (2013). During the first few years, however, the fund failed to generate a surplus, and the fiscal policy guidelines at the time suggested an unchanged use of petroleum revenues, i.e., a neutral fiscal stance, as measured by the structural, non-oil budget balance, see Ministry of Finance (2001). High oil prices, large surpluses on the government budget and high allocations to the GPF in the late 1990s, made it difficult to maintain a neutral fiscal stance. In 2001 the government therefore devised a fiscal policy strategy allowing for a prudent increase in the spending of petroleum revenues. According to the policy guidelines, only the expected real return on the Sovereign Wealth Fund (projected to be 4 percent) was to be returned to the budget for general spending purposes. ${ }^{5}$ This should smooth the spending generated from the oil wealth, while ensuring that Norway maintained a strong international exposed sector, thereby insulating the economy from Dutch disease (crowding out of the private sector).

However, fiscal policy also plays an important role in stabilizing output fluctuations

${ }^{5}$ The fiscal rule is defined as a balanced budget rule, as it restricts the non-oil budget deficit, see Schaechter et al. (2012). Many countries also adopt additional rules restricting spending. For instance, Sweden has both a balanced budget rule and an expenditure rule, the latter defining a ceiling for central government expenditures and pensions. 
in two additional ways. First, it stabilizes the fiscal impulse over and above longer term smoothing by allowing deviations from the 4 percent rule to counteract large cyclical variations in economic activity or sharp swings in the value of the Fund. This should give the government manoeuvrability in fiscal policy should oil prices drop or the mainland economy contract (or vice versa). Second, to prevent fiscal policy from exacerbating the effect of commodity price fluctuations on the Norwegian economy, the rule is expressly defined in terms of the structural non-oil balance. This allows full effect of the automatic fiscal stabilizers in contrast to inherently procyclical rules on the actual deficit.

Since the 2001 adoption of the fiscal rule, the GPF has developed rapidly and is today the largest sovereign wealth fund in the world; it's value being close to 200 percent of GDP in Norway. This notwithstanding, very little is actually known about how, or indeed if, such a rule manages to shield an oil economy from oil price fluctuations, as theory predicts.

\section{The model}

We identify four factors with associated structural shocks, all motivated by findings in the recent oil-macro literature. First, as stressed in the introduction, the price of oil should be treated as endogenous insofar as the macroeconomic responses to higher oil prices differ markedly depending on the cause of the price rise. Accordingly, we include a measure of global activity and the real price of oil as two separate factors in the model to capture developments in the oil market as well as international business cycle conditions. This allows us in turn to identify two "oil market shocks": a global activity shock and an oil price shock, both of which increase the real price of oil, though with potentially very different macroeconomic implications.

Important to our set-up is also the separation of a windfall gain due to resource and spending effects. In particular, we account for spillovers from the petroleum sector to the non-oil sectors due to increased demand for resources, in addition to the spending effect coming via the public sector. Previous studies, such as Pieschacon (2012), typically assume that the output from the resource sector only provides a source of income from export sales, which the government collects. Hence, there will be no spillover to the rest of the economy during the process of extracting the resources. Similar conclusions are drawn in Husain et al. (2008). This is hardly the case for Norway. In particular, as shown theoretically and empirically in Bjørnland and Thorsrud (2015), when the extraction of resources demands complicated technical solutions, as it does in Norway, learning-bydoing spillovers from the resource sector to the non-resource sectors of the economy can be substantial. ${ }^{6}$ For this reason we also identify in the DFM two separate activity factors

\footnotetext{
${ }_{6}$ Similar findings are also found for mineral-abundant Australia in Bjørnland and Thorsrud (2015), and, al-
} 
for the resource and non-resource (domestic) industries of the economy. This allows the public sector (and the domestic economy in general) to respond differently to a windfall gain due to an activity shock in the resource sector (new discoveries, increased extraction rates etc.) and a windfall gain due to higher oil prices.

The four structural shocks, a global activity shock, an oil price shock, a resource activity shock and a domestic activity shock, are identified using a recursive ordering. Our main focus is on the fiscal responses caused by the global activity shock and the oil price shock, which both can affect oil prices. We then ask, has fiscal policy been less procyclical with higher oil prices since adopting the fiscal policy rule, and has this contributed to shelter the economy from oil price fluctuations?

In the DFM, the factors and shocks will be linearly related to a large panel of domestic variables, including tradable and non-tradable, e.g., public, sectors of the economy. The large panel is needed to account for the sectoral spillovers that exists between the different industries of the economy, but also allows us to include a broad range of measures used in the literature to assess the degree of fiscal pro- or countercyclicality. To account for changing policy regimes, due to, e.g., the introduction of the fiscal rule in 2001, we allow for time-varying factor loadings. Finally, to account for changes in the volatility of the structural shocks, due to, e.g., Great Moderation effects, we allow for stochastic volatility.

Technically, the time-varying DFM relates to the set-up used in Del Negro and Otrok (2008). ${ }^{7}$ We deviate in the way we identify the latent factors and the factor loadings. Importantly, due to the identifying assumptions we employ, see Section 3.3, we are able to model the dynamics of the factors as an endogenous system, and thereby identify structural shocks. For the latter we utilize the framework proposed by Primiceri (2005).

\subsection{A time-varying Dynamic Factor Model}

Formally, the observation and transition equations of the time-varying DFM can be written as follows:

$$
\begin{aligned}
& y_{t}=z_{0, t} a_{t}+\cdots+z_{s, t} a_{t-s}+e_{t} \\
& a_{t}=\Phi_{1} a_{t-1}+\cdots+\Phi_{h} a_{t-h}+A 0_{t}^{-1} \Sigma_{t} \epsilon_{t} \\
& e_{t}=\Phi_{1} e_{t-1}+\cdots+\Phi_{p} e_{t-p}+\Upsilon_{t} u_{t}
\end{aligned}
$$

though using a very different methodology, for a variety of resource-rich countries in Allcott and Keniston (2014) and Smith (2014).

${ }^{7}$ Del Negro and Otrok (2008) apply a time-varying DFM to analyse international business cycle synchronization. Related models have also been applied in Eickmeier et al. (2011), Liu et al. (2014), and Ellis et al. (2014) to analyse the transmission of US financial shocks and UK specific business cycle developments. However, time-varying factor models were implemented in the financial literature before the macro economic literature, see, e.g., Aguilar and West (2000) and Lopes and Carvalho (2007). 
Equation (1a) is the observation equation, and the $N \times 1$ vector $y_{t}$ represents the observables at time $t . z_{j, t}$ is a $N \times q$ matrix with dynamic factor loadings for $j=0,1, \cdots, s$, and $s$ denotes the number of lags used for the dynamic factors $a_{t}{ }^{8}$ As mentioned above, we set $q=4$ and identify two foreign factors, global activity and the real oil price; and two domestic factors, one related to the resource sector and the other related to the remaining non-resource sectors. Note here that the two first (foreign) factors are treated as observables, while the latter two (domestic) factors are latent. We turn to the identification of these factors in Section 3.3.

The dynamic factors follow a $\operatorname{VAR}(\mathrm{h})$ process, given by the transition equation in $(1 \mathrm{~b})$. Note that $h>s$ in our application. We work with the convention that $\epsilon_{t} \sim$ i.i.d.N $(0, I)$ such that the covariance matrix of $A 0_{t}^{-1} \Sigma_{t} \epsilon_{t}$ in $(1 b)$ is denoted by $\Omega_{t}$. It follows that:

$$
A 0_{t} \Omega_{t} A 0_{t}^{\prime}=\Sigma_{t} \Sigma_{t}^{\prime}
$$

where $A 0_{t}$ and $\Sigma_{t}$ is a lower triangular matrix and a diagonal matrix, respectively:

$$
A 0_{t}=\left[\begin{array}{cccc}
1 & 0 & \cdots & 0 \\
a o_{21, t} & 1 & \ddots & 0 \\
\vdots & \ddots & \ddots & \vdots \\
a o_{q 1, t} & \cdots & a o_{q q-1, t} & 1
\end{array}\right] \quad \Sigma_{t}=\left[\begin{array}{cccc}
\sigma_{1, t} & 0 & \cdots & 0 \\
0 & \sigma_{2, t} & \ddots & 0 \\
\vdots & \ddots & \ddots & \vdots \\
0 & \cdots & 0 & \sigma_{q, t}
\end{array}\right]
$$

This decomposition of the covariance matrix $\Omega_{t}$ builds on the work of Primiceri (2005), and facilitates identification of the model's structural shocks, $\epsilon_{t}$, and their associated timevarying volatility, captured by $\Sigma_{t}$. In particular, the lower triangular structure of $A 0_{t}$ implies that we can identify the structural shocks using a simple recursive identification scheme. The economic rational for this choice is elaborated on in Section 3.3.

Lastly, equation (1c) describes the time series process for the $N \times 1$ vector of idiosyncratic errors $e_{t}$. We will assume these evolve as independent $\mathrm{AR}(\mathrm{p})$ processes with stochastic volatility. Thus, the parameter matrix $\Phi_{k}$ for $1 \leq k \leq p$ is:

$$
\Phi_{k}=\left[\begin{array}{cccc}
\Phi_{1, k} & 0 & \cdots & 0 \\
0 & \Phi_{2, k} & \ddots & 0 \\
\vdots & \ddots & \ddots & \vdots \\
0 & \cdots & 0 & \Phi_{N, k}
\end{array}\right]
$$

\footnotetext{
${ }^{8}$ In the proposed model the observables are a function of time-varying factor loadings and covariances. An alternative assumption would have been to allow for time variation in the parameters associated with the law of motion for the factors instead, as done in, e.g., Ellis et al. (2014) and Eickmeier et al. (2011). We do not follow this route. As described in Appendix E, the factor loadings in the observation equation of the system can be estimated one equation at the time. The parameters of the law of motion for the factors must be estimated jointly. With four factors and a substantial number of lags in the transition equation, see Section 3.2, this increases the computational burden considerably, and would likely not result in any meaningful estimates.
} 
and similarly to above, denoting the covariance matrix of the heteroscedastic unobservable shocks in $(1 \mathrm{c})$ as $H_{t}$, and under the assumption that $u_{t} \sim$ i.i.d.N $(0, I)$, we have that:

$$
H_{t}=\Upsilon_{t} \Upsilon_{t}^{\prime}
$$

where $\Upsilon_{t}$ is the diagonal matrix:

$$
\Upsilon_{t}=\left[\begin{array}{cccc}
\eta_{1, t} & 0 & \cdots & 0 \\
0 & \eta_{2, t} & \ddots & 0 \\
\vdots & \ddots & \ddots & \vdots \\
0 & \cdots & 0 & \eta_{N, t}
\end{array}\right]
$$

The model's time-varying parameters and stochastic volatilities are assumed to follow Random walk processes. In particular, let:

$$
Z_{t}=\left[z_{0, t}, \ldots, z_{s, t}\right]
$$

and $z_{t}=\operatorname{vec}\left(Z_{t}^{\prime}\right)$ (the matrix $Z_{t}$ stacked by rows) be a vector of the factor loadings at time $t, a o_{t}$ the vector on non-zero and non-one elements of the matrix $A 0_{t}$ (stacked by rows), and finally let $\sigma_{t}$ and $\eta_{t}$ be the vectors of diagonal elements of the matrices $\Sigma_{t}$ and $\Upsilon_{t}$, respectively. The dynamics of the model's time-varying parameters will thus be specified as follows:

$$
\begin{aligned}
z_{t} & =z_{t-1}+w_{t} \\
a o_{t} & =a o_{t-1}+s_{t} \\
h_{t}^{\sigma} & =h_{t-1}^{\sigma}+b_{t} \\
h_{t}^{\eta} & =h_{t-1}^{\eta}+v_{t}
\end{aligned}
$$

where $h_{t}^{\sigma}=\log \left(\sigma_{t}\right)$ and $h_{t}^{\eta}=\log \left(\eta_{t}\right)$

The time-varying factor loadings are introduced in the DFM to capture potential changes in how the variables in the domestic economy relates to the factors, and seems to us like a reasonable assumption given the changing nature of how, e.g., fiscal policy has been conducted in Norway in recent decades, see Section 2. Alternative empirical strategies could have been used; e.g., splitting the sample in two around the time period when the fiscal rule was implemented. One major drawback with this strategy, compared to the time-varying specification we use, is that it implicitly assumes that within each sample split the regimes (or parameters) are constant. As shown below, this is not the case. The random walk assumptions for $h_{t}^{\sigma}$ and $h_{t}^{\eta}$ are common in the macroeconomic literature entertaining stochastic volatility, and simplify estimation of the model as no autoregressive parameters need to be estimated. Given the well-documented changes in 
elasticities in the oil market in recent decades, see, e.g., Baumeister and Peersman (2013), and the increase in the resource industry's share of GDP in Norway since the early 1980s to today, we also allow $a o_{t}$ to vary across time, implying that the contemporaneous spillovers between the factors in the model are time-varying as well. ${ }^{9}$

All the errors in the model are assumed to be jointly normally distributed, and we work with the following assumptions on the covariance matrix of the errors:

$$
\operatorname{var}\left(\left[\begin{array}{c}
u_{t} \\
\epsilon_{t} \\
w_{t} \\
s_{t} \\
b_{t} \\
v_{t}
\end{array}\right]\right)=\left[\begin{array}{cccccc}
I_{N} & 0 & 0 & 0 & 0 & 0 \\
0 & I_{q} & 0 & 0 & 0 & 0 \\
0 & 0 & W & 0 & 0 & 0 \\
0 & 0 & 0 & S & 0 & 0 \\
0 & 0 & 0 & 0 & B & 0 \\
0 & 0 & 0 & 0 & 0 & V
\end{array}\right]
$$

Here, as already indicated above, $I_{N}$ and $I_{q}$ are identity matrices of dimension $N \times N$ and $q \times q$. $W$ and $S$ are assumed to be block diagonal matrices:

$$
W=\left[\begin{array}{cccc}
W_{1} & 0 & \cdots & 0 \\
0 & W_{2} & \ddots & 0 \\
\vdots & \ddots & \ddots & \vdots \\
0 & \cdots & 0 & W_{N}
\end{array}\right] \quad S=\left[\begin{array}{cccc}
S_{1} & 0 & \cdots & 0 \\
0 & S_{2} & \ddots & 0 \\
\vdots & \ddots & \ddots & \vdots \\
0 & \cdots & 0 & S_{q-1}
\end{array}\right]
$$

where $W_{i}$ for $i=1, \ldots, N$ is a $m \times m$ matrix, with $m=q(s+1)$, and $S_{1}$ is a $1 \times 1$ matrix, $S_{2}$ is a $2 \times 2$ matrix, and so on. ${ }^{10} B$ is a $q \times q$ matrix, while $V$ is a diagonal $N \times N$ matrix.

An important aspect of the restrictions put on (8) is their rendering of the structural shocks driving the dynamics of transition equation $\epsilon_{t}$ as independent from the shocks driving the evolution of the time-varying factor loadings $w_{t}$ (and all other disturbances in the model). This allows us to utilize the standard SVAR machinery to analyse impulse responses and variance decompositions to the $\epsilon_{t}$ shocks, but at the same time identify changes in, e.g., systematic fiscal policy, captured by the $w_{t}$ shocks. However, less restrictive assumptions regarding (8) can be justified, see Primiceri (2005) for a broader discussion. Nevertheless, relaxing the number of restrictions comes at a price, requiring us to estimate a substantially larger amount of parameters. As the proposed time-varying DFM is already heavily parametrized we do not believe this to be a feasible option in the current setting.

\footnotetext{
${ }^{9}$ One can question the importance of allowing for changes in the volatility of the idiosyncratic shocks $h_{t}^{\eta}$. We find, but do not report, that also these volatilities change considerably across time.

${ }^{10}$ That is, $S_{1}$ is associated with $a o_{21, t}$ in (3), $S_{2}$ is associated with $a o_{31, t}$ and $a o_{32, t}$ in (3), etc.
} 


\subsection{Model specification and data}

In the model specification used to produce our main results we allow for one lag of the dynamic factors in the observation equation (1a) of the system, i.e., $s=1$. This is somewhat more restrictive than what was found to fit the data best in a related study analysing spillovers from the oil sector on the Norwegian economy, albeit with constant parameters, employed in Bjørnland and Thorsrud (2015). On the other hand, allowing for time-varying parameters increases the potential for good model fit, and therefore also the need for many lags in the observation equation of the system. Further, as shown in, e.g., Hamilton and Herrera (2004) among others, a large number of lags are needed to capture the dynamics in the oil-macro relationship. For this reason we allow for up to eight lags in equation (1b) describing the law of motion of the factors, implying that $h=8$. Finally, to capture autocorrelation in the observables not explained by the common factors we set $p=1$ in the autoregressive processes for the idiosyncratic errors.

To accommodate resource movement and spending effects within the petroleum exporting economy, as well the potential for learning spillovers between the resource sector and the rest of the economy, the observable $y_{t}$ vector includes a broad range of sectoral employment, production and wage series, see also Bjørnland and Thorsrud (2015). Turning to the fiscal variables, as described in, e.g., Kaminsky et al. (2004), many indicators can be used to assess the degree of pro- or countercyclical fiscal policy. An advantage with the factor model methodology is that we can look at many of these at the same time, possibly allowing for more robust conclusions. For this reason we include value added, wages, and employment in the public sector from the quarterly national account statistics. From the central government fiscal account we utilize fiscal revenues, expenditures, transfers to municipalities, and operating costs. Naturally, we also include the real exchange rate, a core variable in the Dutch disease literature. A full description of the data is given in Appendix A.

The two variables meant to capture the developments in the international commodity market are the real price of oil and a world economic activity indicator. The real price of oil is constructed on the basis of Brent Crude oil prices (U.S. dollars), deflated using the U.S. CPI. Our main consideration when constructing the global (or world) activity indicator was to include countries whose economic activity is most likely to affect the global oil market. In addition, to capture possible direct trade linkages, we include the most important trading partners. Hence, for Norway, we construct global activity as the simple mean of four-quarter logarithmic changes in real GDP in Denmark, Germany, the Netherlands, Sweden, the UK, Japan, China, and the U.S.

In sum, this gives a panel of roughly 50 international and domestic data series, covering a sample period from 1981:Q1 to 2012:Q4. Correcting for the number of lags imposed 
on the model leaves us with 124 observations that are used for estimation, covering the sample 1983:Q1-2012:Q4. ${ }^{11}$ To capture the economic fluctuations of interest, we transform all variables to year-on-year growth. Lastly, we remove the local mean (of the growth rates) and then standardize the resulting data before estimation. ${ }^{12}$

\subsection{Identification}

As is common for all factor models, the factors and factor loadings in (1) are not identified without restrictions. To separately identify the factors and the loadings, and to be able to provide an economic interpretation of the factors, we enforce the following identification restrictions on $z_{0, t}$ in (1a):

$$
z_{0, t}=\left[\begin{array}{c}
\tilde{z}_{0, t} \\
\hat{z}_{0, t}
\end{array}\right], \quad \text { for } t=0,1, \ldots, T
$$

where $\tilde{z}_{0, t}$ is a $q \times q$ identity matrix for all $t$, and $\hat{z}_{0, t}$ is left unrestricted. As shown in Bai and Ng (2013) and Bai and Wang (2012), these restrictions uniquely identify the dynamic factors and the loadings, but leave the $\operatorname{VAR}(\mathrm{h})$ dynamics for the factors completely unrestricted. Accordingly, the innovations to the factors, $\epsilon_{t}$, can be linked to structural shocks that are implied by economic theory.

The first two factors in the system, world activity and the real price of oil, are treated as observables and naturally load with one on the corresponding element in the $y_{t}$ vector. The latent domestic factors, resource and non-resource activity, must be inferred from the data. To ensure unique identification we require the domestic resource factor to load with one on value added in the petroleum sector, and the domestic non-resource factor to load with one on total value added excluding petroleum. Note that while these restrictions identify the latent factors, the factors and the observables are generally not identical due to the influence of the idiosyncratic errors.

Based on the recursive structure of $A 0_{t}$ in (3), we identify four structural shocks: a global activity shock; an oil price shock; and two domestic shocks: a resource and nonresource activity shock, respectively. That is, $a_{t}=\left[a_{t}^{\text {gact }}, a_{t}^{\text {oil }}, a_{t}^{r}, a_{t}^{n r}\right]^{\prime}$, where $[$ gact, oil, $r, n r]$ denote global activity, oil price, resource activity and non-resource activity. Accordingly, the vector with structural disturbances is:

$$
\epsilon_{t}=\left[\epsilon_{t}^{g a c t}, \epsilon_{t}^{o i l}, \epsilon_{t}^{r}, \epsilon_{t}^{n r}\right]^{\prime}
$$

${ }^{11}$ The sample periods reflect the longest possible time for which a full panel of observables is available. The vintage of quarterly national account statistics we use was generously provided to us by Statistics Norway. In the official statistics, these numbers (for employment) do not cover the earlier part of our sample. The prolonged vintage of data ends in 2012:Q4.

${ }^{12}$ As the transformed stationary data inhabits very different volatilities, we do the standardization to make the estimation less sensitive to the prior specifications. See Appendix A for details. 
As implied by $A 0_{t}$, we follow the usual assumption made by both theoretical and empirical models of the commodity market, and restrict global activity to respond to oil price disturbances with a lag. This restriction is consistent with the sluggish behavior of global economic activity after each of the major oil price hikes in recent decades, see e.g., Hamilton (2009). Furthermore, we do not treat commodity prices as exogenous to the rest of the global macro economy. Any unexpected news regarding global activity is assumed to affect real oil prices contemporaneously. This is consistent with recent work in the oil market literature, see, e.g., Kilian (2009), Lippi and Nobili (2012), and Aastveit et al. (2015). In contrast to these papers, and to keep our empirical model as parsimonious as possible, we do not explicitly identify a global commodity supply shock. ${ }^{13}$ Turning to the domestic factors, in the very short run, disturbances originating in the Norwegian economy can not affect global activity and the price of oil. These are plausible assumptions insofar as Norway is a small, open economy. However, both of the domestic factors respond to unexpected disturbances in global activity and the real oil price on impact. In small open economies such as Norway's, news regarding global activity will affect variables such as the exchange rate, the interest rate, asset prices, and consumer sentiment contemporaneously, and in consequence overall demand in the economy. Norway is also an oil exporter, and any disturbances to the real price of oil will most likely rapidly affect both the demand and supply side of the economy.

The restrictions suggested here are motivated by the Dutch disease theory model presented in Bjørnland and Thorsrud (2015). As in that study, and as argued above, the identification scheme employed is needed to correctly quantify the domestic spillovers from unexpected windfall gains and changing international business cycle conditions in a small and open resource-rich economy. However, in contrast to the Bjørnland and Thorsrud (2015) study, the domestic shocks and their spillovers are not in focus here and we do not discuss them other than to emphasize that by including the $\epsilon_{t}^{r}$ shock we are able to control for the fact that the domestic economy, and the public sector in particular, might respond differently to a windfall gain due to an activity shock in the resource sector and a windfall gain due to higher oil prices, see the discussion in Section 3.

We note that all observable variables in the model, apart from the ones used to identify the factors, may respond to all shocks on impact inasmuch as they are contemporaneously related to the factors through the unrestricted part of the loading matrix (i.e., the $\hat{\lambda}_{0, t}$ matrix in equation (10)). The recursive structure is therefore only applied to identify the shocks. Together, equations (10) and (11) make the structural DFM uniquely identified.

\footnotetext{
${ }^{13}$ However, as shown in Kilian (2009), and a range of subsequent papers, such supply shocks explain a trivial fraction of the total variance in the price of oil, and do not account for a large fraction of the variation in real activity either (at least during the sample covered here).
} 


\subsection{Estimation}

We estimate the time-varying DFM using Bayesian estimation, decomposing the problem of drawing from the joint posterior of the parameters of interest into a set of much simpler ones using Gibbs simulations. Gibbs simulations are a particular variant of Markov Chain Monte Carlo (MCMC) methods that samples a high dimensional joint posterior by drawing from a set of lower dimensional conditional posteriors. The Gibbs simulation we employ is described in greater detail in Appendix E. Here we describe in brief the sampling algorithm, which consists of sequentially drawing the model's unobserved state variables, $a_{t}, e_{t}, z_{t}, a o_{t}, h_{t}^{\sigma}$, and $h_{t}^{\eta}$, and hyper-parameters, $\Phi, \Phi, W, S, B$, and $V$, utilizing 7 blocks until convergence is achieved. In essence, each block involves exploiting the state space nature of the model using the Kalman filter and the simulation smoother suggested by Carter and Kohn (1994).

In Block 1, conditional on the data $\left(\tilde{y}_{T}\right)$, and all the hyper-parameters and state variables less $\tilde{a}_{T}$, equations (1a) and (1b) constitute a standard linear and conditionally Gaussian state space system, with $\tilde{a}_{T}$ unknown. Accordingly, the simulation smoother proposed by Carter and Kohn (1994) is straight forwardly applied. Conditional on $\tilde{a}_{T}$, equation (1b) is independent of the rest of the system, and reflects a time-varying VAR model. Hence, in Blocks 2 to 4 of the sampler, we can simulate from the conditional posterior distribution of $\tilde{a o}_{T}, \tilde{h}_{T}^{\sigma}, \Phi, S$ and $B$ using the same procedures as described in, e.g., Primiceri (2005). In essence, this simulation consists of three blocks that sequentially draws from the conditional posterior of $\Phi, \tilde{a o}_{T}, S, \tilde{h}_{T}^{\sigma}$, and $B$, in that order, and where the sampling of the time-varying states relies on small reformulations of the system such that the standard simulation smoother can be employed. Especially, we note that to be able to sample $\tilde{h}_{T}^{\sigma}$ we rely on the method presented in Kim et al. (1998), using mixtures of Normal distributions. Drawing from the conditional posterior of $S$ and $B$ is standard, since it is the product of independent Inverse-Wishart distributions.

In Block 5, conditional on the data and all the hyper-parameters and state variables less $\tilde{z}_{T}$, equations (1a) and (1b) again constitute a standard state space system, but now with $\tilde{z}_{T}$ unknown. In the same manner as above, we can use the standard simulation smoother to simulate the conditional posterior of $\tilde{z}_{T}$. Conditional on $\tilde{z}_{T}$, equation (7a) is independent of the rest of the system, and is easy to sample from the conditional posterior of $W$ using the Inverse-Wishart distribution.

Finally, in Blocks 6 and 7, conditional on the data, $\tilde{a}_{T}$, and $\tilde{z}_{T}$, we can infer $\tilde{e}_{T}$. Moreover, conditionally on $\tilde{e}_{T}$, the structure of equation (1c) is similar to that of equation (1b), and the same procedures as those described for Blocks 2 to 4 above, can therefore be applied here too. The problem is now somewhat simpler, however, since we do not need to sample time-varying covariances, only variances. That is, conditionally on $\tilde{e}_{T}$ and 
$h_{t}^{\eta}$, we can sample $\Phi$, and conditional on $\tilde{e}_{T}$ and $\Phi$, we can sample $h_{t}^{\eta}$, and consequently, $V$.

To generate the posterior draws, the simulations in this paper are all based on 20000 iterations of the Gibbs sampler. The first 14000 are discarded and only every sixth of the remaining iterations are used for inference. As shown in Appendix $\mathrm{C}$ the convergence checks seem satisfactory. In Appendix D we describe the priors used for the initial state variables $a_{0}, z_{0}, a o_{0}, h_{0}^{\sigma}$, and $h_{0}^{\eta}$, and for the hyper-parameters $\Phi, S, B, W, \Phi$ and $V$. In the appendix we also report various sensitivity analyses, showing that our main results are robust to a set of alternative assumptions regarding the prior specifications.

\section{Oil market shocks and systematic fiscal policy}

In the following we examine the estimated responses to a set of fiscal and macroeconomic variables from the two oil market shocks; the oil price and the global activity shocks. Our aim is to analyze the response of fiscal policy over time, and in so doing, examine to what extent fiscal policy has contributed to insulate the domestic economy from the effects of the oil price and the global activity shocks, or, conversely, to exacerbate those effects. To organize the discussion, we will in particular examine whether we can observe changes in the response patterns prior to and after the introduction of the fiscal rule in 2001.

A complicating factor is the use in the literature of different measures of fiscal policy to gauge the degree of pro- or countercyclical fiscal policy. ${ }^{14}$ This makes it difficult to compare results across studies. In the following we define fiscal policy to be procyclical (countercyclical) for a given oil market shock if public value added, public wages, public employment, government spending, government operating costs, or transfers increase (decrease) following oil market shocks that increase the price of oil. We first examine the impulse responses in the level of the variables (as in Pieschacon (2012)) and then relative to GDP (as Céspedes and Velasco (2014) and others analyse). Finally, using the data from the central government accounts we define the primary balance as income (non-oil tax revenues) minus spending. A procyclical (countercyclical) fiscal policy implies that the primary balance responds negatively (positively) to positive oil market shocks, i.e, increasing (decreasing) spending ahead of income. In sum, these definitions follow more or less the same usage as in Kaminsky et al. (2004).

\footnotetext{
${ }^{14}$ For instance, while Pieschacon (2012) analyses impulse responses in government purchases and transfers to an exogenous oil price shock, Céspedes and Velasco (2014) estimate the effect of a change in commodity price on government expenditures relative to GDP. Others again do not control for shocks at all, and simply compare the fiscal impulse as a percentage of GDP relative to, say, the change in the output gap, see e.g. Lopez-Murphy and Villafuerte (2010) and Takáts (2012) among many others.
} 


\subsection{The Great Moderation, Recession and the global oil market}

We start by examining whether there has been a change in the volatility of shocks, so as to control for changing volatility when comparing fiscal responses over time. As shown in the first row of Figure 2, the volatility of the structural oil market shocks has indeed varied considerable over the sample. There is a marked decline in the volatility of the global activity shock during the 1980s and 1990s, but a subsequent pick up of volatility at the end of the sample. These "facts" are well known and commonly attributed to the Great Moderation and the Great Recession. The structural oil price shock also shows evidence of declining volatility in periods (i.e., during the 1990s), but with marked spikes of heightened volatility, in the early 1990s (the first Gulf War) and during the Great Recession. Similar patterns have also been reported in Baumeister and Peersman (2013), who explain the decline by a fall in oil supply elasticity.

The last two rows of Figure 2 report the impulse responses for world activity and the real price of oil following a world activity shock (left column) and an oil price shock (right column) for three different time periods; early (1983), intermediate (1997), and late (2012) in the sample. ${ }^{15}$ The results confirm that our identified oil market shocks are in line with the results found in the oil market literature: After an unexpected one standard deviation increase in global activity, the price of oil rises substantially on impact, reflecting that the price of oil is not exogenous to the macro economy, see, e.g., Kilian (2009), Lippi and Nobili (2012). Moreover, after a one standard deviation shock to the real price of oil, world activity falls, although with a lag. This is consistent with the fact that it takes time before the higher production costs associated with the higher oil price work their way through to actual output, see, e.g., Hamilton (2009).

Note also the differences in the response path of world activity and the real oil price to shocks over time. The differences in impact responses reflect the changes in volatility of the structural shocks, as already documented. However, we also observe some changes in the response path that relate to the changes in the overall covariance structure of the oil market, see Section 3.1 and equation (3). In particular, a world activity shock has stronger impact on the oil price at the end of the sample (2012) than it has in the earlier part of the sample (1983). This is consistent with studies documenting the important role for global demand as a driver for the real price of oil the last decade, see, Aastveit et al. (2015). For the oil price shock, the changing effects on world activity across time are minor, with the middle 1990s displaying slightly less volatile oil price shocks, and subsequently also a milder downturn in the world economy.

\footnotetext{
${ }_{15} \mathrm{As}$ will be discussed in more detail below, the dates also reflect periods when fiscal policy was governed
} by different fiscal regimes. Details for all time periods can be obtained on request. 
World activity shock
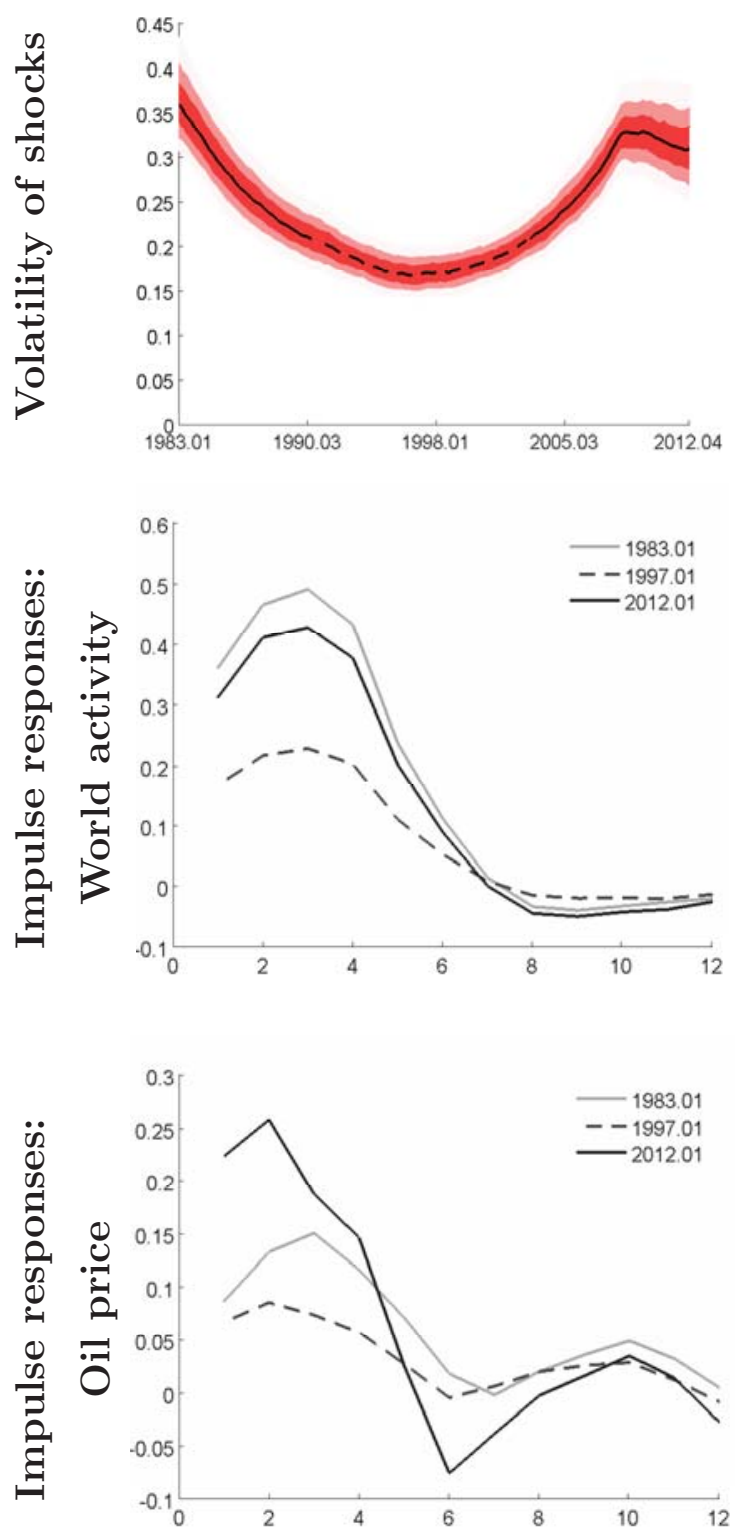

Oil price shock
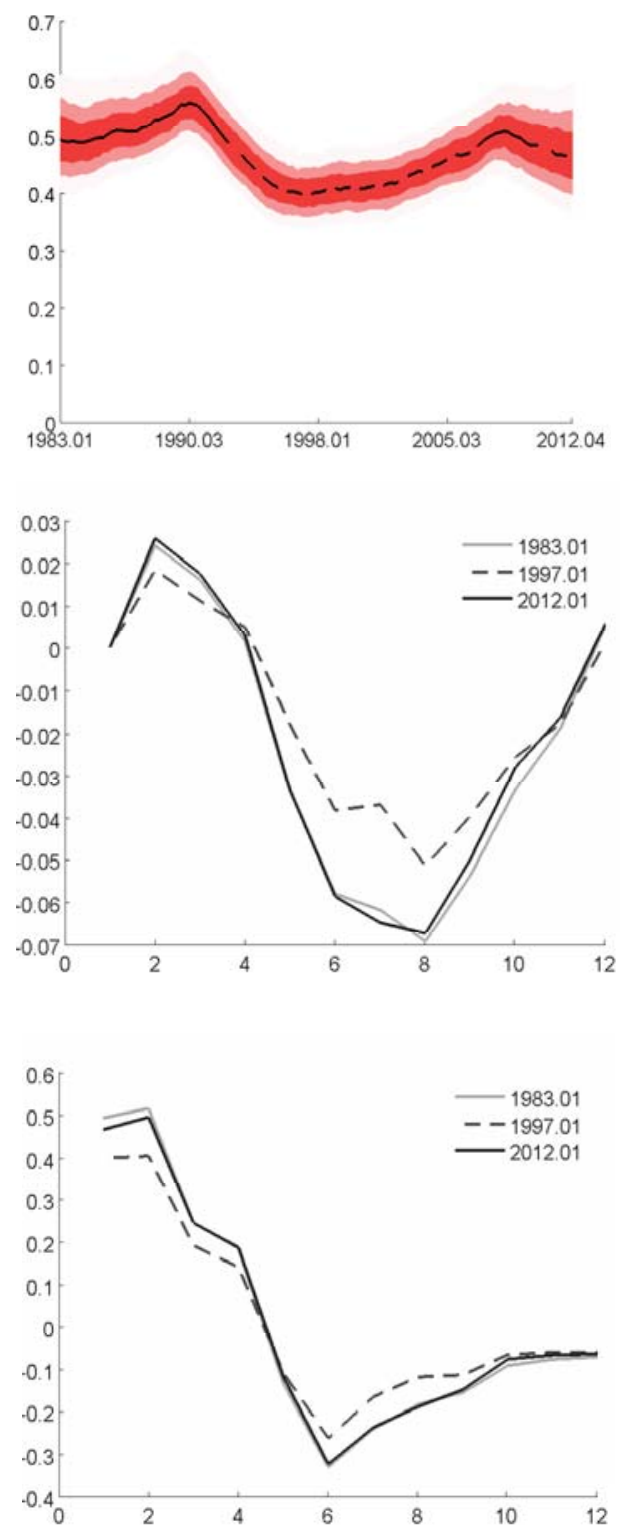

Figure 2. Time-varying volatility and oil market shocks. The first row reports the estimated standard deviation of the shocks across time. The color shadings represent the 70, 50, and 30 percent quantiles of the posterior distribution. The black line is the median estimate. The line is solid (dotted) whenever the median estimate is outside (inside) the 70 percent quantile in 2001:Q1. The two next rows report estimated impulse responses at three different periods of time. The initial shock correspond to a one standard deviation innovation (of the normalized data). All responses are reported in levels (of the normalized data).

\subsection{Procyclical or countercyclical fiscal policy?}

We now discuss the fiscal responses to the two oil market shocks. First, Figure 3 compares the evolution of the responses of some key variables in the public sector (value added, wages, employment and spending) to an oil price shock that increases the price of oil. In 
Horizons 1-12
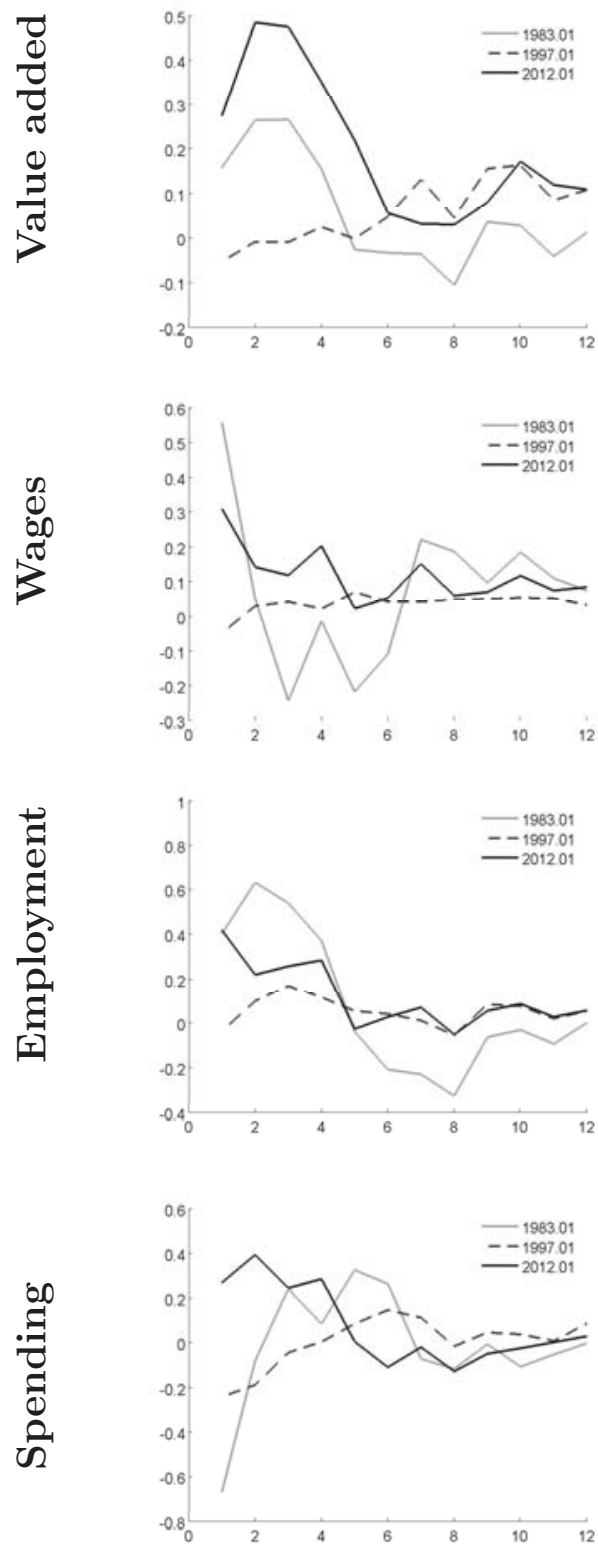

Horizon 1
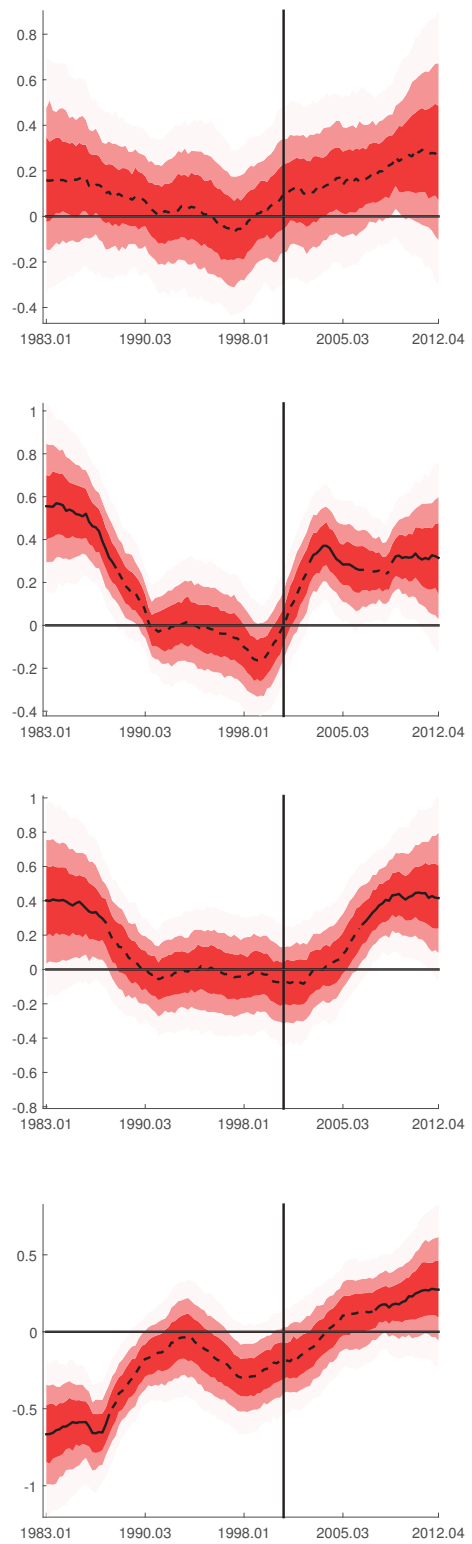

Horizon 4
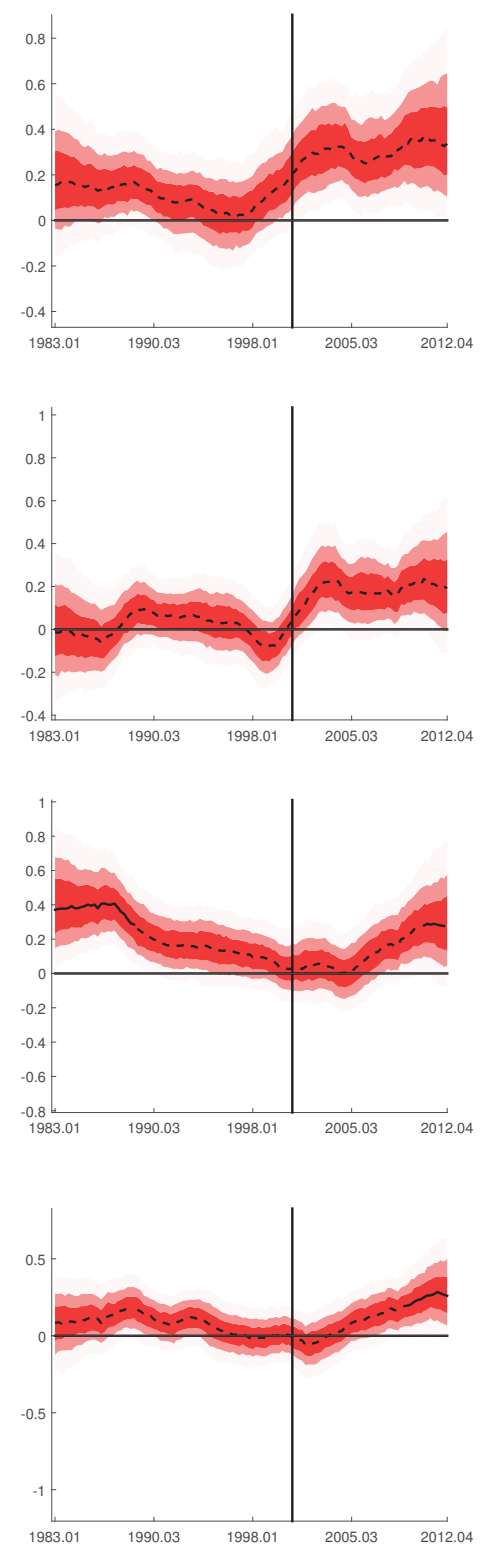

Figure 3. Oil price shock and the public sector: Time-varying responses. The first column displays estimated impulse responses at three different periods of time. The initial shock is normalized to one percent (of the normalized data). All responses are reported in levels (of the normalized data). The subsequent two columns report a snapshot of the responses across the whole sample for two specific response horizons. The color shadings represent the 70, 50, and 30 percent quantiles of the posterior distribution. The black line is the median estimate. The line is solid (dotted) whenever the median estimate is outside (inside) the 70 percent quantile in 2001:Q1. Finally, we plot a vertical line in 2001:Q1 to indicate the introduction of the fiscal rule.

each row, we first graph impulse responses for three specific periods in time: 1983, 1997, and 2012. The dates are chosen to reflect three comparable periods: the initial discovery period during which spending increased rapidly; the period just after the GPF started to generate some revenue (but fiscal policy was yet to be governed by a rule, but was intended 
Horizons 1-12
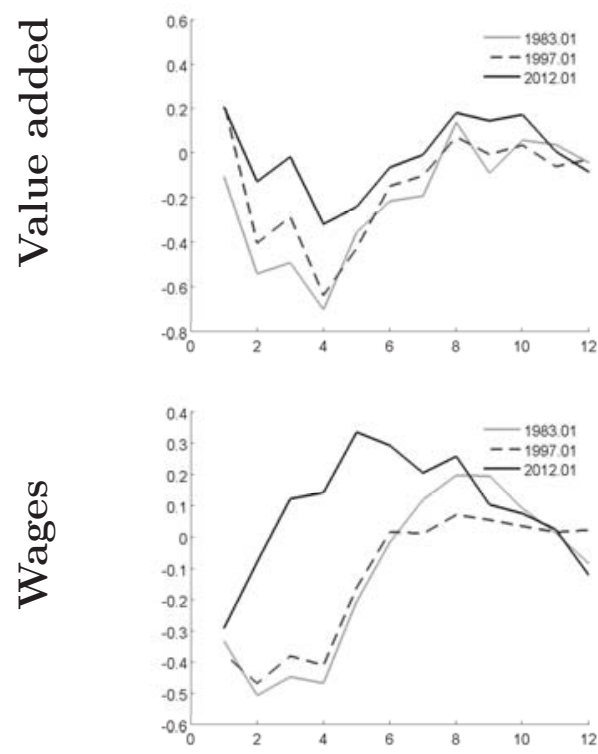

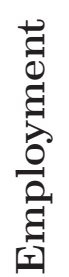
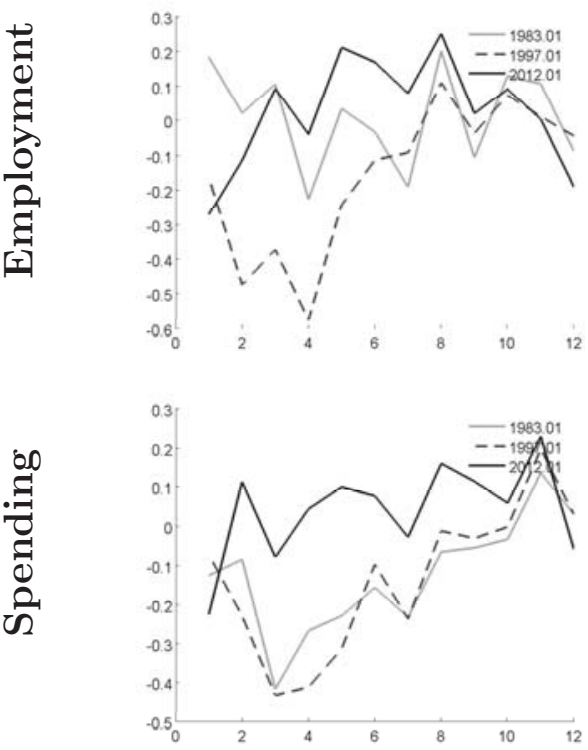

Horizon 1
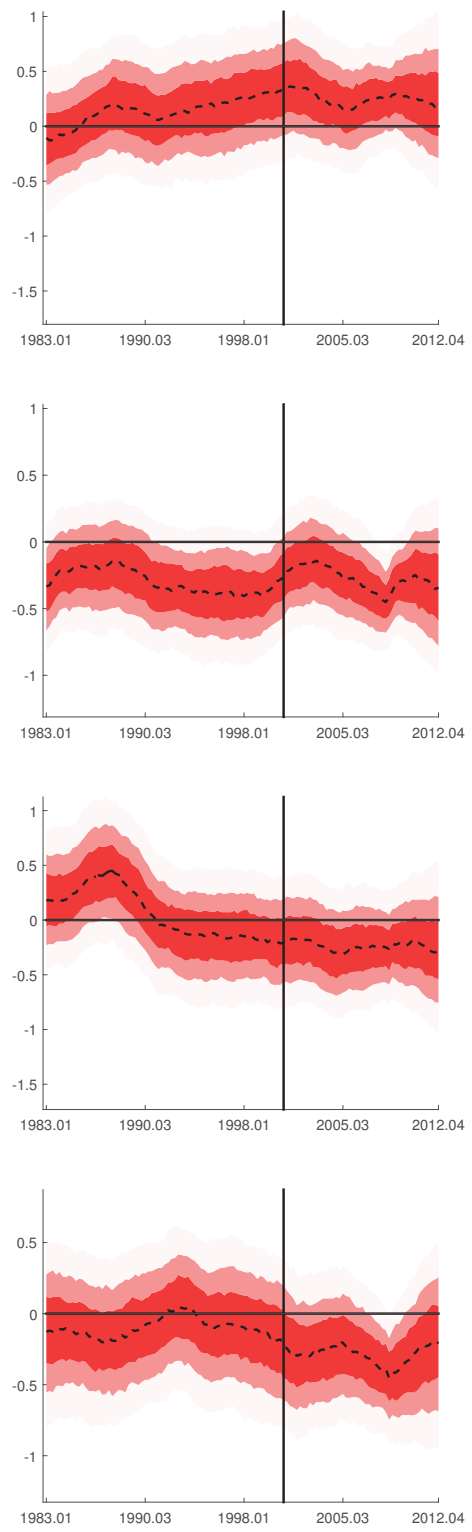

Horizon 4
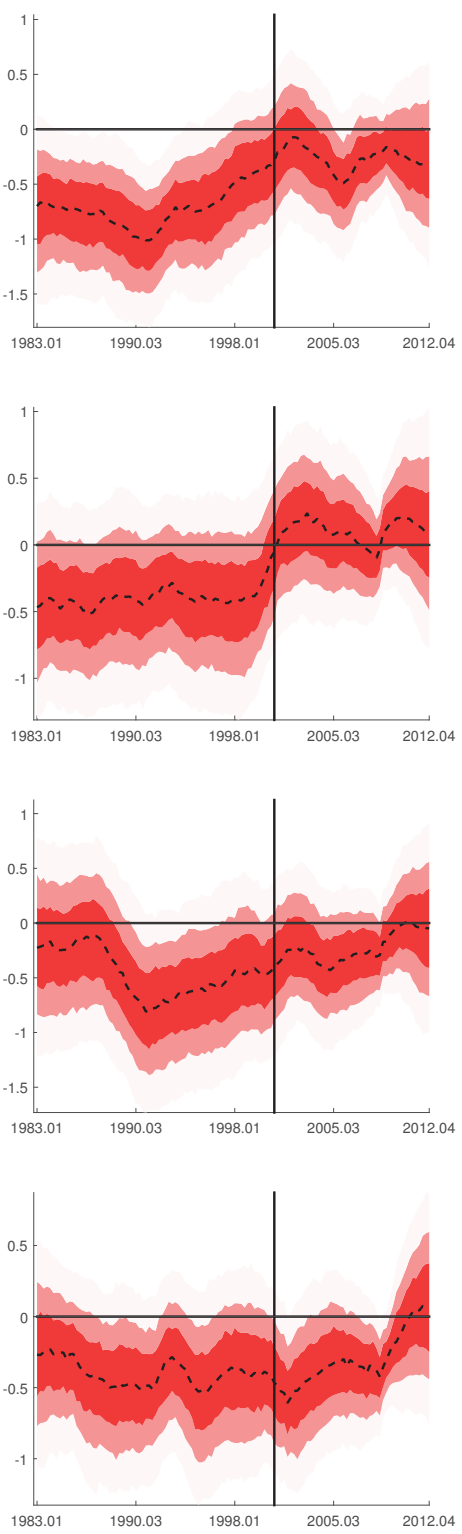

Figure 4. Global activity shock and the public sector: Time-varying responses. See Figure 3.

to remain neutral over the business cycle); and 10 years after the adoption of the fiscal rule. The two subsequent graphs offer more detail on the time-varying responses after 1 and 4 quarters, but now measured over the whole sample, and with probability bands representing the 70,50, and 30 percent quantiles of the posterior distribution. Figure 4 displays similar responses, but now due to a positive global activity shock. ${ }^{16}$

Starting with the oil price shock, i.e., an increase in the oil price that is not due to increased global activity, a few results stand out. First, fiscal policy responds procyclically to the oil price shock over the sample, even more so after the 2001 adoption of the fiscal

${ }^{16}$ Note that from now on we normalize the oil market shocks such that we compare similarly sized innovations across time (see the discussion in Section 4.1). 
framework. In particular, the positive effects of an oil price shock on value added, real wages, employment, and spending in the public sector are more pronounced today than in the decade preceding the rule, and for value added and spending, also more procyclical than in the 1980s, see Figure 3.

Turning to the global activity shock that spurred a rise in oil prices, c.f. Figure 2, the picture is somewhat more nuanced, with some components of public spending (value added and spending) alternating between countercyclical to acyclical during the last decade, while wages, in particular, shifts from a countercyclical pattern in the 1980s to a clearly procyclical pattern after 2001, see Figure 4 . The main message to take from this is still that of a tendency for more (not less) fiscal procyclicality since the adoption of the spending rule. This suggests that following a global downturn accompanied by a contraction of the domestic economy, there is less room for fiscal policy maneuvering. Figures 10 and 11 (Appendix B.2) provide more details on the procylicality of fiscal policy by analysing the effect on additional public sector variables. The graphs show that the increased fiscal procyclicality was particularly pronounced for spending (excluding pensions) and transfers to municipalities, while the increase in administrative expenses to oil price shocks has been more muted over the sample.

Summarizing, we find clear evidence of nonlinearities in the responses of fiscal policy to oil price and global activity shocks. In particular, public spending, employment, and wages have responded significantly more (not less) procyclically to these shocks since the adoption of the fiscal policy framework.

\subsection{Transmission of shocks and the domestic economy}

According to Pieschacon (2012), the fiscal framework adopted by Norway shields the economy from oil price fluctuations, implying only minor responses in domestic variables following an oil price shock. She further claims that had Norway been more like Mexico, without the fiscal policy framework in place, Norway would have had a larger share of variance in the domestic variables attributed to the oil price shock. ${ }^{17}$ Our focus here is not to compare Norway with Mexico, but to examine the extent to which the adoption of the fiscal rule contributed to lessen the exposure to oil market shocks. ${ }^{18}$ This is done in Figure 5. It shows the contribution of the different shocks in the model to the variance in public value added and domestic GDP, measured as the average over all domestic industries except the public sector, over time. We focus on the role of oil price and global

\footnotetext{
${ }_{17}$ The arguments are based on a counterfactual experiment, in which Norway and Mexico change parameters, but otherwise face their original shocks.

${ }^{18}$ Clearly, there may be many reasons why Norway is less exposed to oil market shocks than Mexico, including, for instance, less corruption, more efficient bureaucracy, less mature oil sector etc.
} 
activity shocks, marked blue and dark blue, respectively, for horizons 1, 4, and 8 .

Two features stand out. First, there is a marked difference in the role played by oil price shocks in explaining activity in the public sector since 2001. One year after the shock occurs (horizon 4), more than 40 percent of the variance in public value added is explained by oil price shocks by the end of the sample (2012), compared to 10 percent prior to the adoption of the fiscal rule (1998/1999). This pattern holds for all public variables (results can be obtained on request) and clearly emphasizes the increased role of oil price shocks in fiscal policy since 2001. Global activity shocks, on the other hand, do not explain much of the variation in fiscal policy the last decade. ${ }^{19}$ It is noteworthy that our findings encompass those in Pieschacon (2012), although we reach opposite conclusions. That is, based on an estimation period from 1986 to 2005 she finds that approximately 10 percent of government purchases are explained by oil price shocks after two years, which is not very different from what we also observe on average for the same period, see Figure 5. However, and as seen above, from 2001 the pattern changes markedly, suggesting increased exposure of the public sector to the oil market shocks.

Second, and turning to GDP in the domestic economy, we find that the oil price shocks explain more than 10 percent of the variance in the domestic variables at horizon 4. This is more than twice as much as is being explained in Pieschacon (2012). We also find an increase in the share explained by oil price shocks since 2001, albeit not to the extent of the public sector. Finally, the global activity shocks play an increasing role for GDP throughout the sample and in particular during the commodity price boom (the last decade). Impulse responses for GDP are reported in Figures 12 and 13 in Appendix B.3. As seen there, GDP responds positively to an oil price shock, and the responses are somewhat stronger today (2012) than in the pre-rule periods (1997). After a world activity shock the responses are very much the same as those in 1997.

As the above discussion shows there is evidence of nonlinearity also in the response of the domestic economy to oil market shocks, suggesting a stronger pass-through of oil related shocks to the economy after the 2001 adoption of the fiscal rule. In short, then, the fiscal framework does not effectively shield the economy from oil price fluctuations. If anything, fiscal policy has exacerbated the effects of the oil market shocks on the domestic economy, and even more so after the adoption of the fiscal rule. If Norway has a more muted response to oil price shocks than countries like Mexico, as argued in Pieschacon (2012), it must be for other reasons than the adoption of the fiscal rule.

Having said that, one can easily argue that if the private sector is also stimulated by the oil price and global activity shocks, as indicated by the results in Figures 12

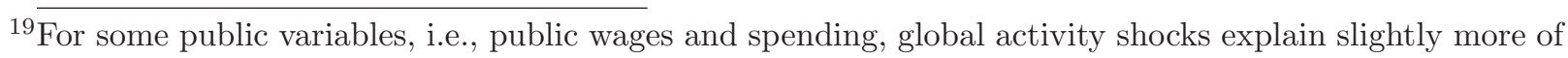
the variance the last decade, but always less than the variance explained by the oil price shock. 

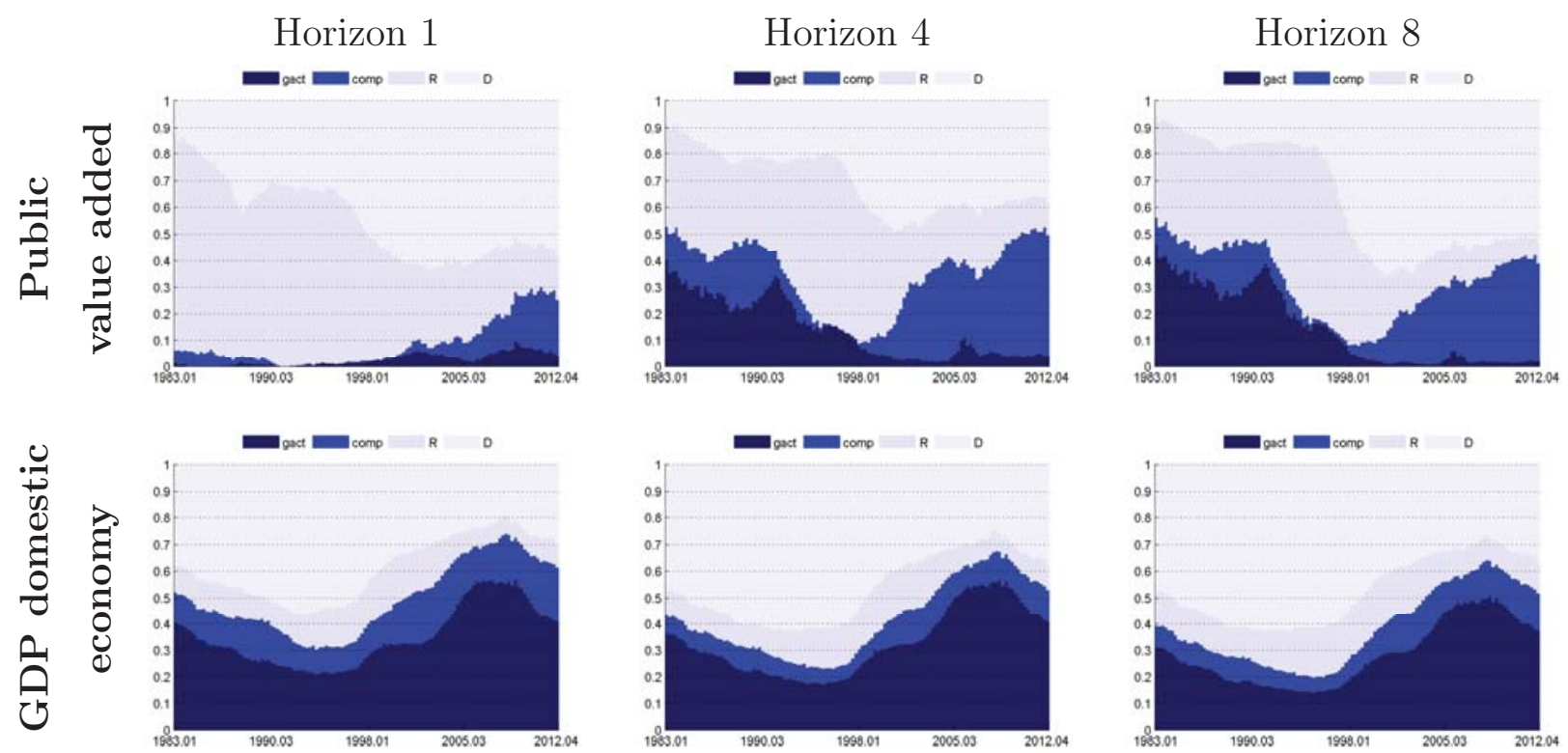

Figure 5. Time-varying variance decompositions. The plots report the median of the estimated variance decompositions associated with the levels response of the variables.

and 13 in Appendix B.3, maybe the stimulus to the public sector is just following the increase in the domestic economy. Some studies, i.e., Céspedes and Velasco (2014) and Husain et al. (2008), estimate the effect of a change in commodity prices on government expenditures relative to GDP, and find that measured in relative terms, fiscal policy has been countercyclical. Figure 6 addresses this issue, as well as highlighting the importance of separating between the shocks driving the oil market and their domestic implications. In particular, the figure reports the response, across time and horizons, of value added, wages and employment in the public sector relative to the response in the domestic economy. A value above zero indicates the public sector responds more positively to the given shock than the private sector. The last row in the figure reports the effect on the primary balance. ${ }^{20}$

We find that for a given oil price shock, the public sector has clearly grown at the expense of the private sector. That is, throughout the last decade, the positive effect on the public sector has grown relative to the private sector. This again suggests fiscal policy exacerbates the effect of the oil price shocks on the domestic economy. This is quite different to what Pieschacon (2012) and others have asserted. There it is argued that fiscal policy regulates the size of the pass-through. Turning to global activity shocks, the results are reversed. The positive effect on GDP is stronger than that on the public sector; as seen by the negative effect in the figures. Hence, when the oil price rises due to global demand, the direct spillovers to the domestic economy are substantial, and much

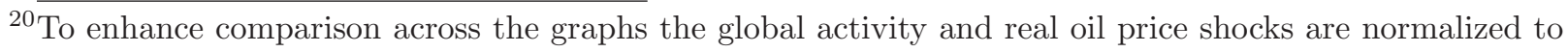
1 and 10 percent, respectively. 
Global activity shock

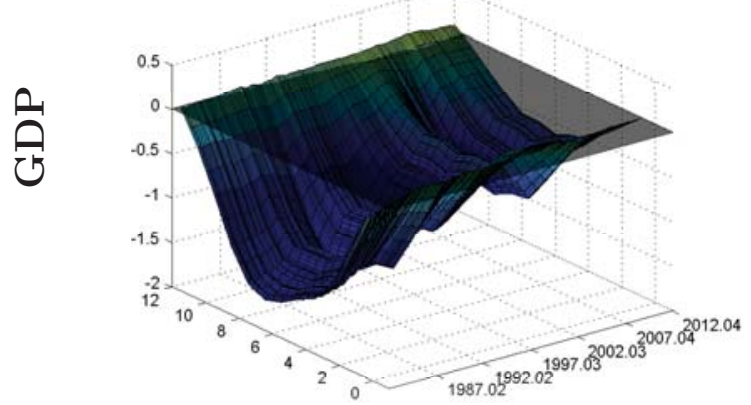

롱
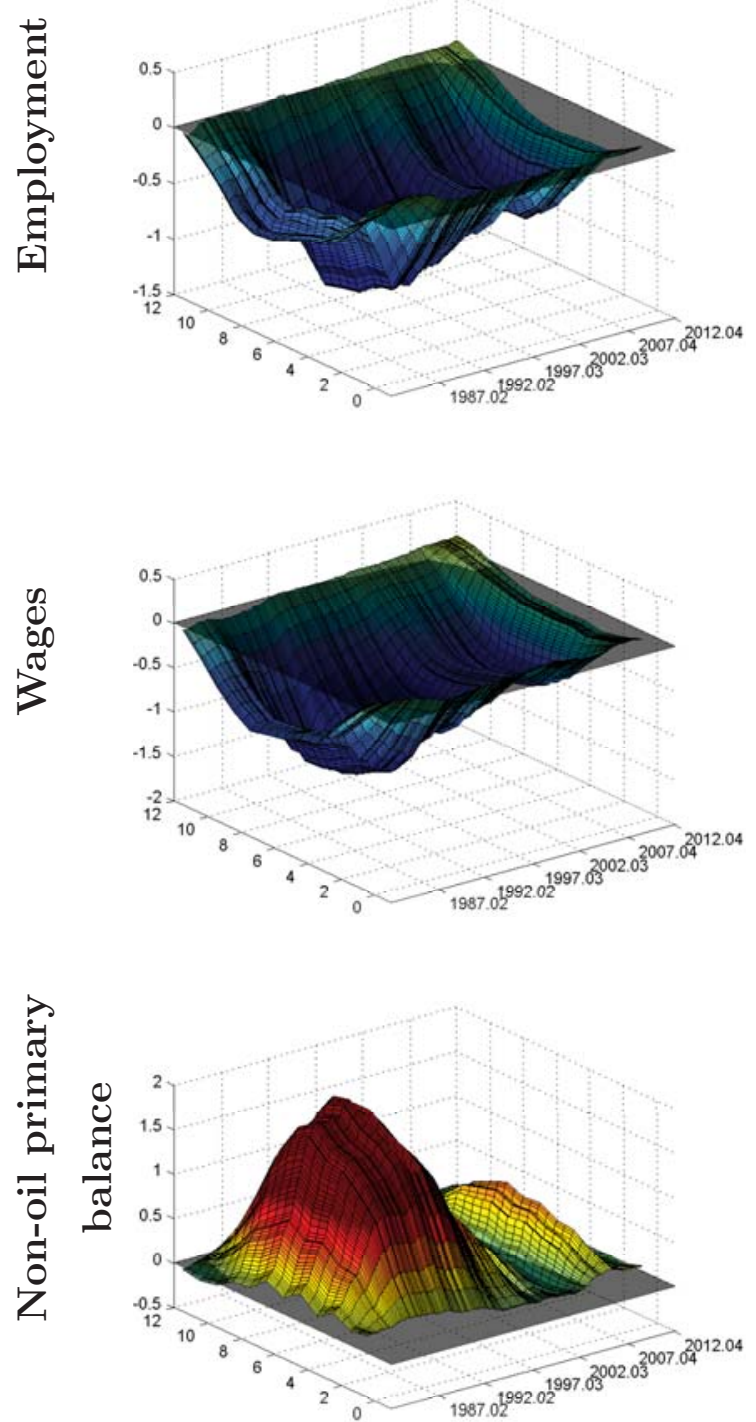

Oil price shock
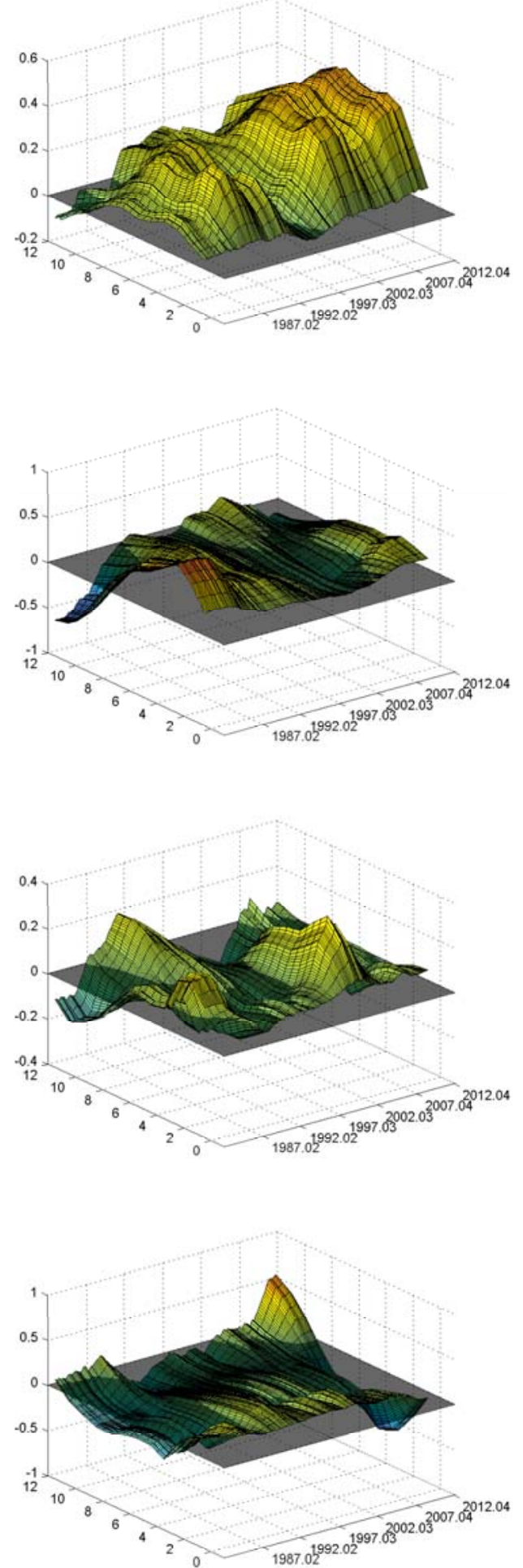

Figure 6. Public sector relative to the domestic economy and the primary balance. Each plot reports the response, across time (x-axis) and horizons (y-axis), of an outcome variable in the public sector relative to the response in the domestic economy. Here, the domestic economy is defined as the average response across all sectors, except the public sector (for wages the domestic economy is defined by the Statistics Norway as mainland economy). The initial shock is normalized to 1 percent (of the normalized data). All responses are reported in levels (of the normalized data). A value above zero indicates a more positive response by the public sector to the given shock than by the mainland economy as a whole. For readability the relative responses are also smoothed by applying a 3 quarter moving average transformation. See the text for the definition of the primary balance. 
stronger than the pass-through via government spending. Yet, we note that, since the start of the millennium, the spillovers to the private sector (relative to the public sector) have diminished, in line with the more procyclical fiscal policy responses reported above.

The transmission of shocks via the primary balance confirms our claim. Following an oil price shock that generates procyclical fiscal responses, we would expect to see negative numbers for the primary balance, all else being equal. We see evidence of this in the lower right frame of Figure 6. However, all else is not equal, as emphasized above. In particular, the oil market shocks are also transmitted to the domestic economy, implying increased tax-receipts and an improvement in the primary balance: hence the more muted response in Figure 6. For the global activity shock, however, we should observe positive numbers for the primary balance, since the stimulus to the domestic economy (and subsequent tax-receipts) is more substantial now than the effect via increased public spending. This is confirmed in the lower left frame in Figure 6. However, note also the steep decline in the prime balance from 2000/2001, consistent with the findings of a more procyclical fiscal policy in recent times.

We therefore conclude that studies suggesting a countercyclical fiscal policy response, as a share of GDP or based on the primary balance, in the recent boom, should attribute it to global activity shocks and their domestic propagation, rather than the adopted fiscal framework.

\subsection{Causes and counterfactuals}

After reading our conclusion, a natural question arises. Why did the fiscal rule induce, against it's intentions (confer Section 2), a procyclical fiscal policy with regard to oil price fluctuations? The answer is not that the fiscal rule has been violated. In fact, the fiscal authorities have in large managed to actually follow the rule by using only roughly 4 percent of the Fund every year, see e.g. Ministry of Finance (2015). Instead, we believe the answer has to do with the design of the fiscal framework and bad luck in timing. When the rule was established, in 2001, the Fund's market value amounted to roughly 20 percent of Norwegian GDP. Going forward, the fiscal authorities assumed the price of oil would remain more or less unchanged, at 200 NOK per barrel. This expectation turned out to be wrong. During the 10-year period from 2001 to 2011, the price of oil increased considerably, to over 600 NOK per barrel. Accordingly, the inflow of money to the Fund was much higher than expected, and by 2013 its market value exceeded 180 percent of Norwegian GDP. Thus, almost by construction, it has been difficult to restrain the close to automatic increase in spending that has followed from taking out a constant fraction (4 


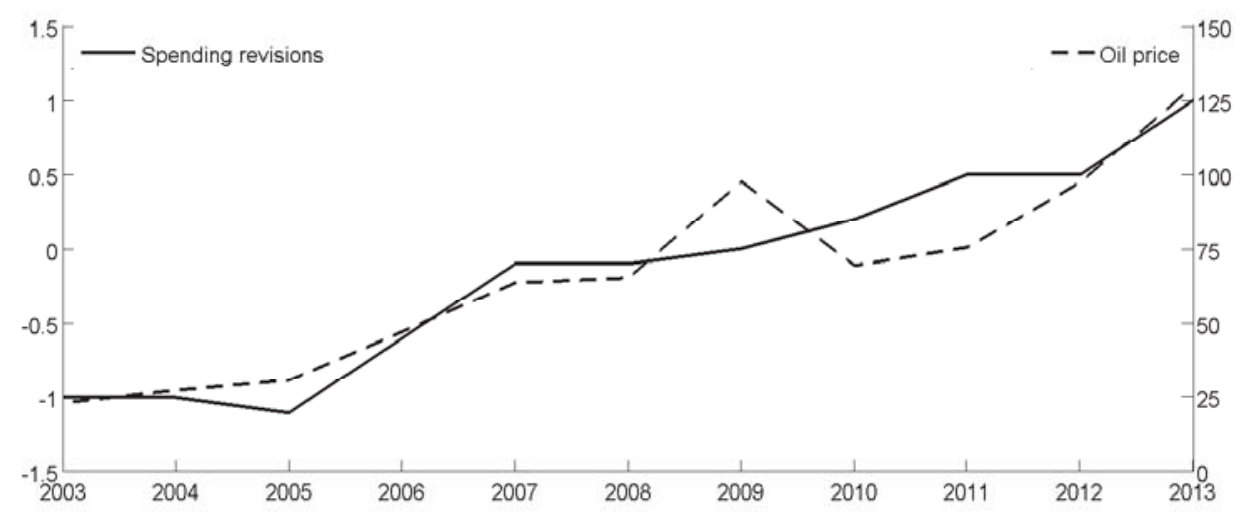

Figure 7. The price of oil and spending revisions. Spending revisions refer to the difference between the assumed path for the fiscal rule in the budget year 2014 (in percentage of GDP) minus the assumed path in the original budget in 2001 (in percentage of GDP).

percent) of a Fund that, for long periods, has been highly correlated with the oil price. ${ }^{21}$

Figure 7 illustrates this point, and shows the close connection between the growth in the price of oil and the revisions of the fiscal rule from 2001 to 2014 . Over this period, the 4 percent rule has been revised upwards in line with growth in the oil price. According to our results, the discretionary deviations from the 4 percent rule that may have taken place during the recent commodity boom have simply not been large enough to counteract the changes in structural policy parameters induced by the introduction of the rule and the associated increase in spending potential from the higher commodity prices. ${ }^{22}$.

Thus far our discussion has focused on the implications of commodity price shocks for fiscal policy before and after the introduction of the fiscal rule in 2001. A relevant question to ask is what would the fiscal stance have been using another rule, or, say, no rule at all? As already mentioned in Section 2, the fiscal rule was introduced in response to the large surpluses on the government budget and high allocations to the GPF in the late 1990s. This made it politically difficult to maintain a neutral fiscal stance, i.e., unchanged use of petroleum revenues. Clearly, without the rule, but using say a spend-as-you-go strategy, fiscal policy could have become even more procyclical than it actually did.

To shed more light on the implications of the fiscal rule relative to some alternatives, we run two counterfactual experiments and analyse how fiscal policy might have been conducted. In the first we use parameters from the late 1990s (1997), representing the

${ }^{21}$ That developments in the Fund have been highly correlated with the oil price in the past ten years has also been emphasized by Norges-Bank (2012).

${ }^{22}$ One objection to the analysis can be raised: Monetary policy also changed around this time. With the adoption of inflation targeting in 2001, monetary policy was given a more active role for economic stabilisation. This is confirmed when we include the short term interest rate and inflation in the model. Yet our result of a procylical fiscal policy remains in the data. For brevity, the results are reported in Appendix B.4 
period before Norway introduced the fiscal framework, and where the fiscal authorities followed guidelines implying an unchanged use of petroleum revenues (as measured by the structural, non-oil budget balance), see Section 2. In the second scenario we assume that the increased spending pressure due to the inflow of petroleum income and reflected by changes in the time-varying factor loadings, are not curbed by a fiscal rule at all, i.e. politicians "spend as they go". We label these two counterfactuals as the Modest and Expansionary alternatives, respectively. ${ }^{23}$

Figure 8 reports the results of the counterfactual experiments. It shows the difference between the historical decomposition obtained from the baseline model and the counterfactual decompositions obtained under either the Modest and Expansionary alternatives. A value above zero indicates the difference is positive and that under the counterfactual scenario fiscal policy would have been more expansionary (and vice versa if the difference is negative). To relate the difference to the business cycle, we also report periods of expansions and recessions in the Norwegian economy in the white and grey area respectively. A more countercyclical policy (under the alternative) implies that the difference should be positive (more expansionary) when the business cycle conditions are low (grey area) or negative (more contractionary) when the business cycle conditions are good (white area).

For the Modest alternative the figure suggests that during the high growth period in the Norwegian economy in the mid 2000s, the fiscal impulse would have been slightly lower had policy been based on the counterfactual policy parameters. During the recession in the early 2000s and during the Great Recession, the difference first widens (as the counterfactual scenario is more expansionary), but then narrows sharply as economic conditions improve. Thus, fiscal policy would have been more countercyclical under the Modest alternative. In contrast, for the Expansionary alternative fiscal policy would have

${ }^{23} \overline{\text { Technically, we first construct a historical }}$ decomposition of the data given the structural shocks and timevarying parameters of our baseline model. We then compute the time path for key (public) observable variables implied by the structural shocks in the model. In the counterfactual experiments we re-compute this historical decomposition, but use different factor loading estimates: For the Modest alternative we use factor loading estimates from 1997:Q1. Accordingly, the historical decomposition computed in the counterfactual experiment will be identical to the baseline decomposition up to 1997. From this period and onwards, the decompositions will differ because the systematic policy parameters will differ; For the Expansionary experiment we compute the average quarterly change in the factor loadings between 1997:Q1 and 2001:Q1, and project synthetic factor loadings from this time period and forwards using these average loading innovations. We note, however, that a general objection to a counterfactual experiment like this is that if rational and forward-looking economic agents had realized that the policy parameters would not change, or change in the manner described above, they could have modified their behaviour accordingly, and therefore also the aggregate economic outcomes (c.f., Lucas (1976)). Still, as argued in Primiceri (2005), in a Bayesian setting where the policy parameters are random, the critique in Lucas (1976) might not be that severe, and the counterfactual experiment might yield interesting results. 
Modest alternative

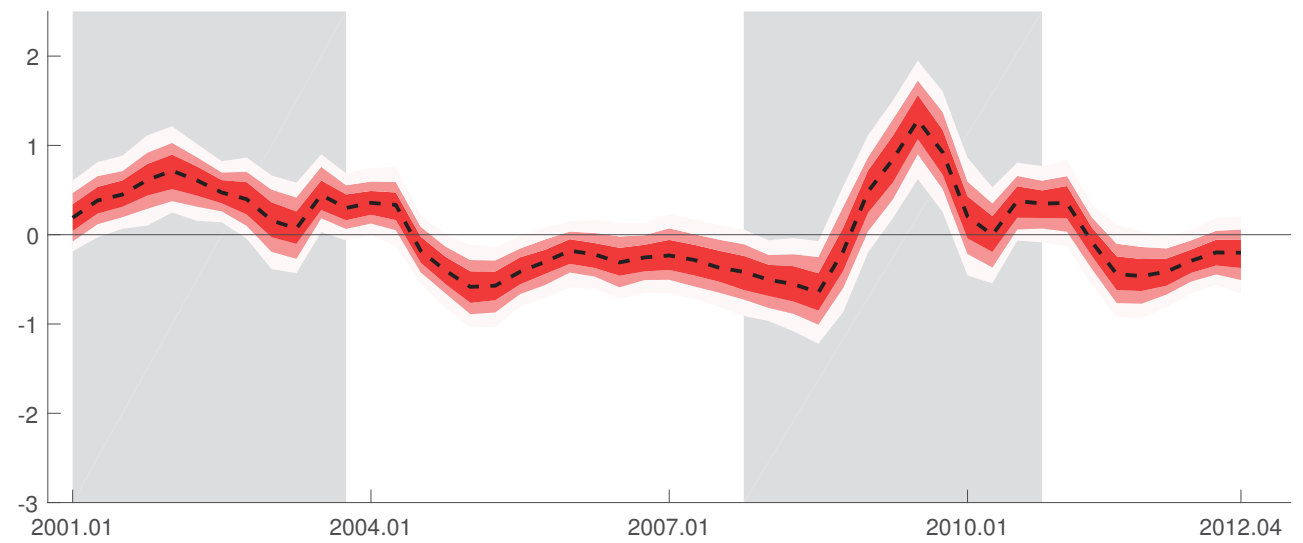

Expansionary alternative

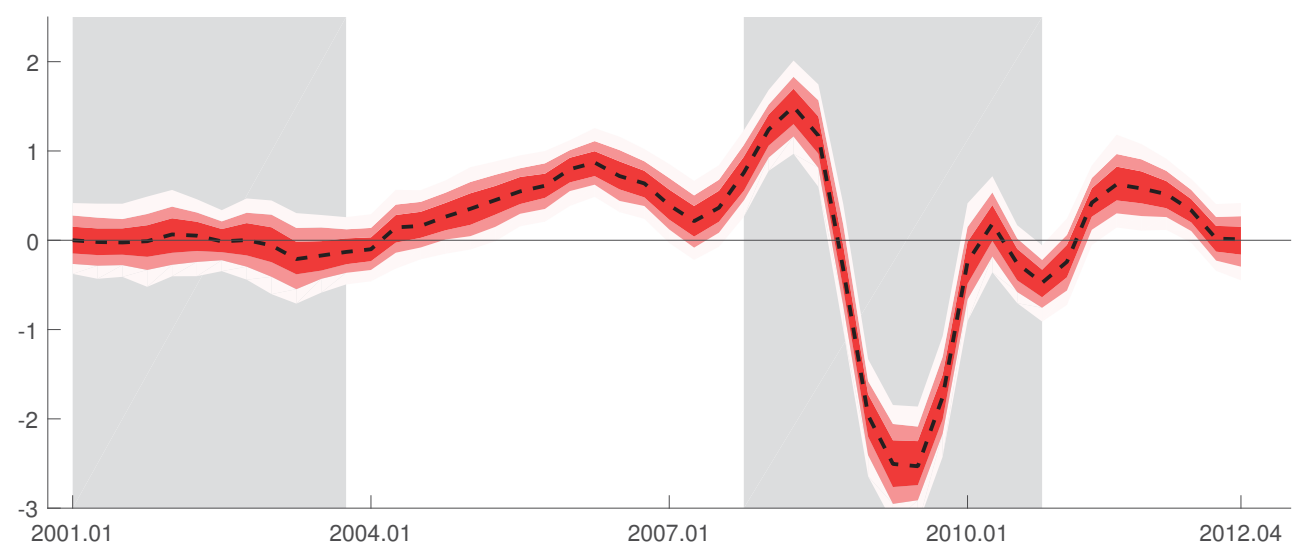

Figure 8. Counterfactuals: Value added in public sector. We graph the historical decomposition of the data, $f\left(y_{i, t}\right)$, minus the counter factual alternative, $f^{c}\left(y_{i, t}\right)$. A positive/negative difference, i.e., whenever the dotted black line is above/below zero, means the growth rate (year-on-year) would have been higher/lower under the counterfactual scenario. The colour shadings represent the 70,50 , and 30 percent quantiles of the posterior distribution. The shaded grey area represents recessions, while the white areas are periods of expansion (We follow NBER business cycle conventions and define an expansion as the period from the through to the peak of the business cycle while the recession is defined as the period from the peak to the through. The cycles are constructed using the Hodrick-Prescott filter $(\lambda=40000)$ for mainland GDP in Norway.) See the text for details about the two alternative scenarios.

been more procyclical during both the high growth period in the mid 2000s (when oil prices increased more than expected) and during the Great Recession (when oil prices fell unexpectedly). In sum, we conclude that fiscal policy could have been designed to be more countercyclical (the Modest alternative), but acknowledge that this may have been politically unattainable. Relative to a more spend as you go strategy (the Expansionary alternative) the adopted fiscal framework have likely induced moderation. But, the findings documented in Section 4.2 remain: Key public sector variables have responded significantly more (not less) procyclically to oil price shocks since the adoption of the fiscal rule in 2001. 


\section{Conclusion}

This paper analyses whether the adoption of fiscal spending rules insulates resourcerich economies from oil price fluctuations. In pursuing the question we develop a timevarying Dynamic Factor Model, in which both the volatility of structural shocks and the systematic fiscal policy responses are allowed to change over time. We focus on Norway. Unlike most oil exporters, Norway has established a sovereign wealth fund operated as a hybrid between a savings- and stabilization fund, and a fiscal rule designed specifically to shield the domestic economy from oil price fluctuations. We find that, contrary to common perceptions, fiscal policy has been more (not less) procyclical with oil price fluctuations since the adoption of the fiscal rule. In so doing, fiscal policy has not effectively sheltered the economy from oil price shocks. In contrast, following a global activity shock that also increases oil prices, the picture is more nuanced, with some components of public spending being countercyclical relative to GDP. We suggest that studies that find a countercyclical fiscal policy response in the recent boom, should attribute it to global activity shocks and their domestic propagation, rather than the adopted fiscal framework.

Still, although the fiscal rule has not managed to shelter the Norwegian economy from oil price fluctuations, the goal of saving resource revenue for future usage has been accomplished. The fiscal authorities have in large managed to actually follow the rule, and by only using roughly 4 percent of the Fund every year the Norwegian sovereign wealth fund is today the largest in the world. From a policy point of view, the implications of our findings are therefore of general interest since they highlight the strengths and weaknesses of the fiscal framework adopted in a resource rich economy and whose handling of resource wealth has been described as exemplary. 


\section{References}

Aastveit, K. A., H. C. Bjørnland, and L. A. Thorsrud (2015). What drives oil prices? Emerging versus developed economies. Journal of Applied Econometrics 30(7), 101328.

Aguilar, O. and M. West (2000, July). Bayesian dynamic factor models and portfolio allocation. Journal of Business \&6 Economic Statistics 18(3), 338-57.

Alexeev, M. and R. Conrad (2009). The elusive curse of oil. The Review of Economics and Statistics $91(3), 586-598$.

Allcott, H. and D. Keniston (2014, September). Dutch disease or agglomeration? the local economic effects of natural resource booms in modern America. Working Paper 20508, National Bureau of Economic Research.

Bai, J. and S. Ng (2013). Principal components estimation and identification of static factors. Journal of Econometrics 176(1), 18 - 29.

Bai, J. and P. Wang (2012). Identification and estimation of dynamic factor models. MPRA Paper 38434, University Library of Munich, Germany.

Barro, R. J. (1979). On the determination of the public debt. The Journal of Political Economy, 940-971.

Baumeister, C. and G. Peersman (2013). The role of time-varying price elasticities in accounting for volatility changes in the crude oil market. Journal of Applied Econometrics 28(7), 1087-1109.

Bjørnland, H. C. and L. A. Thorsrud (2015). Boom or gloom? Examining the Dutch disease in two-speed economies. Economic Journal (forthcoming).

Carter, C. K. and R. Kohn (1994). On Gibbs Sampling for State Space Models. Biometrika 81(3), pp. 541-553.

Céspedes, L. F. and A. Velasco (2014). Was this time different?: Fiscal policy in commodity republics. Journal of Development Economics 106, 92-106.

Charnavoki, V. and J. Dolado (2014). The Effects of Global Shocks on Small CommodityExporting Economies: Lessons from Canada. American Economic Journal: Macroeconomics 6(2), 207-237.

Cogley, T. and T. J. Sargent (2005, April). Drift and Volatilities: Monetary Policies and Outcomes in the Post WWII U.S. Review of Economic Dynamics 8(2), 262-302. 
Creal, D. (2009). A survey of sequential Monte Carlo methods for economics and finance. Serie Research Memoranda 0018, VU University Amsterdam, Faculty of Economics, Business Administration and Econometrics.

Del Negro, M. and C. Otrok (2008). Dynamic factor models with time-varying parameters: measuring changes in international business cycles. Staff Reports 326, Federal Reserve Bank of New York.

Dellaportas, P., J. Forster, and I. Ntzoufras (2002). On Bayesian model and variable selection using MCMC. Statistics and Computing 12(1), 27-36.

Eickmeier, S., W. Lemke, and M. Marcellino (2011). The changing international transmission of financial shocks: Evidence from a classical time-varying FAVAR. CEPR Discussion Papers 8341.

Ellis, C., H. Mumtaz, and P. Zabczyk (2014). What Lies Beneath? A Time-varying FAVAR Model for the UK Transmission Mechanism. Economic Journal 0(576), 668699.

Geweke, J. (1992). Evaluating the accuracy of sampling-based approaches to the calculation of posterior moments. In In BAYESIAN STATISTICS.

Gjedrem, S. (1999). Challenges to economic policy. Technical report, Address at the Annual Foreign Exchange Seminar, arranged by the Association of Norwegian Economists in Gausdal, Norway, 28 January 1999.

Green, P. J. (1995). Reversible jump Markov chain Monte Carlo computation and Bayesian model determination. Biometrika 82(4), 711-732.

Hamilton, J. D. (1983). Oil and the Macroeconomy since World War II. Journal of Political Economy 91 (2), 228-48.

Hamilton, J. D. (2009). Causes and consequences of the oil shock of 2007-08. Brookings Papers on Economic Activity 40(1), 215-283.

Hamilton, J. D. and A. M. Herrera (2004). Oil Shocks and Aggregate Macroeconomic Behavior: The Role of Monetary Policy: Comment. Journal of Money, Credit and Banking 36(2), 265-86.

Husain, A., K. Tazhibayeva, and A. Ter-Martirosyan (2008). Fiscal policy and economic cycles in oil-exporting countries. IMF Working Papers 253.

Johnson-Calari, J. and M. Rietveld (2007). Sovereign wealth management. Central Banking Publications. 
Kaminsky, G. L., C. M. Reinhart, and C. A. Vegh (2004, September). When it Rains, it Pours: Procyclical Capital Flows and Macroeconomic Policies. NBER Working Papers 10780, National Bureau of Economic Research, Inc.

Kilian, L. (2009). Not all oil price shocks are alike: Disentangling demand and supply shocks in the crude oil market. American Economic Review 99(3), 1053-69.

Kim, S., N. Shephard, and S. Chib (1998, July). Stochastic Volatility: Likelihood Inference and Comparison with ARCH Models. Review of Economic Studies 65(3), 361-93.

Lie, E. (2013). Bukken og pengesekken: Om folketrygdfondet og oljefondets tilblivelse. Nytt Norsk Tidsskrift (4), 323-335.

Lippi, F. and A. Nobili (2012). Oil and the macroeconomy: A quantitative structural analysis. Journal of the European Economic Association 10(5), 1059-1083.

Liu, P., H. Mumtaz, and A. Theophilopoulou (2014). The transmission of international shocks to the UK. Estimates based on a time-varying factor augmented VAR. Journal of International Money and Finance 46(C), 1-15.

Lopes, H. and M. West (2004, JAN). Bayesian model assessment in factor analysis. STATISTICA SINICA 14(1), 41-67.

Lopes, H. F. and C. M. Carvalho (2007). Factor Stochastic Volatility with Time Varying Loadings and Markov Switching Regimes. Journal of Statistical Planning and Inference (137), 3082-3091.

Lopez-Murphy, P. and M. Villafuerte (2010). Fiscal policy in oil producing countries during the recent oil price cycle. IMF Working Papers 28.

Lucas, R. J. (1976, January). Econometric policy evaluation: A critique. CarnegieRochester Conference Series on Public Policy 1(1), 19-46.

Ministry of Finance (2001). Report no. 29 to the Storting (2000-2001). White paper, Norway.

Ministry of Finance (2015). Norwegian public report (NOU) 2015:9.

Nakov, A. and A. Pescatori (2010, 03). Oil and the Great Moderation. Economic Journal 120(543), 131-156.

Norges-Bank (2012). Økonomiske perspektiver. Sentralbanksjef Øystein Olsen foredrag til Norges Banks representantskap og inviterte gjester, torsdag 16. februar 2012. 
OECD (2005). OECD economic surveys: Norway. OECD Economic Surveys 2005/17.

OECD (2007). OECD economic surveys: Norway. OECD Economic Surveys 2007/2.

Peersman, G. and I. Van Robays (2012). Cross-country differences in the effects of oil shocks. Energy Economics 34(5), 1532-1547.

Pieschacon, A. (2012). The value of fiscal discipline for oil-exporting countries. Journal of Monetary Economics 59(3), 250-268.

Portes, J. and S. Wren-Lewis (2014). Issues in the design of fiscal policy rules. CFM discussion paper series 12, Centre For Macroeconomics.

Primiceri, G. E. (2005). Time varying structural vector autoregressions and monetary policy. The Review of Economic Studies 72(3), 821-852.

Raftery, A. E. and S. Lewis (1992). How many iterations in the Gibbs sampler. In In BAYESIAN STATISTICS.

Schaechter, A., T. Kinda, N. T. Budina, and A. Weber (2012). Fiscal rules in response to the crisis-toward the 'next-generation' rules: A new dataset. IMF working paper $187 / 12$.

Smith, B. (2014). Dutch Disease and the Oil and Boom and Bust. OxCarre Working Papers 133, Oxford Centre for the Analysis of Resource Rich Economies, University of Oxford.

Stock, J. and M. Watson (2012). Disentangling the channels of the 2007-2009 recession. Brookings Papers on Economic Activity Spring 2012, 81-135.

Stock, J. H. and M. W. Watson (2005). Understanding changes in international business cycle dynamics. Journal of the European Economic Association 3(5), 968-1006.

Takáts, E. (2012). Countercyclical policies in emerging markets. BIS Quarterly Review, $25-31$.

Velculescu, D. (2008). Norway's oil fund shows the way for wealth funds. IMF Survey Magazine 9. 


\section{Appendices}

\section{Appendix A Data}

Table 1. Data. The vintage of Norwegian data are collected from Statistics Norway (SSB). We use data from the quarterly national account and the central government fiscal account. In the official statistics, data for some of the series (e.g. for employment), do not cover the earlier part of our sample, but were generously made available to us by SSB. The international data, with the exception of the exchange rate, were sourced from the GVAR database constructed by Gang Zhang, Ambrogio Cesa Bianchi, and Alessandro Rebucci at the Inter-American Development Bank. In the column head "Empl.", an "x" indicates that we use both value added and employment data for the variable at hand. All value added data are measured in real terms, as calculated by SSB. The following transformation codes applies: $9=$ year-on-year percentage growth $\left(y_{t}=x_{t} / x_{t-4} \times 100-100\right), 11=$ year-on-year logarithmic difference $\left(y_{t}=\ln \left(x_{t}\right)-\ln \left(x_{t-4}\right)\right)$. See Section 3.2 and the text for additional details.

\begin{tabular}{|c|c|c|c|c|}
\hline Source & Variable & Empl. & Trans. & Description \\
\hline \multirow{17}{*}{ 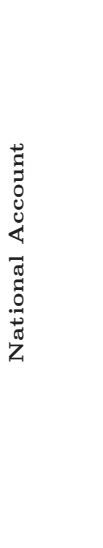 } & Res. extraction & $\mathrm{x}$ & 11 & Oil and natural gas extraction/mining \\
\hline & Res. service & $\mathrm{x}$ & 11 & Service activities in oil and gas/mining \\
\hline & Manufacturing & $\mathrm{x}$ & 11 & Manufacturing \\
\hline & Construction & $\mathrm{x}$ & 11 & Construction \\
\hline & Retail & $\mathrm{x}$ & 11 & Wholesale and retail trade \\
\hline & Transp. ocean & $\mathrm{x}$ & 11 & Ocean transport \\
\hline & Transportation & $\mathrm{x}$ & 11 & Transport activities excl. ocean transport \\
\hline & Hotel and food & $\mathrm{x}$ & 11 & Accommodation and food service activities \\
\hline & Financial & $\mathrm{x}$ & 11 & Financial and insurance activities \\
\hline & Scientific & $\mathrm{x}$ & 11 & Professional, scientific and technical activities \\
\hline & Business & $\mathrm{x}$ & 11 & Administrative and support service activities \\
\hline & Non-resource & $\mathrm{x}$ & 11 & Total excl. oil and gas extraction/mining \\
\hline & Public & $\mathrm{x}$ & 11 & General government \\
\hline & Public consumption & & 11 & General government \\
\hline & Wages petroleum & & 11 & Wages petroleum sector \\
\hline & Wages public & & 11 & Wages public sector \\
\hline & Wages non-res. & & 11 & Total excl. wages to petroleum sector \\
\hline \multirow{6}{*}{ 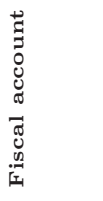 } & Spending & & 11 & Central government total expenditures \\
\hline & Spending excl. pensions & & 11 & Central government total expenditures excluding pensions \\
\hline & Operating costs & & 11 & Central government operating costs \\
\hline & Transfers & & 11 & Central government transfers to municipalities and county authorities \\
\hline & Tax revenue & & 9 & Tax revenue excl. petroleum \\
\hline & Tax revenue petroleum & & 9 & Tax revenue from petroleum \\
\hline \multirow{3}{*}{ 莣 } & World activity & & 11 & World economic activity indicator, see Section 3.2 \\
\hline & Oil price & & 11 & Real price of oil, see Section 3.2 \\
\hline & Exchange rate & & 11 & $\begin{array}{l}\text { Bank of International Settlements (BIS) effective exchange rate index, } \\
\text { broad basket }\end{array}$ \\
\hline
\end{tabular}

Table 1 summarizes the data entertained, their sources, and the transformations used. As described briefly in Section 3.2 of the main paper, we also remove the local mean (of the transformed data) and then standardize the resulting data before estimation. The local mean adjustment is done prior to the standardization to control for low frequent movements in the growth rates (changes in the mean) across time, see, e.g., Stock and 
Watson (2012). We have experimented with different methods of doing the local mean adjustment. In the benchmark case we simply subtract a deterministic linear time trend from the transformed data. In two alternatives we estimate the local mean as the average of the transformed data over a centered moving window of ${ }_{-}^{+} 30$ quarters, and as the components of the time series with fluctuations between 150 and 200 quarters, obtained from a band-pass filter. Irrespective of which method we use the resulting time series are highly similar. ${ }^{24}$ Finally, some of the series also inhabit clear outliers or measurement errors (e.g., Transfers). We define outliers as observations being outside $3 \times$ interquartile range, and automatically remove them by using linear interpolation.

\section{Appendix B Additional results}

\section{B.1 Business cycle factors}

World activity

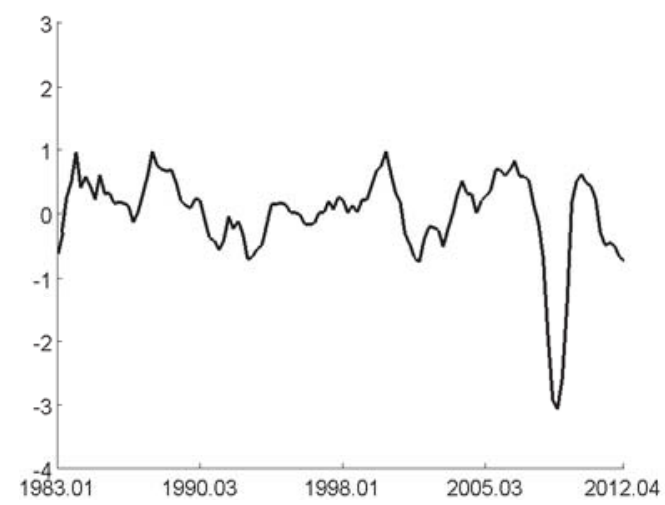

Resource activity

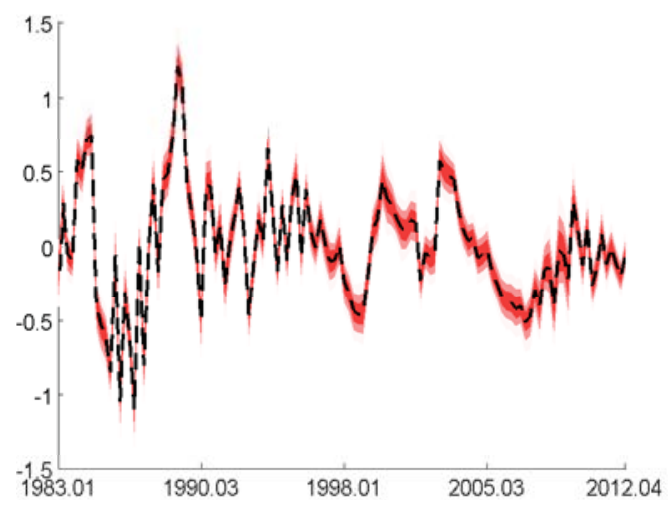

Real price of oil

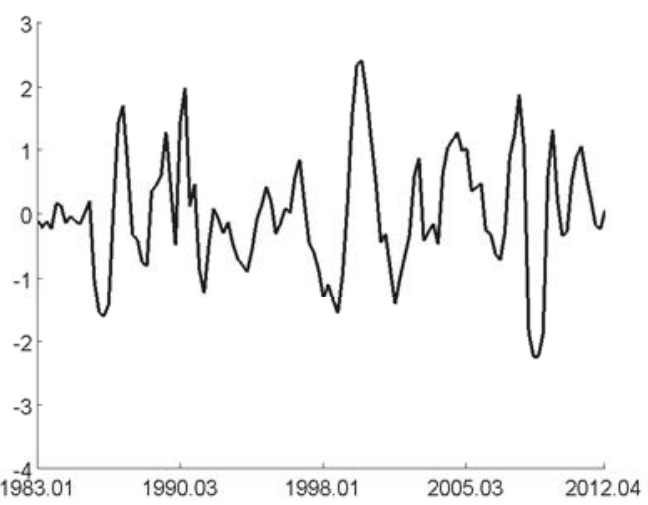

Mainland (domestic) activity

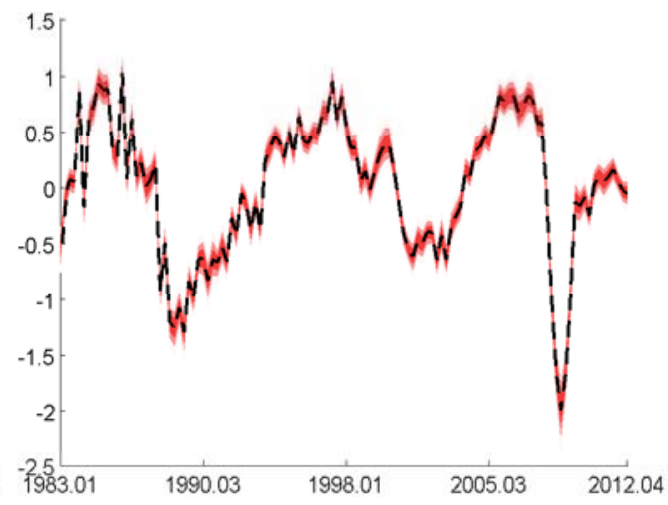

Figure 9. Observable and latent factors. The figures display the two observable factors together with the two estimated latent factors. The color shadings represent the 70, 50, and 30 percent quantiles of the posterior distribution. The black line is the median estimate.

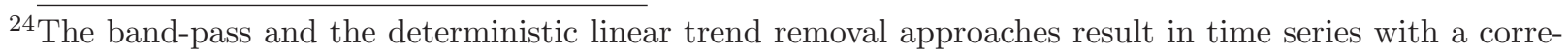
lation coefficients well above 0.95 for most series. 


\section{B.2 Components of public spending}

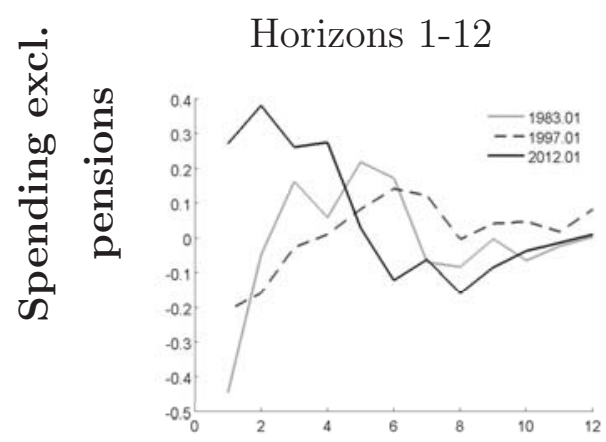

Horizon 1
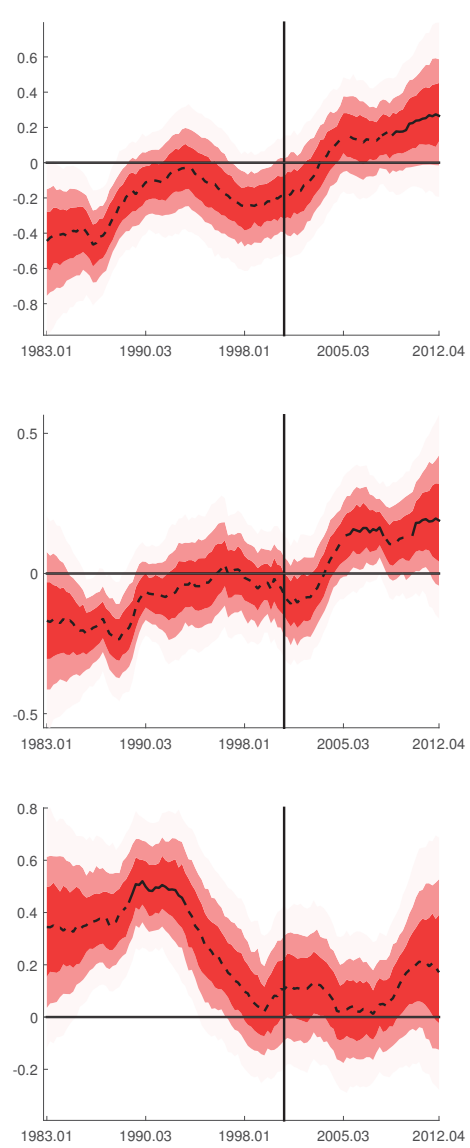

Horizon 4
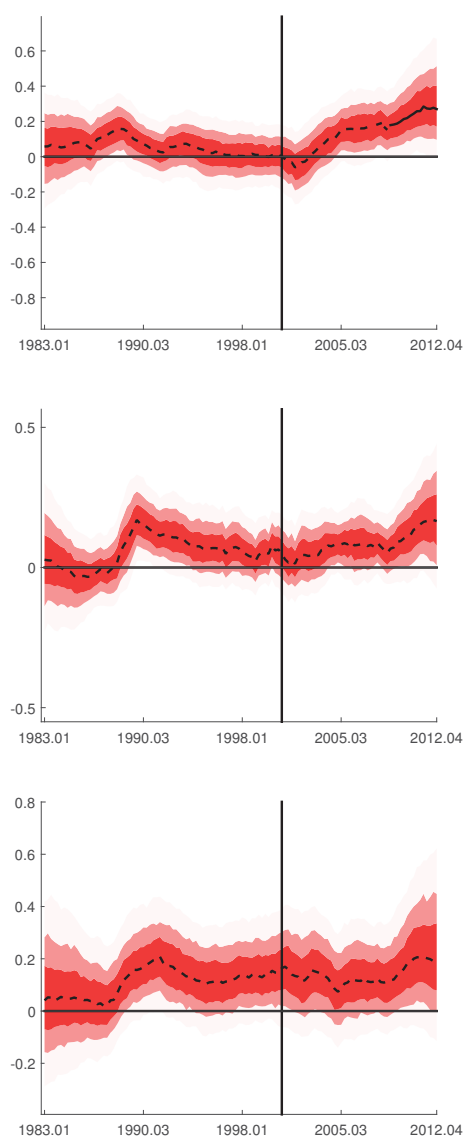

Figure 10. Oil price shock and the fiscal budget: Time-varying responses. The first column displays estimated impulse responses at three different periods of time. The initial shock is normalized to 1 percent (of the normalized data). All responses are reported in levels (of the normalized data). The subsequent two columns report a snapshot of the responses across the whole sample for two specific response horizons. The color shadings represent the 70, 50, and 30 percent quantiles of the posterior distribution. The black line is the median estimate. The line is solid (dotted) whenever the median estimate is outside (inside) the 70 percent quantile in 2001:Q1. 
Horizons 1-12
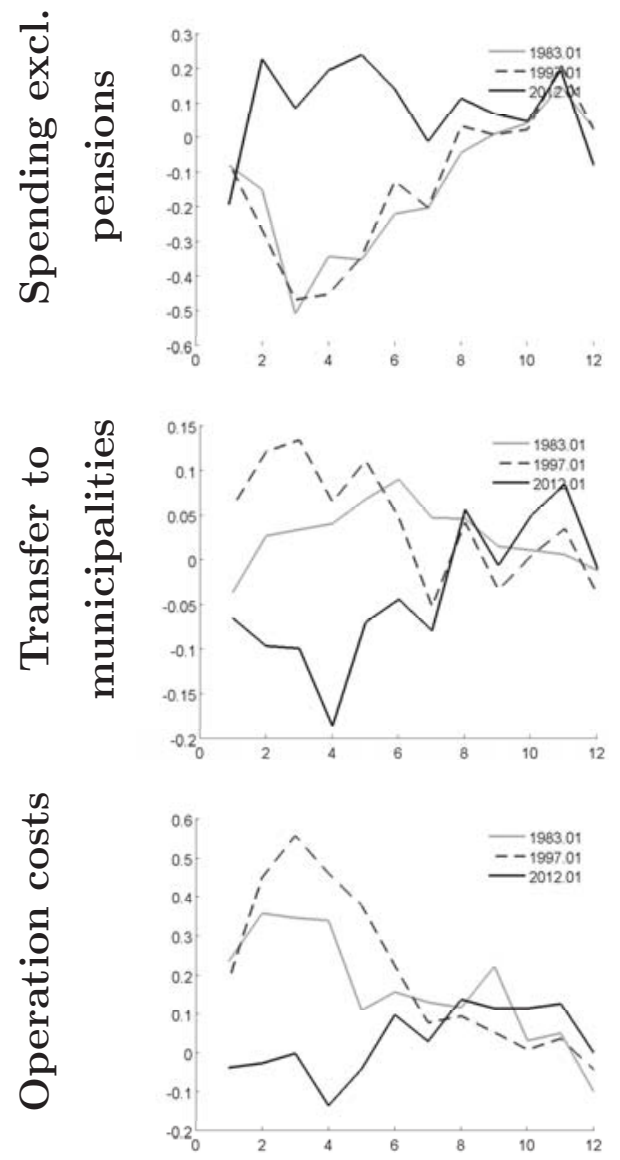

Horizon 1
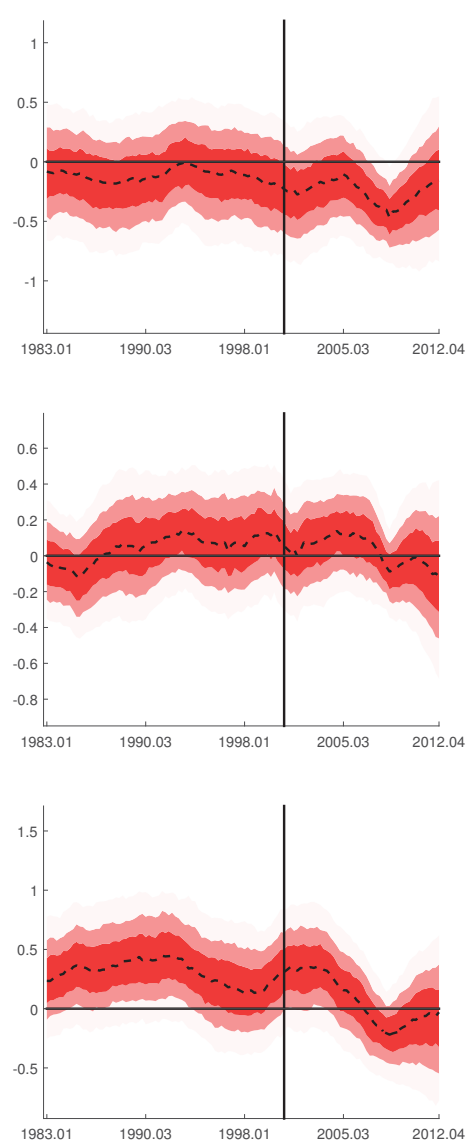

Horizon 4
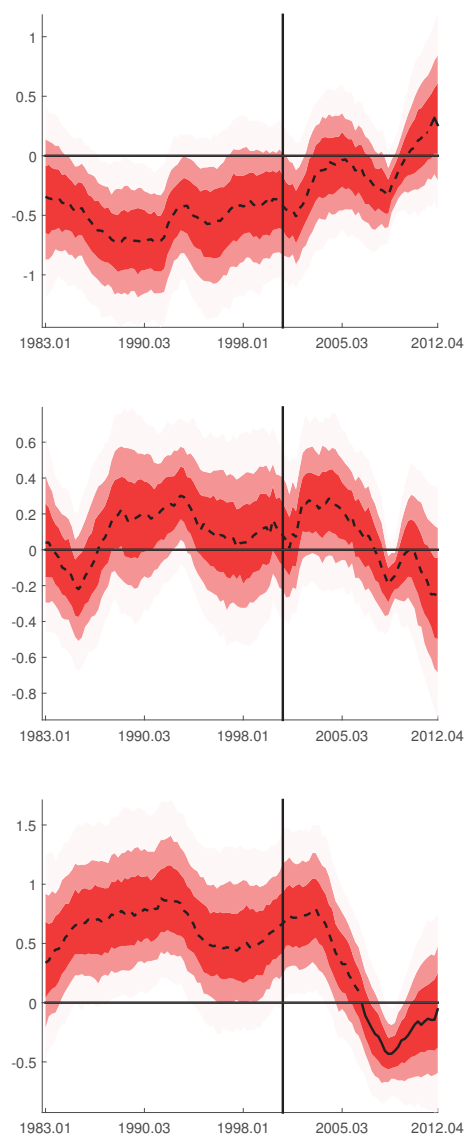

Figure 11. World activity shock and the fiscal budget: Time-varying responses. See Figure 10. 


\section{B.3 The domestic economy}
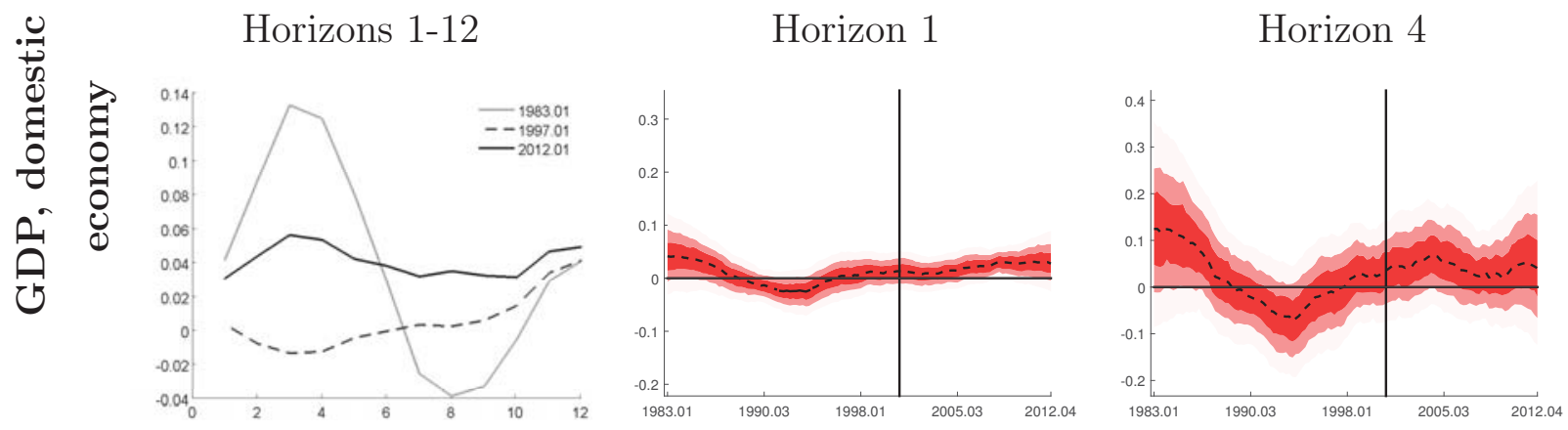

Figure 12. Oil price shock and the macroeconomy: Time-varying responses. See Figure 10.
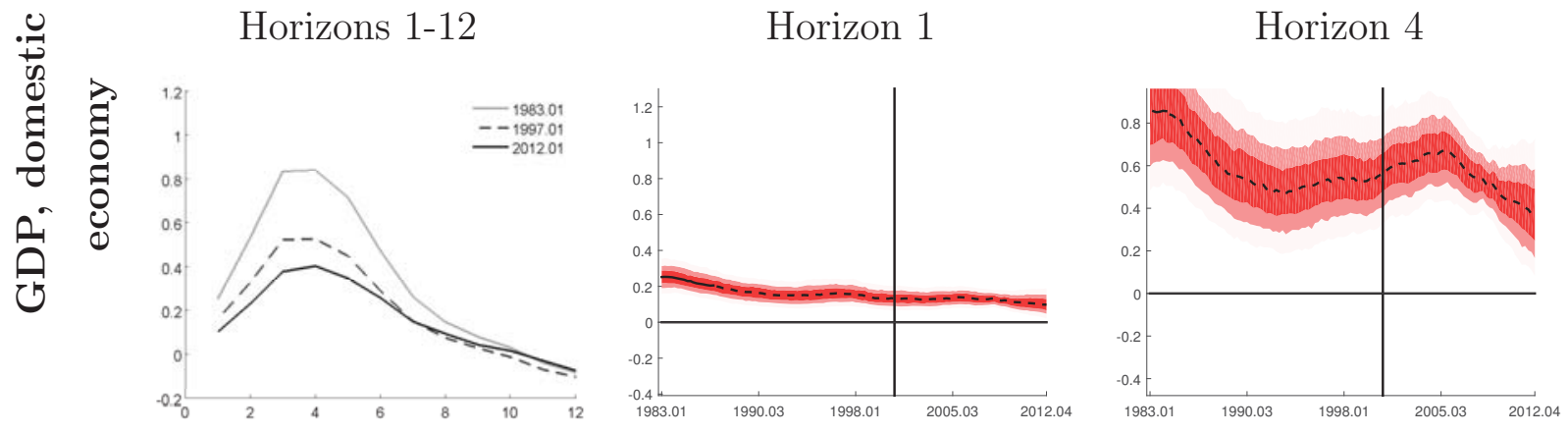

Figure 13. World activity shock and the macroeconomy: Time-varying responses. See Figure 10.

\section{B.4 Monetary policy}

One objection to the analysis can be raised. First, monetary policy also changed around this time. During the 1980s and 1990s, Norway practised a quasi fixed exchange rate regime, which may have limited the role of monetary policy. With the formal adoption of inflation targeting in 2001 (but informally as early as 1999, see Gjedrem (1999)), monetary policy was given a more active role for economic stabilisation. Interestingly, this mechanism is confirmed when we include the short term interest rate and inflation in the model. We observe that the pass-through from world activity and oil price shocks to inflation increase markedly around the turn of the millennium, the period from which fiscal policy also becomes more procyclical. Monetary policy now turns countercyclical, responding more timely to the inflation pressure, see Figure 14. Thus, with monetary policy taking a more active role in stabilizing the economy, we can not exclude an easing of the burden on fiscal policy for stabilization, allowing for a more expansionary fiscal policy during oil price booms. We doubt, however, whether this is the only explanation. Such a strategy would have implied a loss of credibility, with strong price and cost inflation leading to considerable restructuring problems for the international exposed sector (Dutch 

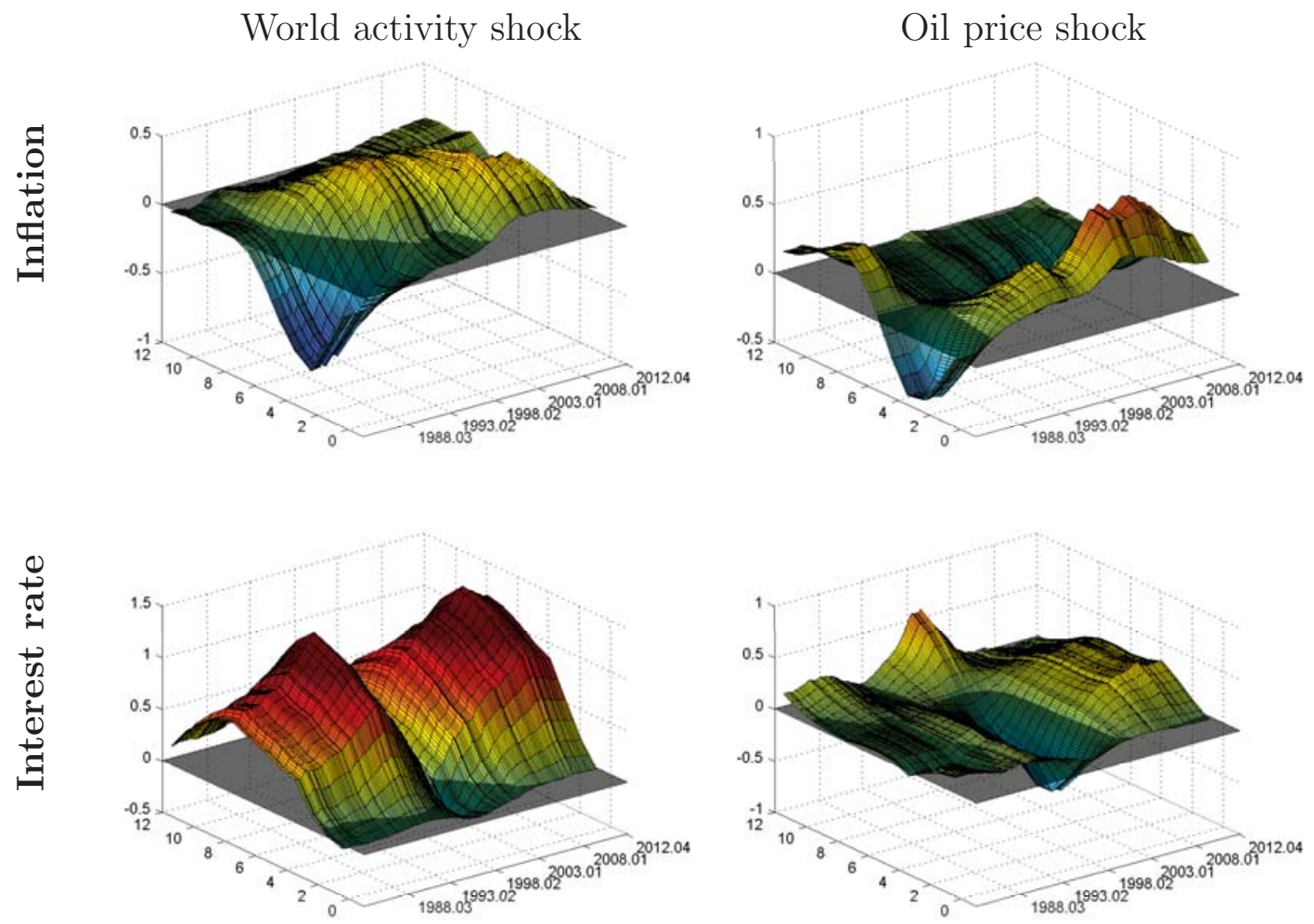

Figure 14. Systematic interest rate and inflation responses across time. The plots report the response, across time (x-axis) and horizons (y-axis), of inflation and the short term interest rate to two different oil market shocks; world activity and oil price shocks. The initial shocks are normalized to one percent (of the normalized data).

disease). We find no such evidence in the data. Instead we find that fiscal policy has been governed by a rule, which has turned out to be far more expansionary than anticipated, allowing for procyclical fiscal policy the last decade. 
ONLINE APPENDIX 


\section{Appendix C Convergence of the Markov Chain Monte Carlo Algorithm}

Table 2. Convergence statistics. The AutoCorr row reports the 10th-order sample autocorrelation of the draws, the $R N E$ row reports the relative numerical efficiency measure, proposed by Geweke (1992), while the IRL row reports the i-statistic, proposed by Raftery and Lewis (1992). For each entry we report the mean value together with the minimum and maximum value obtained across all parameters in parentheses. Finally, for computational convenience, the scores for $Q_{t}^{*}, H_{t}^{*}$, and $Z_{t}^{*}$ are only computed for observations $10,40,70$, and 100 .

\begin{tabular}{|c|c|c|c|c|c|c|c|c|}
\hline \multirow[b]{2}{*}{ Statistic } & \multicolumn{8}{|c|}{ Parameters } \\
\hline & $\mathbf{W}$ & $\mathbf{S}$ & B & $\mathbf{V}$ & $Q_{t}^{*}$ & $H_{t}^{*}$ & $Z_{t}^{*}$ & $a_{t}$ \\
\hline AutoCorr & $\begin{array}{c}-0.0 \\
(-0.1,0.1)\end{array}$ & $\begin{array}{c}-0.0 \\
(-0.1,0.0)\end{array}$ & $\begin{array}{c}-0.0 \\
(-0.0,0.1)\end{array}$ & $\begin{array}{c}0.0 \\
(-0.1,0.1)\end{array}$ & $\begin{array}{c}0.0 \\
(-0.1,0.1)\end{array}$ & $\begin{array}{c}0.0 \\
(-0.1,0.1)\end{array}$ & $\begin{array}{c}0.0 \\
(-0.1,0.1)\end{array}$ & $\begin{array}{c}0.0 \\
(-0.1,0.1)\end{array}$ \\
\hline RNE & $\begin{array}{c}0.9 \\
(0.4,1.7)\end{array}$ & $\begin{array}{c}0.3 \\
(0.3,0.5)\end{array}$ & $\begin{array}{c}0.7 \\
(0.4,1.0)\end{array}$ & $\begin{array}{c}0.2 \\
(0.1,0.3)\end{array}$ & $\begin{array}{c}0.5 \\
(0.2,1.5)\end{array}$ & $\begin{array}{c}1.0 \\
(0.6,1.8)\end{array}$ & $\begin{array}{c}0.8 \\
(0.3,2.1)\end{array}$ & $\begin{array}{c}0.4 \\
(0.1,1.2)\end{array}$ \\
\hline IRL & $\begin{array}{c}1.0 \\
(1.0,1.1)\end{array}$ & $\begin{array}{c}1.3 \\
(1.3,1.3)\end{array}$ & $\begin{array}{c}1.1 \\
(1.1,1.1)\end{array}$ & $\begin{array}{c}1.5 \\
(1.0,2.1)\end{array}$ & $\begin{array}{c}1.2 \\
(1.1,1.3)\end{array}$ & $\begin{array}{c}1.0 \\
(1.0,1.0)\end{array}$ & $\begin{array}{c}1.0 \\
(0.9,1.6)\end{array}$ & $\begin{array}{c}1.0 \\
(1.0,1.0)\end{array}$ \\
\hline
\end{tabular}

Table 2 summarizes the main convergence statistics used to check that the Gibbs sampler mixes well. In the table we first report the mean, as well as the minimum and maximum, of the 10th-order sample autocorrelation of the posterior draws across all parameters. A low value indicates that the draws are close to independent. The second row of the table reports the relative numerical efficiency measure (RNE), proposed by Geweke (1992). Here we use an RNE version controlling for autocorrelation in the draws by employing a 4 percent tapering of the spectral window used in the computation of the RNE. The RNE measure provides an indication of the number of draws that would be required to produce the same numerical accuracy if the draws represented had been made from an i.i.d. sample drawn directly from the posterior distribution. An RNE value close to or below unity is regarded as satisfactory. The last row, labeled IRL, reports the mean of the i-statistic. This statistic was proposed by Raftery and Lewis (1992). In essence it measures the ratio of two other statistics: the total number of draws needed to achieve the desired accuracy for each parameter, and the number of draws that would be needed if the draws represented an i.i.d. chain, see Raftery and Lewis (1992) for details. ${ }^{25}$ Values of IRL exceeding 5 indicate convergence problems with the sampler.

As can be seen from the results reported in Table 2, the sampler seems to have converged. That is, the mean autocorrelations are all very close to zero, and the minimum or maximum values obtained seldom exceed 0.1 in absolute value. Moreover, the mean RNE statistic does not exceed unity by a large margin for any of the parameters. However,

25 The parameters used for computing these diagnostics are as follows: quantile $=0.025$; desired accuracy $=0.025$; required probability of attaining the required accuracy $=0.95$. 
for $W, Q_{t}^{*}, H_{t}^{*}$, and $Z_{t}^{*}$ there are signs that some of the parameters have higher scores. For example, for $Z_{t}^{*}$, the maximum obtained score is 2.1 , indicating that only roughly 20 percent of the numbers of draws would be required to achieve the same accuracy from an i.i.d. set of draws. Finally, the IRL statistics are always well below 5. Additional convergence results can be obtained on request. 


\section{Appendix D Prior specification and sensitivity}

As noted in Section 3, to implement the MCMC algorithm, and estimate the model, we need priors for the initial state variables $a_{0}, z_{0}, a o_{0}, h_{0}^{\sigma}$, and $h_{0}^{\eta}$, and for the hyperparameters $\Phi, S, B, W, \Phi$ and $V$. In a high dimensional model such as ours, the prior specification will never be innocent. Below, we first describe the prior specification used in the benchmark model, i.e., the model on which the results in Section 4 build. We proceed then to elaborate the reasons why this specific prior specification was adopted, and subsequently also discuss the sensitivity of our main results to other prior specifications.

In sum, the priors for the initial states take the following form:

$$
\begin{aligned}
a_{0} & \sim N\left(\underline{y}, I_{q h}\right) & & z_{0} \sim N\left(\hat{z}_{O L S}, I_{\tilde{m}}\right) \\
a o_{0} & \sim N\left(0, I_{q q}\right) & & h_{0}^{\sigma} \sim N\left(0, I_{q}\right) \\
h_{0}^{\eta} & \sim N\left(0, I_{N}\right) & &
\end{aligned}
$$

where $\tilde{m}=q(s+1) N, q q=\frac{q(q-1)}{2}$, and $\underline{y}$ is a stacked column vector of the observed values for the first $q$ variables in $y_{t}$ for $t=0, \ldots,-h$. $\hat{z}_{O L S}$ are constant parameter OLS estimates of the matrix $Z$ (stacked by rows) in equation (1a), covering the sample 1981:Q3-1990:Q1. In these initial estimates the unknown elements of $a_{t}$ are approximated by principal components estimates of the panel of observables in $\tilde{y}_{T} \cdot{ }^{26}$

The priors for the hyper-parameters $\Phi$ and $\Phi$ are set to:

$$
\begin{aligned}
\underline{\Phi} & \sim N\left(\hat{\Phi}_{O L S}, V\left(\hat{\Phi}_{O L S}\right)\right) & \\
\underline{\Phi}_{i} & \sim N\left(0, I_{p} \cdot 0.5\right) & \text { for } i=1, \ldots, N
\end{aligned}
$$

where $\hat{\Phi}_{O L S}$ are OLS estimates of equation (1b), covering the sample 1982:Q1-2012:Q4. As above, when estimating the OLS quantities, the unknown elements of $a_{t}$ are approximated by principal components estimates of the panel of observables in $\tilde{y}_{T}$. $V\left(\hat{\Phi}_{O L S}\right)$ is a diagonal matrix where the non-zero entries are the variance terms associated with the $\hat{\Phi}_{O L S}$ elements.

The priors for the remaining hyper-parameters are all from the Inverse-Wishart distribution:

$$
\begin{aligned}
& \underline{W}_{i} \sim I W\left(\underline{T}^{W}, \underline{T}^{W} \cdot I_{m} \cdot \kappa_{W}^{2}\right) \quad \underline{T}^{W}=125, \kappa_{W}=0.1 \quad \text { for } i=1, \ldots, N \\
& \underline{S}_{l} \sim I W\left(\underline{T}^{S}, \underline{T}^{S} \cdot I_{l} \cdot \kappa_{S}^{2}\right) \quad \underline{T}^{S}=25, \kappa_{S}=0.05 \quad \text { for } l=1, \ldots, q-1 \\
& \underline{B} \sim I W\left(\underline{T}^{B}, \underline{T}^{B} \cdot I_{q} \cdot \kappa_{B}^{2}\right) \quad \underline{T}^{B}=100, \kappa_{B}=0.1 \\
& \underline{V}_{i} \sim I W\left(\underline{T}^{V}, \underline{T}^{V} \cdot I_{p} \cdot \kappa_{V}^{2}\right) \quad \underline{T}^{V}=10, \kappa_{V}=0.1 \quad \text { for } i=1, \ldots, N
\end{aligned}
$$

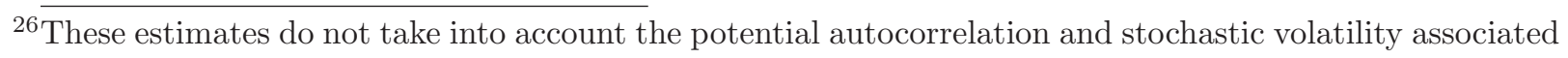
with the idiosyncratic errors. 
where the first element in each prior distribution is the degrees of freedom parameter, and the second the scale parameter. We note that for the Inverse-Wishart distribution the prior scale matrix has the interpretation of the prior sum of squared residuals. ${ }^{27}$

\section{D.1 Prior discussion}

In the following we elaborate our reasons for choosing the prior specification described above. We focus our discussion of alternative specifications of $\underline{T}_{\nu}$ and $\kappa_{\nu}$ for $\nu=\{W, S, B, V\}$, since the prior specifications for the other priors, $\hat{z}_{O L S}, \hat{\Phi}_{O L S}$, and $V\left(\hat{\Phi}_{O L S}\right)$, seem to be of minor empirical importance. ${ }^{28}$

Before going into the details it is worth considering a simplified example. Assume a parameter $\alpha_{t}$ follows a Random Walk like $\alpha_{t}=\alpha_{t-1}+e_{t} \sim N(0, Q)$, where $Q \sim I W(\underline{T}, \underline{T}$. $\kappa^{2}$ ). Then, for a given $\underline{T}$, but varying the size of $\kappa$ will result in very different prior beliefs about the amount of time variation in $\alpha_{t}$. For example, letting $\kappa=\{0.05,0.1,0.15\}$, will roughly result in a 95 percent prior probability of a 100 percent, 200 percent and 300 percent cumulative change in $\alpha_{t}$, respectively, over a period of 100 observations. Accordingly, the priors on $V, S, B$ and $W$, defines our prior belief on the amount of time variation in the parameters. We will discuss the latter three first, since our results do not seem to be sensitive to the prior settings for $\underline{T}_{V}$ and $\kappa_{V}$.

The setting of $S$ and $B$ defines our prior beliefs about the amount of time variation in equations (7b) and (7c), and ultimately the stochastic volatility part of the transition equation in (1b). The setting of $W$ defines our prior belief about the amount of time variation in (7a), i.e., the time-varying factor loadings $\left(z_{t}\right)$. Unfortunately, there is a trade-off between these two. For example, for a similarly sized prior belief on $\underline{T}_{B}, \underline{T}_{S}$, and $\underline{T}_{W}$, setting $\kappa_{B}$ and $\kappa_{S}$ very low, but $\kappa_{W}$ very high, will force most of the model fit to end up through the time-varying factor loadings. That is, the estimated latent business cycle factors in $a_{t}$ will be close at the extreme to straight lines. In the reverse case, setting $\kappa_{B}$ and $\kappa_{S}$ very high and $\kappa_{W}$ very low, will almost remove the time variation in $z_{t}$.

The unfortunate trade-off faced in setting the priors for $\kappa_{B}, \kappa_{S}$ and $\kappa_{W}$ make their role important. Fortunately, our research question and earlier literature can guide us in setting these priors. The time-varying parameters and stochastic volatilities are introduced in the Dynamic Factor Model to capture important "stylized facts" associated with global

$27 \overline{\text { Therefore, each scale matrix is multiplied }}$ by the degrees of freedom parameter. Also, for the InverseWishart prior to be proper, the degrees of freedom parameter must be larger than the dimension of the scale matrix. This is the case in all our prior specifications.

${ }^{28}$ This finding is common in the literature entertaining time-varying parameter models, and is also found in, e.g., Primiceri (2005) and Del Negro and Otrok (2008), all of whom estimate models that are related to ours. 
business cycles in general and the Norwegian domestic business cycle in particular. That is, we want to allow for: 1) A changing dependence structure, where the panel of domestic variables have a time-varying exposure to the aggregate business cycle factors, due to, e.g., changes in systematic fiscal policy, and 2) Great Moderation and Recession effects, where the volatility in aggregate business cycle variables seems to have fallen and then increased again over the last decades.

To allow for 1 ) we set $\kappa_{W}=0.1$ and $\underline{T}_{W}=125$. This prior belief permits the factor loadings to vary considerably across time. For our purpose, which is to uncover any potential changes in the parameters due to structural changes in the conduct of fiscal policy, this seems reasonable. Importantly, as described in Appendix E, the sampling algorithm used to estimate the time path for the structural parameters is essentially a smoothing algorithm. However, across the time period evaluated in this analysis many fiscal regimes have been present, see Section 2. Each new regime will plausibly be associated with a new set of policy parameters, that should not be smoothed out. Thus, by allowing for a high degree of variability in the process driving the time evolution of the structural factor loadings, we ensure these parameters are free to jump in response to new policy regimes. The downside of imposing this prior belief is, of course, that the factor loadings might change considerably over time, but just in order to explain outliers and push the in-sample errors to zero. As noted in Primiceri (2005), this type of behavior by the time-varying parameters is typical of very narrow likelihood peaks in possibly uninteresting regions of the parameter space, where the level of the likelihood is not informative of the model's fit. However, our focus is not on, e.g., forecasting, where the above problem might be a bigger concern, but on uncovering jumps in the systematic policy parameters across time and the associated implications for the Norwegian macro economy.

To allow for 2 ), we set $\kappa_{S}=0.05$ and $\kappa_{B}=0.1$. This belief is in accordance with a large literature that have already established that the volatility of international business cycle shocks have indeed changed a great deal in recent decades. For example, both Stock and Watson (2005) and Del Negro and Otrok (2008) document drops in volatility among G7 countries of over 50 percent since the late 1970s. The findings in Del Negro and Otrok (2008) suggest moreover that the fall in the volatility in the Norwegian business cycle is even bigger, close to 150 percent over the period from the early 1980s to the mid 2000s. And according to findings in Baumeister and Peersman (2013), the conditional standard deviation in the change in the real price of oil has moved from around 20 in the mid 1980s, to 10 in the mid 1990s, and back again to above 20 at the late 2000s, reflecting changes of over 100 percent within a period of 10 years. Our setting of $\underline{T}_{B}=100$ reflects our confidence in this evidence. Conversely, our setting of $\underline{T}_{S}=25$ reflects our lack of strong prior beliefs about time-variation in $a o_{t}$, at least for the Norwegian economy. Moreover, 
as described above, both $\kappa_{S}, \kappa_{B}$, and their associated degrees of freedom parameters must be set in relation to $\kappa_{W}$ and $\underline{T}_{W}$. Since we allow for a large degree of variation in the factor loadings, we must also allow for a large degree of variation in the volatilities. If not, our experience is that most of the model fit is tilted toward variation in one of them, which is not a desirable property. ${ }^{29}$

We have neither good evidence nor prior belief as to the amount of time variation to expect in the stochastic volatilities associated with the idiosyncratic errors. Therefore, $\kappa_{V}$ is set equal to $\kappa_{B}$ for consistency, and $\underline{T}_{V}=10$, reflecting that we are reasonably uninformative about this parameter.

Finally, it should be remembered that the posterior estimates will be a weighted average of our prior beliefs and the information contained in the data (the likelihood function). As the sample size grows, the posterior mean converges to the maximum likelihood estimate.

\section{D.2 Prior sensitivity}

To gauge the extent to which our results are sensitive to alternative prior beliefs, we ran the model using a set of alternatives. In the light of our discussion in Section D.1, we focus on the priors for $B$ and $W$, and the setting of $\kappa$. Especially, we estimate the model letting $\kappa$ be in the set $\kappa=\{0.05,0.1,0.15\}$ for all combinations of $B(\kappa)$ and $W(\kappa)$. In total this amounts to 9 different model estimates, encompassing our benchmark model but also allowing for models which a-priori allow for somewhat lower and higher parameter variability. We evaluate the appropriateness of these models both informally and formally.

In a Bayesian setting, the natural formal scoring metric is the marginal likelihood. However, for high dimensional and complex time-varying factor models such as ours, computing this statistic is difficult, and we are not aware of any good agreed upon method for how to do so. For this reason we developed a Reversible Jump Markov Chain Monte Carlo (RJMCMC) algorithm to assess the marginal likelihood implied by the different model and prior specifications. A full description of how our implementation of the RJMCMC algorithm is provided in Appendix F. Here we note that we in a simulation experiment have validated that the algorithm seems to be able to select the correct model among a

${ }^{29}$ As a check of whether or not these priors are sensible we have also estimated a Dynamic Factor Model with no time-varying parameters over two different sub-samples: 1982:Q1-1995:Q4 and 1996:Q1-2012:Q4. By computing the absolute change in the factor loadings and the standard deviation of the errors in equation (1b) across those two sub-samples we find that the absolute change in $z$ is well above 100 percent, for many variables, and that the absolute change in $\Sigma$ is in fact close to 150 percent for the Norwegian business cycle factors. Thus, although somewhat on the high end, our prior belief on the amount of time variation in $z_{t}$ (reflected by the $W$ prior) and $\Sigma_{t}$ (reflected by the $B$ prior) seem reasonable also according to this criteria. 
set of competing specifications, but that the convergence properties of the algorithm are poor and that the estimates have a large degree of uncertainty. ${ }^{30}$ Still, conditional on these shortcomings, the marginal likelihood assessment seems to favor models with prior specifications that imply that $\kappa=0.05$ for the $W$ prior and $\kappa \geq 0.05$ for the $B$ prior, or in other words, a somewhat lower variability in the factor loadings than what we believe to be true in the benchmark model, but more or less the same variability for the time-varying volatilities. Given the attendant caveats as explained above, however, we do not put too much confidence in these results.

More important, then, is the informal evaluation in which we assess the extent to which our main results change depending on the prior specification. As explained in Section D.1, we want to allow for substantial time variation in the factor loadings and the volatilities, but not enforce it such that the results are solely driven by our prior beliefs. As documented in Sections 4.1 and 4, when allowing for a large degree of time variation in both the volatilities and factor loadings, i.e., setting $\kappa_{W}$ and $\kappa_{B}$ high, the results point to a large degree of time-varying impulse responses. However, the main conclusion regarding increased procyclical fiscal policy after the implementation of the fiscal rule holds also for models with priors that allow for much less time variation. Indeed, even for combinations of $B(\kappa)$ and $W(\kappa)$ where $\kappa=0.05$, we observe time variation in the result implying a more procyclical fiscal policy after the adoption of the fiscal rule. These additional results are summarized in Figure 15. The figure reports the same type of results as reported in Figure 6, but for different prior specifications. ${ }^{31}$ As is clearly seen in the figure, after a positive world activity shock, fiscal policy has become less countercyclical over time. After a positive oil price shock, the public sector grows relative to the mainland economy, and particularly so after the adoption of the fiscal rule. Both findings confirm what have already documented in Section 4.

In sum, the sensitivity analysis shows that our main results are not driven by the prior specification. We leave it to future research to devise better ways of formally computing posterior model probabilities, or marginal likelihoods, for high dimensional and complex models as the one entertained here.

${ }^{30}$ This might be because the likelihood surface is highly complex, or because our implementation of the algorithm is inefficient. Another reason might be that we have to be parsimonious regarding the number of simulations due to computational issues, see the discussion in Appendix F.1.

${ }^{31}$ To make the results across different prior specifications presentable in one figure, we report average impulse responses across horizons 1-8 for each time period. Additional results for each prior specification and all impulse response horizons can be obtained on request. 

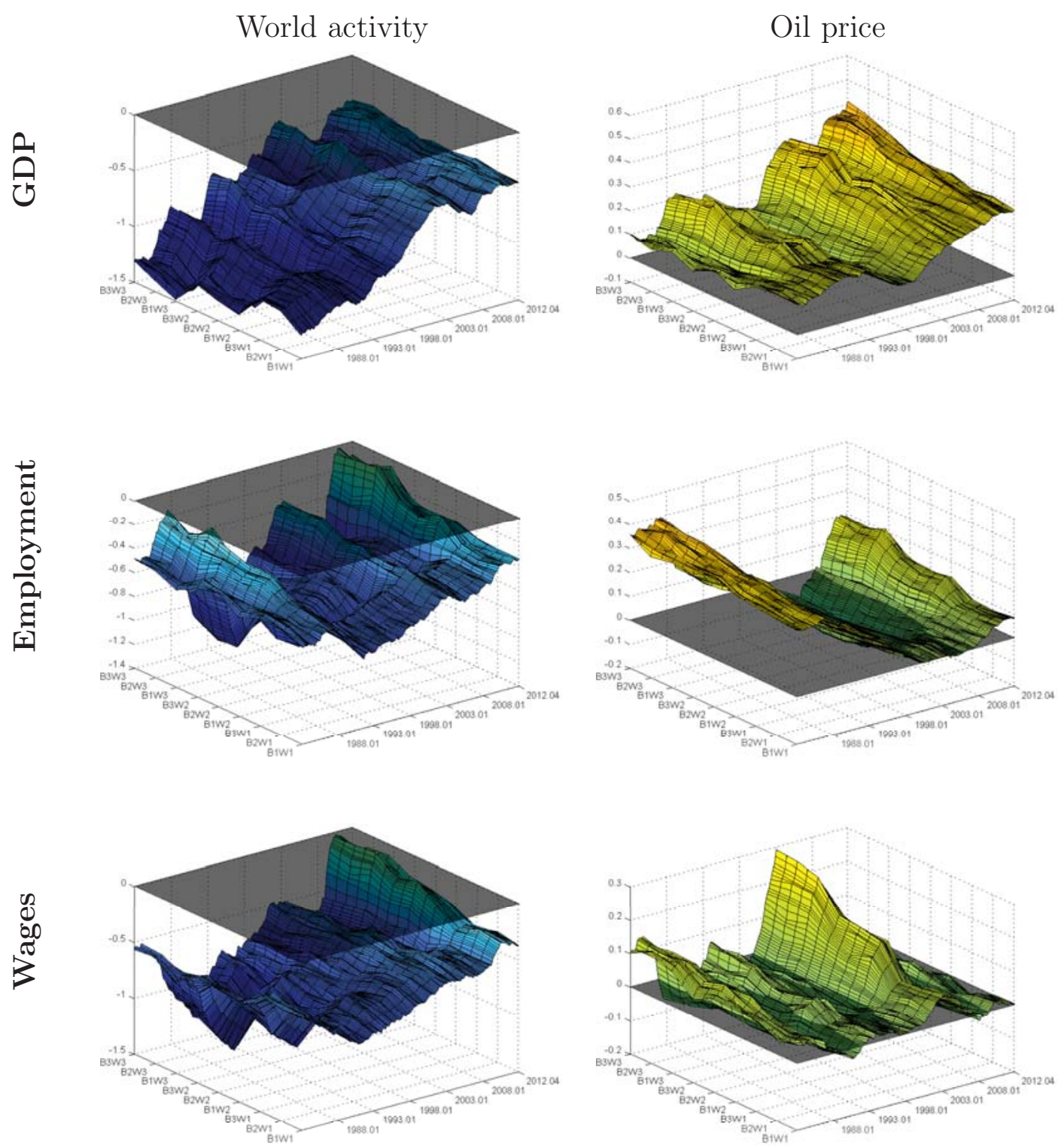

Figure 15. Public sector relative to the mainland economy using different priors. Each plot reports the response, across time (x-axis) and prior specification (y-axis), of an outcome variable in the public sector relative to the response in the mainland economy. Here, the mainland economy is defined as the average response across all sectors, except the public sector. The initial shock is normalized to 1 percent (of the normalized data). All the relative responses are reported as averages across impulse response horizons 1 to 8 . A value above zero indicates that the public sector responds more positively to the given shock than the mainland economy as a whole. The different prior specifications listed on the y-axis correspond to different combinations of $\kappa$ for the $B$ and $W$ priors. In particular, we compare models letting $\kappa$ be in the set $\kappa=\{0.05,0.1,0.15\}$ for all combinations of $B(\kappa)$ and $W(\kappa)$. Thus, $B 1 W 1$ corresponds to setting $\kappa=0.05$ for both $B$ and $W, B 1 W 2$ corresponds to setting $\kappa=0.05$ for $B$ and $\kappa=0.1$ for $W$, etc. The main results reported in Sections 4.1 and 4 correspond to using a model with the B2W2 prior specification. 


\section{Appendix E The Gibbs sampling approach}

Section 3.4 of the main paper gives a short overview of how the DFM is estimated. Here we provide a more detailed overview. For convenience, we repeat the main system equations:

$$
\begin{aligned}
& y_{t}=z_{0, t} a_{t}+\cdots+z_{s, t} a_{t-s}+e_{t} \\
& a_{t}=\Phi_{1} a_{t-1}+\cdots+\Phi_{h} a_{t-h}+A 0_{t}^{-1} \Sigma_{t} \epsilon_{t} \\
& e_{t}=\Phi_{1} e_{t-1}+\cdots+\Phi_{p} e_{t-p}+\Upsilon_{t} u_{t}
\end{aligned}
$$

where (15a) is the observation equation, (15b) the transition equation, and finally, (15c) the equation describing the law of motion for the idiosyncratic errors. Moreover, the time-varying parameters and covariances of the model follow random walk processes:

$$
\begin{aligned}
z_{t} & =z_{t-1}+w_{t} \sim N(0, W) \\
a o_{t} & =a o_{t-1}+s_{t} \sim N(0, S) \\
h_{t}^{\sigma} & =h_{t-1}^{\sigma}+b_{t} \sim N(0, B) \\
h_{t}^{\eta} & =h_{t-1}^{\eta}+v_{t} \sim N(0, V)
\end{aligned}
$$

where $Z_{t}=\left[z_{0, t}, \ldots, z_{s, t}\right]$ and $z_{t}=\operatorname{vec}\left(Z_{t}^{\prime}\right)$ (the matrix $Z_{t}$ stacked by rows). $a o_{t}$ is the vector on non-zero and non-one elements of the matrix $A 0_{t}$ (stacked by rows), and $h_{t}^{\sigma}=\log \left(\sigma_{t}\right)$ and $h_{t}^{\eta}=\log \left(\eta_{t}\right)$, see equations (2), (3), (5) and (6). Thus, the model's hyper-parameters are defined by $\Phi, \Phi, W, S, B$, and $V$, while the model's unknown state variables are defined by $a_{t}, e_{t}, z_{t}, a o_{t}, h_{t}^{\sigma}$, and $h_{t}^{\eta}$.

This system is then estimated using Gibbs simulations, which draw the conditional posterior utilizing 7 blocks. Blocks 1 to 4 draws the states and hyper-parameters associated with equations (15b), (16b) and (16c). Block 5 draws the state and hyper-parameter associated with equation (16a), and Blocks 6 and 7 draw the state and hyper-parameters associated with equations (15c) and (16d). Below we describe each block in greater detail. For future reference and notational simplicity it will prove useful to define the following: $\tilde{y}_{T}=\left[y_{1}, \ldots, y_{T}\right]^{\prime}, \quad \tilde{a}_{T}=\left[a_{1}, \ldots, a_{T}\right]^{\prime}, \tilde{z}_{T}=\left[z_{1}, \ldots, z_{T}\right]^{\prime}, \tilde{e}_{T}=\left[e_{1}, \ldots, e_{T}\right]^{\prime}$, $\tilde{a o}_{T}=\left[a o_{1}, \ldots, a o_{T}\right]^{\prime}, \quad \tilde{h}_{T}^{\sigma}=\left[h_{1}^{\sigma}, \ldots, h_{T}^{\sigma}\right]^{\prime}, \quad \tilde{h}_{T}^{\eta}=\left[h_{1}^{\eta}, \ldots, h_{T}^{\eta}\right]^{\prime}, \Phi=\left[\Phi_{1}, \ldots, \Phi_{h}\right]$, and $\Phi=\left[\Phi_{1}, \ldots, \Phi_{p}\right]$.

\section{E.1 Block 1: $\tilde{a}_{T} \mid \tilde{y}_{T}, \tilde{z}_{T}, \tilde{e}_{T}, \tilde{h}_{T}^{\eta}, \tilde{a o}_{T}, \tilde{h}_{T}^{\sigma}, \Phi, \Phi$}

Equations (15a) and (15b) constitute a state space system we can use to draw the unobserved state $a_{t}$ using the Carter and Kohn's multimove Gibbs sampling approach, see Section E.8. However, to do so we need to make the errors in the observation equation 
conditionally i.i.d. This is easy, given knowledge of equation (15c) and $\Phi$, we can define $\Phi(L)=\left(I-\sum_{k=1}^{p} \Phi_{k} L^{k}\right)$ and pre-multiply equation (15a) by $\Phi(L)$ to obtain the system:

$$
\begin{array}{rlrl}
y_{t}^{*} & =z_{0, t}^{*} a_{t}+\cdots+z_{s, t}^{*} a_{t-s}+\Upsilon_{t} u_{t} & \Upsilon_{t} u_{t} & \sim N\left(0, H_{t}\right) \\
a_{t} & =\Phi_{1} a_{t-1}+\cdots+\Phi_{h} a_{t-h}+A 0_{t}^{-1} \Sigma_{t} \epsilon_{t} & A 0_{t}^{-1} \Sigma_{t} \epsilon_{t} & \sim N\left(0, \Omega_{t}\right)
\end{array}
$$

where $y_{t}^{*}=\left(I-\sum_{k=1}^{p} \Phi_{k} L^{k}\right) y_{t}$ and $z_{j, t}^{*}=\left(I-\sum_{k=1}^{p} \Phi_{k} L^{k}\right) z_{j, t}$ for $j=0, \ldots, s$.

Since all hyper-parameters and state variables, less $\tilde{a}_{T}$, are known (or conditionally known), it follows from equations (2), (3), (5) and (6) that $\Omega_{t}$ and $H_{t}$ are also known for all $t$. Accordingly, we can use the equations in (17) together with Carter and Kohn's multimove Gibbs sampling approach, to sample $a_{t}$ from:

$$
\begin{aligned}
& a_{T} \mid \cdots \sim N\left(a_{T \mid T}, P_{T \mid T}^{a}\right), \quad t=T \\
& a_{t} \mid \cdots \sim N\left(a_{t \mid t, a_{t+1}}, P_{t \mid t, a_{t+1}}^{a}\right), \quad t=T-1, T-2, \cdots, 1
\end{aligned}
$$

to get $\tilde{a}_{T}$.

\section{E.2 Block 2: $\Phi \mid \tilde{a}_{T}, \tilde{a o}_{T}, \tilde{h}_{T}^{\sigma}$}

Conditional on $\tilde{a}_{T}$, the transition equation in $(15 \mathrm{~b})$ is independent of the rest of the model. As above, conditional on knowing $\tilde{a o}_{T}$ and $\tilde{h}_{T}^{\sigma}$, also makes $\Omega_{t}$ known. Accordingly, we can draw $\Phi$ based on a conditional posterior that accounts for the heteroscedasticity in the error terms in (15b). This can be achieved by putting the transition equation on SUR form. ${ }^{32}$ To do so, we define:

$$
Y_{t}=\left[\begin{array}{c}
a_{1, t} \\
a_{2, t} \\
\vdots \\
a_{q, t}
\end{array}\right] \quad X_{t}=\left[\begin{array}{cccc}
x_{t, 1} & 0 & \cdots & 0 \\
0 & x_{t, 2} & \ddots & 0 \\
\vdots & \ddots & \ddots & \vdots \\
0 & \cdots & 0 & x_{t, q}
\end{array}\right] \quad \varepsilon_{t}=\left[\begin{array}{c}
\omega_{1, t}^{A} \\
\omega_{2, t}^{A} \\
\vdots \\
\omega_{q, t}^{A}
\end{array}\right] \quad \beta^{\Phi}=\left[\begin{array}{c}
\beta_{1}^{\Phi} \\
\beta_{2}^{\Phi} \\
\vdots \\
\beta_{q}^{\Phi}
\end{array}\right]
$$

where $\beta_{l}^{\Phi}=\left[\Phi_{l, 1}, \ldots, \Phi_{l, h}\right]^{\prime}$ and $x_{t, l}=\left[Y_{t-1}^{\prime}, \ldots, Y_{t-h}^{\prime}\right]$ for $l=1, \ldots, q$, i.e., the autoregressive coefficients from the lth equation in the transition equation and the lagged dependant variables, and $\omega_{t}^{A}=A 0_{t}^{-1} \Sigma_{t} \epsilon_{t}$.

Stacking $Y_{t}, X_{t}$ and $\varepsilon_{t}$ together across time lets us write the transition equation as:

$$
Y=X \beta^{\Phi}+\varepsilon \sim N(0, \Psi)
$$

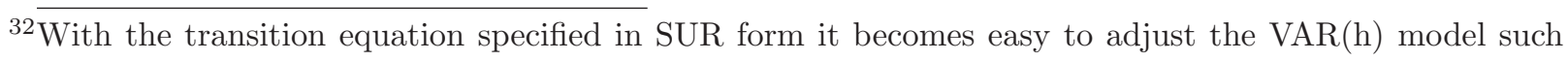
that different regressors enter the q equations of the $\operatorname{VAR}(\mathrm{h})$.
} 
where $Y=\left[Y_{1}^{\prime}, \ldots, Y_{T}^{\prime}\right]^{\prime}, X=\left[X_{1}, \ldots, X_{T}\right]^{\prime}, \varepsilon=\left[\varepsilon_{1}^{\prime}, \ldots, \varepsilon_{T}\right]^{\prime}$, and $\Psi$ is a $(T \times q) \times(T \times q)$ block diagonal matrix given by:

$$
\Psi=\left[\begin{array}{cccc}
\Omega_{1} & 0 & \cdots & 0 \\
0 & \Omega_{2} & \ddots & 0 \\
\vdots & \ddots & \ddots & \vdots \\
0 & \cdots & 0 & \Omega_{T}
\end{array}\right]
$$

The conditional posterior draws of $\beta^{\Phi}$, and thus $\Phi$, are:

$$
\beta^{\Phi} \mid \cdots \sim N\left(\bar{\beta}^{\Phi}, \bar{V}_{\beta^{\Phi}}\right)_{I\left[s\left(\beta^{\Phi}\right)\right]}
$$

where $I\left[s\left(\beta^{\text {varphi }}\right)\right]$ is an indicator function used to denote that the roots of $\beta$ lie outside the unit circle, and:

$$
\begin{gathered}
\bar{V}_{\beta^{\Phi}}=\left(\underline{V}_{\beta^{\Phi}}^{-1}+X^{\prime} \Psi^{-1} X\right)^{-1} \\
\bar{\beta}^{\Phi}=\bar{V}_{\beta^{\Phi}}\left(\underline{V}_{\beta^{\Phi}}^{-1} \underline{\beta}^{\Phi}+X^{\prime} \Psi^{-1} Y\right)
\end{gathered}
$$

\section{E.3 Block 3: $\tilde{a O}_{T} \mid \tilde{a}_{T}, \tilde{h}_{T}^{\sigma}, \Phi, S$ and $S \mid \tilde{a O}_{T}$}

Conditional on $\tilde{a}_{T}$ and $\Phi$ we can define $\hat{a}_{t}=a_{t}-\left(\Phi_{1} a_{t-1}+\ldots+\Phi_{h} a_{t-h}\right)$, and write equation (15b) as:

$$
A 0_{t} \hat{a}_{t}=\Sigma_{t} \epsilon_{t}
$$

Since $A 0_{t}$ is a lower triangular matrix with ones on the diagonal, equation (24) together with equation $(16 b)$ can be written as the state space system:

$$
\begin{aligned}
\hat{a}_{t} & =\tilde{Z}_{t} a o_{t}+\Sigma_{t} \epsilon_{t} & \Sigma_{t} \epsilon_{t} & \sim N\left(0, \Sigma_{t}^{\prime} \Sigma_{t}\right) \\
a o_{t} & =a o_{t-1}+s_{t} & s_{t} & \sim N(0, S)
\end{aligned}
$$

where $\tilde{Z}_{t}$ is the following $q \times \frac{q(q-1)}{2}$ matrix:

$$
\tilde{Z}_{t}=\left[\begin{array}{cccc}
0 & \cdots & \cdots & 0 \\
-\hat{a}_{1, t} & 0 & \cdots & 0 \\
0 & -\hat{a}_{[1,2], t} & \ddots & 0 \\
\vdots & \ddots & \ddots & \vdots \\
0 & \cdots & 0 & -\hat{a}_{[1, \ldots, q-1], t}
\end{array}\right]
$$

where $\hat{a}_{[1, \ldots, j], t}$ denotes the row vector $\left[\hat{a}_{1, t}, \hat{a}_{2, t}, \ldots, \hat{a}_{j, t}\right]$.

Now, although the equations in (25) have a (conditional) Gaussian state space representation, the system is nonlinear since $\hat{a}_{t}$ essentially shows up on both sides of the equality sign in equation (25). Still, under the assumption that the $S$ matrix is block 
diagonal, see equation (9), we can apply Carter and Kohn's multimove Gibbs sampling approach, see Section E.8, and draw $\tilde{a O}_{T}$ in a recursive manner that is consistent with the assumptions on $A 0_{t}$. That is:

$$
\begin{aligned}
a o_{T} \mid \cdots & \sim N\left(a o_{T \mid T}, P_{T \mid T}^{a o}\right), \quad t=T \\
a o_{t} \mid \cdots & \sim N\left(a o_{t \mid t, a o_{t+1}}, P_{t \mid t, a o_{t+1}}^{a o}\right), \quad t=T-1, T-2, \cdots, 1
\end{aligned}
$$

Once $\tilde{a o}_{T}$ has been drawn in this manner, the innovations in (16b) are observable, and we can compute the residual sums of squares. Thus, the conditional posterior of $S_{l}$ for $l=1, \ldots, q-1$ can be sampled from the Inverse-Wishart distribution:

$$
S_{l} \mid \cdots \sim I W\left(\bar{v}^{S}, \bar{S}_{l}\right)
$$

where $\bar{v}^{S}=T+\underline{\mathrm{T}}^{S}, \bar{S}_{l}=\left[\underline{\mathrm{S}}_{l}+\sum_{t=1}^{T} \xi_{l, t}^{S^{\prime}} \xi_{l, t}^{S}\right]$, and $\xi_{l, t}^{S}=a o_{l, t}-a o_{l, t-1}$ are the errors associated with the lth block. ${ }^{33}$

\section{E.4 Block 4: $\tilde{h}_{T}^{\sigma} \mid \tilde{a}_{T}, \tilde{a o}_{T}, \Phi, B$ and $B \mid \tilde{h}_{T}^{\sigma}$}

Conditional on $\tilde{a o}_{T}, \Phi$ and $\tilde{a}_{T}$, the L.H.S of equation (24) is known, and can be written as:

$$
\hat{a}_{t}^{*}=\Sigma_{t} \epsilon_{t}
$$

where $\hat{a}_{t}^{*}=A 0_{t} \hat{a}_{t}$ is an observable.

Together with the transition equation in (16c), the observation equation in (29) constitutes a nonlinear state space system. The nonlinearity can be converted into a linear one by squaring and taking logarithms of every element of (29), yielding:

$$
\begin{gathered}
\hat{a}_{t}^{* *}=2 h_{t}^{\sigma}+d_{t}^{\sigma} \\
h_{t}^{\sigma}=h_{t-1}^{\sigma}+b_{t}
\end{gathered}
$$

where $d_{l, t}^{\sigma}=\log \left(\epsilon_{l, t}^{2}\right), h_{l, t}^{\sigma}=\log \left(\sigma_{l, t}\right), \hat{a}_{l, t}^{* *}=\log \left[\left(\hat{a}_{l, t}^{*}\right)^{2}+\bar{c}\right]$ for $l=1, \ldots, q \cdot \bar{c}=0.001$ is an offsetting constant added to the latter expression to avoid potentially taking the log of zero.

Now the system in (30) is linear, but it has a non-Gaussian state space form, because the innovations in the observation equation are distributed as $\log \chi^{2}(1)$. In order to further transform the system into a Gaussian one, a mixture of normals approximation of the $\log \chi^{2}(1)$ distribution is used. Following Kim et al. (1998), we select a mixture of seven normal densities with component probabilities $q_{\gamma}$, mean $m_{\gamma}-1.2704$, and variances $v_{\gamma}^{2}$, for

${ }_{33} \overline{\text { Remember that the } l=1 \text { elements of } \xi_{l, t}^{S}}$ and $S_{l}$ are associated with the $l+1$ row of $A 0_{t}$. Accordingly, for $l=1, S_{1}$ will be a $1 \times 1$ matrix, for $l=2, S_{2}$ will be a $2 \times 2$ matrix, etc. See also Section 3.1. 
$\gamma=1, \ldots, 7$. The constants $q_{\gamma}, m_{\gamma}, v_{\gamma}^{2}$ are chosen to match a number of moments of the $\log \chi^{2}(1)$ distribution. Since the covariance matrix of $\epsilon$ is an identity matrix, this implies that the covariance matrix of $d^{\sigma}$ is also a diagonal, and we can use the same (independent) mixture of normals approximation for any element of $d^{\sigma}$. Accordingly, conditionally on $\hat{a}_{j, t}^{* *}$ and $h_{t}$, we can sample a selection matrix $\tilde{s}_{T}=\left[s_{1}, \ldots, s_{T}\right]^{\prime}$ as:

$$
\operatorname{Pr}\left(s_{l, t}=\gamma \mid \hat{a}_{l, t}^{* *}, h_{l, t}^{\sigma}\right) \propto q_{\gamma} f_{N}\left(\hat{a}_{l, t}^{* *} \mid 2 h_{l, t}^{\sigma}+m_{\gamma}-1.2704, v_{\gamma}^{2}\right) \quad \gamma=1, \ldots, 7 \quad l=1, \ldots, q
$$

and use this to select which member of the mixture of the normal approximations that should be used to construct the covariance matrix of $d^{\sigma}$ and adjust the mean of $\hat{a}_{t}^{* *}$ at every point in time.

Denoting the adjusted observations and covariances as $\hat{a}_{t}^{* * *}=\hat{a}_{t}^{* *}-m_{\gamma=s_{t}}+1.2704$ and $D_{t}^{\sigma}$, respectively, the system in (30) finally has an approximate linear and Gaussian state space form. Again, like above, this allows one to recursively recover $h_{t}^{\sigma}$ for $t=1, \ldots, T$ using the Carter and Kohn algorithm:

$$
\begin{aligned}
& h_{T}^{\sigma} \mid \cdots \sim N\left(h_{T \mid T}^{\sigma}, P_{T \mid T}^{h^{\sigma}}\right), \quad t=T \\
& h_{t}^{\sigma} \mid \cdots \sim N\left(h_{t \mid t, h_{t+1}^{\sigma}}^{\sigma}, P_{t \mid t, h_{t+1}^{\sigma}}^{h^{\sigma}}\right), \quad t=T-1, T-2, \cdots, 1
\end{aligned}
$$

Likewise, conditional on $\tilde{h}_{T}^{\sigma}$, the posterior of $B$ is drawn from the Inverse-Wishart distribution:

$$
B \mid \cdots \sim I W\left(\bar{v}^{B}, \bar{B}\right)
$$

where $\bar{v}^{B}=T+\underline{\mathrm{T}}^{B}, \bar{B}=\left[\underline{\mathrm{B}}+\sum_{t=1}^{T} \xi_{t}^{B^{\prime}} \xi_{t}^{B}\right]$, and $\xi_{t}^{B}=h_{t}^{\sigma}-h_{t-1}^{\sigma}$.

\section{E.5 Block 5: $\tilde{z}_{T} \mid \tilde{y}_{T}, \tilde{a}_{T}, \tilde{e}_{T}, \tilde{h}_{T}^{\eta}, \Phi, W$ and $W \mid \tilde{z}_{T}$}

Conditionally on $\tilde{a}_{T}$ the errors in (15a) are independent across $i$. Moreover, we have assumed that the covariance matrix of $z_{t}$ in equation (16a) is block diagonal. Consequently, we can draw $\tilde{z}_{T}$ one equation at a time. As in Appendix E.1 we deal with the fact that the errors in the observation equation are not conditionally i.i.d. by applying the quasi differencing operator, $\Phi(L)=\left(I-\sum_{k=1}^{p} \Phi_{k} L^{k}\right)$, to each equation. Thus, for each $i=q+1, \ldots, N$, we define $\hat{z}_{j, t}$ as the ith row of $z_{j, t}$ and $\hat{w}_{j, t}$ as the errors in (16a) associated with $\hat{z}_{j, t}$ (for $j=0, \ldots, s$ ), and obtain the following Gaussian state space system:

$$
\begin{aligned}
y_{i, t}^{*} & =a_{t}^{*} \hat{z}_{0, t}+\cdots+a_{t-s}^{*} \hat{z}_{s, t}+\eta_{i, t} u_{i, t} & \eta_{i, t} u_{i, t} & \sim N\left(0, \eta_{i, t}^{\prime} \eta_{i, t}\right) \\
\hat{z}_{t} & =\Xi \hat{z}_{t-1}+\hat{w}_{t} & \hat{w}_{t} & \sim N\left(0, W_{i}\right)
\end{aligned}
$$

where $a_{t}^{*}=\left[\left(I-\sum_{k=1}^{p} \Phi_{k} L^{k}\right) a_{t}\right]^{\prime}, \hat{z}_{t}=\left[\hat{z}_{0, t}, \ldots, \hat{z}_{s, t}\right]^{\prime}, \hat{w}_{t}=\left[\hat{w}_{0, t}, \ldots, \hat{w}_{s, t}\right]^{\prime}$ and $\Xi$ is a $(s+1) \times(s+1)$ identity matrix. Since $W_{i}$ and $\eta_{i, t}^{\prime} \eta_{i, t}$ are conditionally known for each 
$i$, the Carter and Kohn algorithm is implemented on (34), in the same manner as before, to sample:

$$
\begin{aligned}
& \hat{z}_{T} \mid \cdots \sim N\left(\hat{z}_{T \mid T}, P_{T \mid T}^{\hat{z}}\right), \quad t=T \\
& \hat{z}_{t} \mid \cdots \sim N\left(\hat{z}_{t \mid t, h_{t+1}}, P_{t \mid t, \hat{z}_{t+1}}^{\hat{z}}\right), \quad t=T-1, T-2, \cdots, 1
\end{aligned}
$$

Conditionally on $\tilde{\hat{z}}_{T}$, we sample $W_{i}$ from the Inverse-Wishart distribution:

$$
W_{i} \mid \cdots \sim I W\left(\bar{v}^{W}, \bar{W}_{i}\right)
$$

where $\bar{v}^{W}=T+\underline{\mathrm{T}}^{W}, \bar{W}_{i}=\left[\underline{\mathrm{W}}_{i}+\sum_{t=1}^{T} \xi_{i, t}^{W^{\prime}} \xi_{i, t}^{W}\right]$, and $\xi_{i, t}^{W}=\hat{z}_{t}-\hat{z}_{t-1}$.

Repeating this algorithm for $i=q+1 \ldots, N$, gives us $\tilde{z}_{T}$ and $W{ }^{34}$

\section{E.6 Block 6: $\tilde{e}_{T} \mid \tilde{y}_{T}, \tilde{a}_{T}, \tilde{z}_{T}$ and $\Phi \mid \tilde{e}_{T}, \tilde{h}_{T}^{\eta}$}

For each observation we have that:

$$
e_{t}=y_{t}-z_{0, t} a_{t}+\cdots+z_{s, t} a_{t-s}
$$

Thus, conditional on $\tilde{y}_{T}, \tilde{a}_{T}$ and $\tilde{z}_{T}, \tilde{e}_{T}$ is observable.

As above, since $\tilde{e}_{T}$ is independent across $i$, we can sample $\Phi$ in (15c) one equation at the time. Conditional on $h_{T}^{\eta}$, this is done in the same manner as in Appendix E.2, with the difference that now the definitions in (19) are replaced by: $Y_{t}=\left[e_{1, t}, \ldots, e_{N, t}\right]^{\prime}$, and $\varepsilon_{t}=$ $\left[\omega_{1, t}^{E}, \ldots, \omega_{N, t}^{E}\right]^{\prime}$, with $\omega_{t}^{E}=\Upsilon_{t} u_{t}$. Further, $\beta^{\Phi}=\left[\beta_{1}^{\Phi}, \ldots, \beta_{N}^{\Phi}\right]^{\prime}$ with $\beta_{i}^{\Phi}=\left[\Phi_{i, 1}, \ldots, \Phi_{i, p}\right]^{\prime}$, and

$$
\Psi=\left[\begin{array}{cccc}
H_{1} & 0 & \cdots & 0 \\
0 & H_{2} & \ddots & 0 \\
\vdots & \ddots & \ddots & \vdots \\
0 & \cdots & 0 & H_{T}
\end{array}\right]
$$

The conditional posterior draws of $\beta^{\Phi}$, and thus $\Phi$, are therefore:

$$
\beta^{\Phi} \mid \cdots \sim N\left(\bar{\beta}^{\Phi}, \bar{V}_{\beta^{\Phi}}\right)_{I\left[s\left(\beta^{\Phi}\right)\right]}
$$

where $I\left[s\left(\beta^{\Phi}\right)\right]$ is an indicator function used to denote that the roots of $\beta$ lie outside the unit circle, and:

$$
\begin{aligned}
\bar{V}_{\beta^{\Phi}} & =\left(\underline{V}_{\beta^{\Phi}}^{-1}+X^{\prime} \Psi^{-1} X\right)^{-1} \\
\bar{\beta}^{\Phi} & =\bar{V}_{\beta^{\Phi}}\left(\underline{V}_{\beta^{\Phi}}^{-1} \underline{\beta}^{\Phi}+X^{\prime} \Psi^{-1} Y\right)
\end{aligned}
$$

\footnotetext{
${ }^{34}$ For the first $q$ elements in $y_{t}$, the identification restriction given by (10) implies that the factor loading
} is equal to one for all $t$. 


\section{E.7 Block 7: $\tilde{h}_{T}^{\eta} \mid \tilde{e}_{T}, \Phi, V$ and $V \mid \tilde{h}_{T}^{\eta}$}

Conditionally on having sampled $\tilde{e}_{T}$ and $\Phi$, we can continue to sample $\tilde{h}_{T}^{\eta}$ for each equation independently. This is done as in Appendix E.4.

For concreteness, we define, for $i=1, \ldots, N$ :

$$
\hat{e}_{i, t}^{*}=\eta_{i, t} u_{i, t}
$$

where $\hat{e}_{i, t}^{*}=\left[e_{i, t}-\Phi_{i, 1} e_{i, t-1}+\cdots+\Phi_{i, p} e_{i, t-p}\right]$ is now an observable. Squaring and taking logarithms on each element in (41) and using the law of motion for the stochastic volatilities in (16d), we get the following non-Gaussian state space system:

$$
\begin{aligned}
& \hat{e}_{i, t}^{* *}=2 h_{i, t}^{\eta}+d_{i, t}^{\eta} \\
& h_{i, t}^{\eta}=h_{i, t-1}^{\eta}+v_{i, t}
\end{aligned}
$$

where $d_{i, t}^{\eta}=\log \left(u_{i, t}^{2}\right), h_{i, t}^{\eta}=\log \left(\eta_{i, t}\right), \hat{e}_{i, t}^{* *}=\log \left[\left(\hat{e}_{i, t}^{*}\right)^{2}+\bar{c}\right]$, and $\bar{c}=0.001$.

The state space system in (42) is linear but non-Gaussian, and simulation of:

$$
\begin{aligned}
& h_{T}^{\eta} \mid \cdots \sim N\left(h_{T \mid T}^{\eta}, P_{T \mid T}^{h^{\eta}}\right), \quad t=T \\
& h_{t}^{\eta} \mid \cdots \sim N\left(h_{t \mid t, h_{t+1}^{\eta}}^{\eta}, P_{t \mid t, h_{t+1}^{\eta}}^{h^{\eta}}\right), \quad t=T-1, T-2, \cdots, 1
\end{aligned}
$$

is conducted as described in Appendix E.4.

Finally, conditionally on $\tilde{h}_{T}^{\eta}$, we sample $V_{i}$, for $i=1, \ldots, N$, from the Inverse-Wishart distribution:

$$
V_{i} \mid \cdots \sim I W\left(\bar{v}^{V}, \bar{V}_{i}\right)
$$

where $\bar{v}^{V}=T+\underline{\mathrm{T}}^{V}, \bar{V}_{i}=\left[\underline{\mathrm{V}}_{i}+\sum_{t=1}^{T} \xi_{i, t}^{V^{\prime}} \xi_{i, t}^{V}\right]$, and $\xi_{i, t}^{V}=h_{i, t}^{\eta}-h_{i, t-1}^{\eta}$ are the errors associated with the ith equation.

\section{E.8 The Carter and Kohn algorithm}

Consider a generic state space system, written in companion form, and described by:

$$
\begin{aligned}
& y_{t}=Z_{t} a_{t}+e_{t} \sim N\left(0, H_{t}\right) \\
& a_{t}=\Gamma a_{t-1}+G u_{t} \sim N\left(0, \Omega_{t}\right)
\end{aligned}
$$

where we assume $Z_{t}, \Gamma, G, H_{t}$ and $\Omega_{t}$ are known, and we wish to estimate the latent state $a_{t}$ for all $t=1, \ldots, T$. To do so, we can apply Carter and Kohn's multimove Gibbs sampling approach (see Carter and Kohn (1994)).

First, because the state space model given in equation (45) is linear and (conditionally) Gaussian, the distribution of $a_{t}$ given $\tilde{y}_{T}$ and that of $a_{t}$ given $a_{t+1}$ and $\tilde{y}_{t}$ for $t=T-1, \cdots, 1$ 
are also Gaussian:

$$
\begin{aligned}
a_{T} \mid \tilde{y}_{T} & \sim N\left(a_{T \mid T}, P_{T \mid T}\right), \quad t=T \\
a_{t} \mid \tilde{y}_{t}, a_{t+1} & \sim N\left(a_{t \mid t, a_{t+1}}, P_{t \mid t, a_{t+1}}\right), \quad t=T-1, T-2, \cdots, 1
\end{aligned}
$$

where

$$
\begin{aligned}
a_{T \mid T} & =E\left(a_{T} \mid \tilde{y}_{T}\right) \\
P_{T \mid T} & =\operatorname{Cov}\left(a_{T} \mid \tilde{y}_{T}\right) \\
a_{t \mid t, a_{t+1}} & =E\left(a_{t} \mid \tilde{y}_{t}, a_{t+1}\right)=E\left(a_{t} \mid a_{t \mid t}, a_{t \mid t+1}\right) \\
P_{t \mid t, a_{t+1}} & =\operatorname{Cov}\left(a_{t} \mid \tilde{y}_{t}, a_{t+1}\right)=\operatorname{Cov}\left(a_{t} \mid a_{t \mid t}, a_{t \mid t+1}\right)
\end{aligned}
$$

Given $a_{0 \mid 0}$ and $P_{0 \mid 0}$, the unknown states $a_{T \mid T}$ and $P_{T \mid T}$ needed to draw from (46a) can be estimated from the (conditionally) Gaussian Kalman Filter as:

$$
\begin{aligned}
a_{t \mid t-1} & =\Gamma a_{t-1 \mid t-1} \\
P_{t \mid t-1} & =\Gamma P_{t-1 \mid t-1} \Gamma^{\prime}+G \Omega_{t} G^{\prime} \\
K_{t} & =P_{t \mid t-1} Z_{t}^{\prime}\left(Z_{t} P_{t \mid t-1} Z_{t}^{\prime}+H_{t}\right)^{-1} \\
a_{t \mid t} & =a_{t \mid t-1}+K_{t}\left(y_{t}-Z_{t} a_{t \mid t-1}\right) \\
P_{t \mid t} & =P_{t \mid t-1}-K_{t} Z_{t} P_{t \mid t-1}
\end{aligned}
$$

That is, at $t=T$, equation $48 \mathrm{~d}$ and $48 \mathrm{e}$ above, together with equation $46 \mathrm{a}$, can be used to draw $a_{T \mid T}$. Moreover, $a_{t \mid t, a_{t+1}}$ for $t=T-1, T-2, \cdots, 1$ can also be simulated based on $46 \mathrm{~b}$, where $a_{t \mid t, a_{t+1}}$ and $P_{t \mid t, a_{t+1}}$ are generated from the following updating equations:

$$
\begin{aligned}
& a_{t \mid t, a_{t+1}}=a_{t \mid t}+P_{t \mid t} \Gamma^{\prime}\left(\Gamma P_{t \mid t} \Gamma^{\prime}+G \Omega_{t} G^{\prime}\right)^{-1}\left(a_{t+1}-\Gamma a_{t \mid t}\right) \\
& P_{t \mid t, a_{t+1}}=P_{t \mid t}+P_{t \mid t} \Gamma^{\prime}\left(\Gamma P_{t \mid t} \Gamma^{\prime}+G \Omega_{t} G^{\prime}\right)^{-1} \Gamma P_{t \mid t}
\end{aligned}
$$

\section{Appendix F Marginal Likelihood computation and the Reversible Jump Markov Chain Monte Carlo (RJMCMC) algorithm}

The RJMCMC was first proposed by Green (1995), and has since been applied, and modified, in a number of different settings, including model selection. Dellaportas et al. (2002) and Lopes and West (2004) provide two, of many extant, examples. The algorithm derived here extends that presented in Primiceri (2005) to a dynamic factor model setting, accounting for time-varying parameters. 
Following the notation in Primiceri (2005) we consider a set of $M$ competing models. In our setting these models differ in the prior assumptions, see Section D.2. Essentially, the RJMCMC algorithm is nothing more than a Metropolis-Hastings (MH) sampler, where the goal is to sample the joint posterior distribution of model $m \in M$ and the associated model parameters, here denoted $\theta^{m}$. This is done by generating a proposal value of $\left(m^{\prime}, \theta^{m^{\prime}}\right)$ from a proposal distribution $q_{p}\left(m^{\prime}, \theta^{m^{\prime}}\right)=q\left(\theta^{m^{\prime}} \mid m^{\prime}\right) \cdot J\left(m^{\prime}\right)$. The new proposal is accepted using a $\mathrm{MH}$ acceptance probability. If the proposal is rejected, it is replaced by the previous element of the chain. After a sufficient number of draws, an approximation to the posterior of $\left(m^{\prime}, \theta^{m^{\prime}}\right)$ can be computed, as can posterior probabilities over the models' space.

More specifically, the sampler used is an independence chain Metropolis Hastings algorithm, and we proceed as follows:

1. For every $m \in M$ we approximate the posterior based on the Gibbs sampler algorithm explained in Section E. These approximate posteriors are then used as proposal distributions for the elements in $\theta^{m}$ :

$$
\begin{aligned}
q\left(\Phi^{m} \mid m\right) & =N\left(\overline{\Phi^{m}}, \overline{\operatorname{var}\left(\Phi^{m}\right)} \cdot 1\right) \\
q\left(\Phi^{m} \mid m\right) & =N\left(\overline{\Phi^{m}}, \overline{\operatorname{var}\left(\Phi^{m}\right)} \cdot 1\right) \\
q\left(W^{m} \mid m\right) & =I W\left(125, \overline{W^{m}} \cdot 125\right) \\
q\left(S^{m} \mid m\right) & =I W\left(25, \overline{S^{m}} \cdot 25\right) \\
q\left(B^{m} \mid m\right) & =I W\left(100, \overline{B^{m}} \cdot 100\right) \\
q\left(V^{m} \mid m\right) & =I W\left(10, \overline{V^{m}} \cdot 10\right)
\end{aligned}
$$

The variables denoted with an upper bar are the posterior means and variances from the initial Gibbs sampler. The variances are made more diffuse than the exact ones to facilitate the convergence of the $\mathrm{MH}$ algorithm. ${ }^{35}$

2. Initialize $m$ and draw $\theta^{m}$ from the proposal distribution $q\left(\theta^{m} \mid m\right)$.

3. Draw $m^{\prime}$ from an unconditional proposal distribution $J\left(m^{\prime}\right)$ over the models (here we use the uniform distribution), and draw $\theta^{m^{\prime}}$ from the conditional proposal distribution $q\left(\theta^{m^{\prime}} \mid m^{\prime}\right)$, such that $q_{p}\left(m^{\prime}, \theta^{m^{\prime}}\right)=q\left(\theta^{m^{\prime}} \mid m^{\prime}\right) \cdot J\left(m^{\prime}\right)$.

4. Accept the new couple $\left(m^{\prime}, \theta^{m^{\prime}}\right)$ with probability:

$$
\alpha\left(m, m^{\prime}\right)=\min \left\{1, \frac{p\left(y_{T} \mid m^{\prime}, \theta^{m^{\prime}}\right) p\left(\theta^{m^{\prime}} \mid m^{\prime}\right) p\left(m^{\prime}\right) q_{p}\left(m, \theta^{m}\right)}{p\left(y_{T} \mid m, \theta^{m}\right) p\left(\theta^{m} \mid m\right) p(m) q_{p}\left(m^{\prime}, \theta^{m^{\prime}}\right)}\right\}
$$

\footnotetext{
${ }^{35}$ However, as noted in Section D.2, the convergence properties of the proposed algorithm are not good. Although we have not been able to do this, it could probably be improved upon by a better specification of the proposal distributions. See also the discussion at the end of Appendix F.1.
} 
where $p\left(y_{T} \mid m, \theta^{m}\right)$ is the likelihood of the model, computed using a particle filter, see Appendix F.1. $p\left(\theta^{m} \mid m\right)$ being the prior of $\theta^{m}$ within model $m$, with $p(m)$ being the prior model probability. We employ equal prior probabilities, so these terms cancel out. If the new draw is not accepted, keep the previous couple $\left(m, \theta^{m}\right)$.

5. Go to 3.

The MH sampler is run using a handful of independent chains. The approximate posteriors, constructed in step 1, are based on 8000 iterations of the Gibbs sampler for each $m \in M$. The first 4000 iterations are discarded and only every fourth of the remaining iterations is used for inference.

\section{F.1 The particle filter and likelihood computation}

In step 4 of the reversible jump algorithm described above we need to calculate the likelihood of the proposed model; $p\left(y_{T} \mid m, \theta^{m}\right)$. For traditional (conditional) Gaussian state space models the likelihood can easily be computed through the Kalman filter, which integrates out the dependence of the stochastic latent factors. However, computing the likelihood of the state space model described by the equations in (15) and (16) is more complicated since the parameters are stochastic and the expressions involve products of stochastic variables. To evaluate the likelihood we therefore employ a Rao-Blackwellized particle filter. This particle filter is particularly suitable for state space systems, like ours, where part of the problem can be solved analytically, see Creal (2009) for a short overview and further references. Below we provide a brief description of the algorithm.

Consider a non-linear state space system with hyper-parameters $\theta$, state variable $x$ (in our model the state variable $x$ contains both the time-varying factor loadings, the stochastic volatilities, and the factors), and observable data given by $y_{t}$. Then, the goal is to estimate the joint smoothing distribution of the latent state, given by:

$$
p\left(x_{0: t} \mid y_{1: t} ; \theta\right)=\frac{p\left(y_{1: t}, x_{0: t} ; \theta\right)}{p\left(y_{1: t} ; \theta\right)}=\frac{p\left(y_{t} \mid x_{t} ; \theta\right) p\left(x_{t} \mid x_{t-1} ; \theta\right)}{p\left(y_{t} \mid y_{1: t-1} ; \theta\right)} p\left(x_{0: t-1} \mid y_{1: t-1} ; \theta\right)
$$

However, solving (51) analytically is difficult due to the assumed non-linearity of the system. This motivates the use of Sequential Monte Carlo methods, such as the particle filter. Instead of solving (51) directly, these methods utilize the recursive structure of the joint smoothing distribution, as highlighted by the last equality sign in (51), and two of it's marginal distributions, namely the predictive distribution $p\left(x_{t} \mid y_{1: t-1} ; \theta\right)$ and the filtering distribution given by:

$$
p\left(x_{t} \mid y_{1: t} ; \theta\right)=\frac{p\left(y_{t}, x_{t} \mid y_{1: t-1} ; \theta\right)}{p\left(y_{t} \mid y_{1: t-1} ; \theta\right)}=\frac{p\left(y_{t} \mid x_{t} ; \theta\right) p\left(x_{t} \mid y_{1: t-1} ; \theta\right)}{p\left(y_{t} \mid y_{1: t-1} ; \theta\right)}
$$


Here, $p\left(y_{t}, x_{t} \mid y_{1: t-1} ; \theta\right)=p\left(y_{t} \mid x_{t} ; \theta\right) p\left(x_{t} \mid y_{1: t-1} ; \theta\right)$ is the joint distribution of the data and the state variables, and $p\left(y_{t} \mid y_{t-1} ; \theta\right)$ is the contribution to the likelihood function (or the normalizing constant). Accordingly, to sequentially solve 51, starting from an initial draw of the state, the last period's filtering distribution is projected forward using the predictive distribution and then updated using the filtering distribution. These iterations continue until the end of the sample.

Difficulty arises because the predictive distribution $\left(p\left(x_{t} \mid y_{1: t-1} ; \theta\right)\right)$ and the contribution to the likelihood $\left(p\left(y_{t} \mid y_{t-1} ; \theta\right)\right)$ involves integrals that typically cannot be calculated analytically. To see this, we can re-write the two terms as:

$$
p\left(y_{t} \mid y_{1: t-1} ; \theta\right)=\int p\left(y_{t} \mid x_{t} ; \theta\right) p\left(x_{t} \mid y_{1: t-1} ; \theta\right) d x_{t}
$$

and

$$
p\left(x_{t} \mid y_{1: t-1} ; \theta\right)=\int p\left(x_{t} \mid x_{t-1} ; \theta\right) p\left(x_{t-1} \mid y_{1: t-1} ; \theta\right) d x_{t-1}
$$

Still, these integrals can be approximated using Monte Carlo integration. Draw N particles from $p\left(x_{0} \mid y_{0} ; \theta\right)$ and use (54) to calculate the predicted value of the state. Then update the value of the state variables based on the information in the data using (52). The latter step is conducted as an importance sampling step, where the particle draws are re-weighted. By conducting these prediction and updating steps for $t=1, \ldots, T$, the joint smoothing distribution in (51) can be obtained. Importantly for our purpose, the contribution to the likelihood at each time period, equation (53), can in most cases be obtained directly from the estimated importance weights.

Partly due to the importance sampling step, which creates options regarding importance distribution, many different particle filters have been proposed. In our model, part of the joint smoothing distribution can be solved analytically, and we take advantage of this fact when designing the filter by decomposing the state $x_{t}$ into two blocks; $x_{t}=\left(x_{1, t}^{\prime}, a_{t}^{\prime}\right)^{\prime}$. That is, we group the time-varying factor loadings and the stochastic volatilities into $x_{1, t}$ while the factors are grouped into $a_{t}$. In short, we have the state space system:

$$
\begin{aligned}
& y_{t}=Z_{t}\left(x_{t}\right) a_{t}+e_{t} \sim N\left(0, H_{t}\left(x_{t}\right)\right) \\
& a_{t}=\Gamma a_{t-1}+G u_{t} \sim N\left(0, \Omega_{t}\left(x_{t}\right)\right)
\end{aligned}
$$

The marginal filtering distribution can then be decomposed as:

$$
p\left(x_{1, t}, a_{t} \mid y_{1: t} ; \theta\right)=p\left(a_{t} \mid x_{1, t}, y_{1: t} ; \theta\right) p\left(x_{1, t} \mid y_{1: t} ; \theta\right)
$$

Particles are only simulated randomly from $p\left(x_{1, t} \mid y_{1: t} ; \theta\right)$ while conditional on each draw of $x_{1, t}^{i}$, the distribution of $p\left(a_{t} \mid x_{1, t}^{i}, y_{1: t} ; \theta\right)$ can be evaluated analytically. In sum, we proceed as follows: 
1. At $t=0$ and for $i=1, \ldots, N$, draw $x_{1,0}$ and $a_{0}$ from some unconditional distributions and set $w_{0}^{i}=\frac{1}{N}$

2. Set $t=t+1$. For $i=1, \ldots, N$, run the prediction step of the Kalman filter to obtain the conditional likelihood (using the prediction error decomposition), and calculate the importance weights as $\hat{w}_{t}^{i}=\frac{w_{t}^{i}}{\sum_{j=1}^{N} w_{t}^{j}}$, where $w_{t}^{i}$ is the conditional likelihood associated with particle $i$.

3. By the law of large numbers, the contribution to the likelihood can be approximated as $\log \left(p\left(y_{t} \mid y_{t-1} ; \theta\right)\right)=\log \left(\frac{\sum_{i=1}^{N} w_{t}^{i}}{N}\right)$

4. Re-sample the $N$ particles $\left\{x_{1, t-1 \mid t-1}^{i}, a_{t-1 \mid t-1}^{i}\right\}_{i=1}^{N}$ with probabilities $\left\{\hat{w}_{t}^{i}\right\}_{i=1}^{N}$, and set $w_{t}^{i}=\frac{1}{N}$

5. For $i=1, \ldots, N$, draw $x_{1, t}$ conditional on $x_{1, t-1}$ and run the Kalman filter on each particle to obtain $a_{t \mid t}$.

6. Return to 2 .

We confirmed in a simulation experiment the ability of the particle filter approach described above to estimate the latent state variables (the time-varying factor loadings, the stochastic volatilities, and the factors) with a high degree of precision. That said, in systems with a high number of states, as is the case here, a substantial number of particles needs to be entertained to obtain reliable estimates of the joint smoothing distribution. This, however, makes the use of the particle filter within the RJMCMC algorithm described above infeasible. The computation time is simply too large. However, it is our experience that a substantially lower number of particles is needed to obtain reasonably stable estimates of the contribution to the likelihood function. We take advantage of this when we employ the particle filter within the RJMCMC sampler, but emphasize that this downscaling of the number of particles likely contributes to increased sampling variation and thus worse convergence properties of the algorithm as a whole, cf. the discussion in Section D.2. 